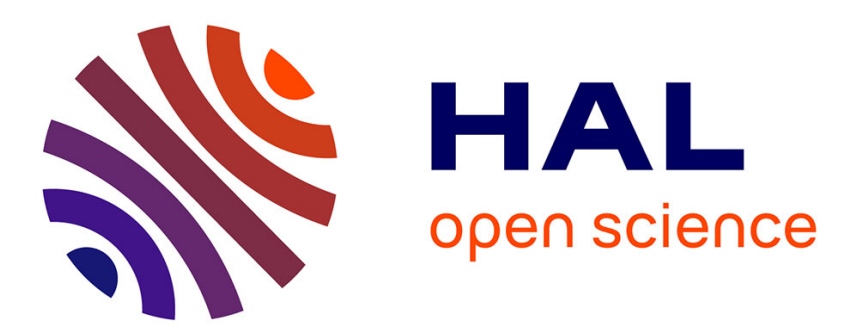

\title{
Recent developments in penta-, hexa- and heptadentate Schiff base ligands and their metal complexes
}

\author{
Xiang Liu, Jean-René Hamon
}

\section{To cite this version:}

Xiang Liu, Jean-René Hamon. Recent developments in penta-, hexa- and heptadentate Schiff base ligands and their metal complexes. Coordination Chemistry Reviews, 2019, 389, pp.94-118. 10.1016/j.ccr.2019.03.010 . hal-02161327

HAL Id: hal-02161327 https://hal-univ-rennes1.archives-ouvertes.fr/hal-02161327

Submitted on 5 Jul 2019

HAL is a multi-disciplinary open access archive for the deposit and dissemination of scientific research documents, whether they are published or not. The documents may come from teaching and research institutions in France or abroad, or from public or private research centers.
L'archive ouverte pluridisciplinaire HAL, est destinée au dépôt et à la diffusion de documents scientifiques de niveau recherche, publiés ou non, émanant des établissements d'enseignement et de recherche français ou étrangers, des laboratoires publics ou privés. 
Ref: CCR_2018_285

Revised Manuscript R2

Recent developments in penta-, hexa- and heptadentate Schiff base ligands and their metal complexes

Xiang Liu , * Jean-René Hamon $^{\mathrm{b}}$ **

${ }^{a}$ College of Materials and Chemical Engineering, Key Laboratory of Inorganic Nonmetallic Crystalline and Energy Conversion Materials, China Three Gorges University, Yichang, Hubei 443002, P. R. China

bUniv Rennes, CNRS, ISCR (Institut des Sciences Chimiques de Rennes) - UMR 6226, F-35000 Rennes, France

This review is dedicated with best wishes to our distinguished colleague David Carrillo (PUC Valparaiso), a great friend and scientist, at the occasion of his $80^{\text {th }}$ birthday.

* Corresponding authors.

e-mail address: xiang.liu@ctgu.edu.cn (X. Liu)

e-mail address: jean-rene.hamon@univ-rennes1.fr (J.-R. Hamon) 


\begin{abstract}
Novel ligand platforms that promote reactivity are of long standing and continued interest in coordination chemistry, with Schiff base ligands and their metal complexes representing one of the most versatile and long standing topics of interest. The synthesis and structure of polydentate Schiff bases and their metal complexes is fascinating, because it reveals a great richness of structural, physico-chemical and catalytic properties. Given the simplicity and ease of access to multidentate Schiff bases and their metal complexes, investigation of such compounds is essential to precise and understand structure-property relationships in order to optimize and improve their use in a wide range of fields, including catalysis, supramolecular chemistry, magnetism, electrochemistry, nanoscience, energy materials, and biological applications. This review highlights the recent developments of pentadentate, hexadentate, heptadentate and macrocyclic Schiff base ligands containing various donor sets made of different combinations of $\mathrm{N}, \mathrm{O}, \mathrm{S}$ or $\mathrm{P}$ donor atoms and their metal complexes (essentially mononuclear), as well as presenting synthetic methods and interesting structures of complexes formed by first-to-third row transition metals (from group 4-12), main group elements, lanthanides and actinides. This review is divided into three main sections, each of them corresponding to one type of denticity of the Schiff base under consideration. Each category is described with representative examples according to a periodic order, and emphasis is given to the coordination aspects. Their catalytic, magnetic and biological properties are also outlined. This review that contains 359 references should act as a source of information to researchers interested to work in this domain and stimulate further investigation in this fascinating area of Schiff base coordination compounds.
\end{abstract}

Keywords: pentadentate Schiff base ligands; hexadentate Schiff base ligands; heptadentate Schiff base ligands; Schiff base complexes; solid-state structure 


\section{Contents}

1. Introduction

2. Pentadentate Schiff base ligands and their metal complexes

2.1. N,O-containing pentadentate Schiff base complexes

2.1.1.Pentadentate Schiff base $\mathrm{Zr}(\mathrm{IV})$ complexes

2.1.2 Pentadentate Schiff base V complexes

2.1.3.Pentadentate Schiff base Mo complexes

2.1.4.Pentadentate Schiff base Mn(II) complexes

2.1.5.Pentadentate Schiff base Fe(III) complexes

2.1.6.Pentadentate Schiff base Co complexes

2.1.7.Pentadentate Schiff base $\mathrm{Ni}(\mathrm{II})$ and $\mathrm{Cu}(\mathrm{II})$ complexes

2.1.8.Pentadentate Schiff base Zn(II) complexes

2.1.9.Pentadentate Schiff base Cd(II) complexes

2.1.10.Pentadentate Schiff base Sn complexes

2.1.11.Pentadentate Schiff base Eu(III) complexes

2.1.12.Pentadentate Schiff base $\mathrm{UO}_{2}$ complexes

2.2.Macrocyclic pentadentate Schiff base ligands and their metal complexes

2.3.P-containing pentadentate Schiff base Re complexes

2.4.S-containing pentadentate Schiff base ligand and their metal complexes

3. Hexadentate Schiff base ligands and their metal complexes.

3.1. Hexadentate Schiff base Mn(II), Zn (II) and Cd(II) complexes

3.2. Hexadentate Schiff base Al(III) complexes 
3.3. Hexadentate Schiff base lanthanide(III) complexes

4. Heptadentate Schiff base ligands and their metal complexes.

5.Summary and outlook.

Acknowledgements

References

\section{Introduction}

Schiff bases are named in honor of Hugo Schiff (1834-1915), the Italian-German chemist who synthesized the first members of this class of products containing an azomethine $(-\mathrm{HC}=\mathrm{N}-)$ or imine $(>\mathrm{C}=\mathrm{N}-)$ group in $1864[1,2]$. The classical synthesis reported by Schiff involved the condensation of a carbonyl compound (aldehyde or ketone) with an primary amine under azeotropic distillation [3]. In fact, this condensation is a reversible reaction, which generally needs the removal of the generated water to balance the reaction to the right, via a carbinolamine intermediate, for high yields

(Fig. 1).

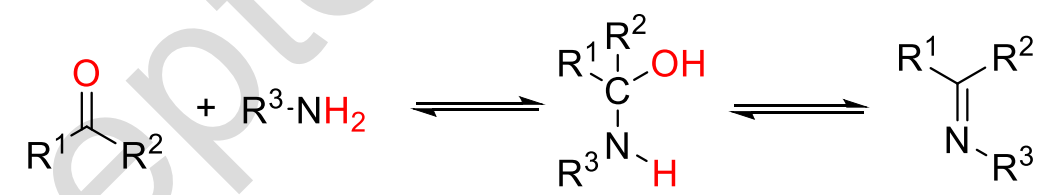

Fig. 1 The general strategy to synthesize Schiff bases.

Schiff bases are among the most widely used organic compounds, exhibiting a broad range of applications, such as intermediates in organic synthesis [4-7], chemosensors [8-10] and polymer stabilisers [11-13], in food industry [14,15], as dye [16-18] and pigments[19-21], catalysis [22,23] and others [24-26]. Schiff bases also present a broad range of biological activities[27-30] for which the azomethine or imine group present in their structures, seems to play a critical role [31-33]. However, the precise mechanisms of action of the Schiff bases are not yet fully understood and, 
therefore, continue to deserves further investigations $[34,35]$. On the other hand, Schiff bases have also been extensively explored for the synthesis of covalent organic frameworks, comprising the two- or three-dimensional porous crystalline structures via the covalent molecular assembly of Schiff base interactions with the layer-by-layer method [36,37]. In addition, most of Schiff bases have the fascinating abilities to coordinate with metallic ions to form their corresponding complexes of main group, transition metal and lanthanide and actinides elements, with their properties being significantly improved by coordinating to the metal ion [38-40]. This ability is due to their stereoelectronic and flexible structures leading to highly versatile coordination compounds with a broad scope of applications rranging from subterranean fluid flow tracking $[41,42]$ to bioinorganic and medicinal chemistry $[43,44]$. For instance, in the rational design of metal-based therapeutics, Meade and co-workers developed a serries of N-heterocyclic cobalt(III) Schiff base Complexes as potent enzyme and transcription factor inhibitors [45]. The Co(III) Schiff base derivatives of the long known equatorial tetradentate ligand bis(acetylacetone)ethylenediimine (acacen) [46], $\left[\mathrm{Co} \text { (acacen) } \mathrm{L}_{2}\right]^{+}\left(\mathrm{L}=\mathrm{NH}_{3}\right.$, imidazoles $)$ [47], inhibit histidine-containing proteins through dissociative exchange of the labile axial ligands $\mathrm{L}$. The subsequent irreversible interaction of Co(III) metal ion with specific histidine residues of a protein alters structure and causes inhibition. Interestingly, the protein inhibitory action of a substitutionally inert Co(III) Schiff base complex can be externally triggered by light through photoinduced electron transfer from colloidal $\mathrm{PbS}$ quantum dots [48], or a $\mathrm{Ru}(\mathrm{II})$ bipyridyl moiety covalently attached to the $\mathrm{Co}(\mathrm{III})$ complex [49], thus demonstrating the promise of light-activatable inorganic therapeutic agents for pro-drug strategies, utilizing redox-active metal centers.

During the last decade, considerable attention has focused on the development of Schiff base metal complexes due to their electroluminescent properties [50], biological activities (such as antiviral, antibacterial, antiapoptotic, antifungal, anti-inflammatory activities and as urease inhibitors) [51-54]. Schiff base complexes show nonlinear optical (NLO) properties [55-57], DNAbinding properties [58-61] and fluorescence properties [62-65]. They also found applications in polymeric materials [66,67], sensors [26,68], organic photovoltaic materials [69], energy materials [70], nuclear medicine [71] and as components of pharmaceutically active cocrystals [72]. Schiff base complexes exhibit also remarkable catalytic activities for a wide variety of organic 
transformations [73-87]. For instance, the use, efficiency, scope and recyclability of a $\mathrm{Cu}(\mathrm{II})$ complex featuring an unsymmetrical $\mathrm{N}_{2} \mathrm{O}_{2}$-tetradentate Schiff-base ligand and its covalently poly(methyl) (methacrylate) (PMMA)-grafted counterpart were disclosed, for the first time, as catalysts in the copper-catalyzed azides to alkynes cycloaddition (CuAAC) [88-90] for the regioselective formation of a wide variety of 1,4-disubstituted 1,2,3-triazoles via "click" reactions of organic azides and terminal alkynes [91].

Due to their highly modular synthesis allowing the control of the nature of donor atoms, denticity and chelating ability, as well as their electronic and steric properties, Schiff bases appear as "privileged ligands" $[92,93]$ and, therefore, their metal complexes have been intensively studied because of their specific and multiple physico-chemical and structural properties, including in particular eminent catalytic activity, selectivity and stability, and this field has been the subject of numerous reviews [74,93-98]. Those reviews mainly focused on complexes with tri- or tetradentate Schiff base ligands and their applications. In contrast with the tremendous progress made in the field of tridentate and especially tetradentate Schiff base ligands and their complexes, Schiff base compounds with higher denticity (penta- to hepta-, or even octadentate) are much less developed. Here we provide a review that covers the most significant developments in the penta-, hexa- , and heptadentate Schiff bases and their metal complexes, summarizing advances from recent research based, in general, on publications of the 21 st century, with a special emphasis on their functional materials properties and applications. The article is intended to introduce readers to the topic and to report recent progress in this area. Rather than being fully comprehensive in scope, the main objective is to give a general overview of the major structural characteristics of the type of systems under consideration. The review is divided in three main sections. The first and most important one is divided in four subsets: (i) Schiff bases containing N and O donors, (ii) macrocyclic Schiff bases, (iii) P-containing Schiff bases and (iv) S-containing Schiff bases. This section is organized according to the periodic order: from early to late transition metals (from group 4-12), main group elements, lanthanides and actinides. The second section describes hexadentate Schiff bbases and their complexes of $\mathrm{Mn}, \mathrm{Zn}, \mathrm{Cd}, \mathrm{Al}$, and of four lanthanides. The third section is devoted to heptadentate Schiff bases and their complexes of Mo, Mn, Cd, four lanthanides and Th(IV). The present review aims at gaining fundamental understanding and assists in the judicious design and 
construction of flexible polydentate Schiff base compounds for material science, catalytic and biological applications.

\section{Pentadentate Schiff base ligands and their metal complexes}

\subsection{N,O-containing pentadentate Schiff base complexes}

For this family of N,O-containing pentadentate ligands, the two most common types are by far those containing $\mathrm{N}_{2} \mathrm{O}_{3}$ and $\mathrm{N}_{3} \mathrm{O}_{2}$ donor sets [99], even though $\mathrm{N}_{5}$ donor set is sometimes encountered [100]. They have attracted wide attention due to their use in construction of octahedral $3 \mathrm{~d}^{4}-3 \mathrm{~d}^{7}$ transition metal complexes exhibiting spin crossover phenomenon [101,102]. Particularly, when the pentadentate ligand lies in octahedral complexes, the spin crossover behavior strongly depends on the nature of the sixth simple small ligand [103]. Though plenty of pentadentate Schiff base ligands and their metal complexes have been reported [95,104-115], the pentadentate Schiff base ligand and their metal complexes are still rare and expected to be given more attention.

\subsubsection{Pentadentate Schiff base $\operatorname{Zr}(I V)$ complexes}

The zirconium ion of Schiff base $\mathrm{Zr}$ complexes are generally in oxidation state (IV) due to its high charge-to-size ratio $\left(\mathrm{Z}^{2} / \mathrm{r}=22.22 \mathrm{e}^{2} \mathrm{~m}^{-10}\right)[116,117]$, and used for their catalytic properties. For instance, the dinuclear stable light yellow $\mathrm{Zr}$ (IV) complex 1 (Fig. 2) is synthesized by the ligand

exchange of $\mathrm{Zr}(\mathrm{acac})_{4}$ with the pentadentate Schiff base ligand of N,N'-bis(3-salicylidenaminopropyl)amine, obtained by 1:3 condensation reaction of diethylenetriamine and salicylaldehyde [118]. X-ray crystallography of $\mathbf{1}$ exhibits that each $\mathrm{Zr}(\mathrm{IV})$ metal center is seven coordinated in a distorted pentagonal bipyramidal geometry, and that two monomeric units are linked through a $\mu$-oxo bridge to form a centrosymmetric dinuclear structure. In addition, complex $\mathbf{1}$ has been used as a efficient catalyst in the reaction of indole condensation with a variety of benzaldehyde derivatives under mild conditions (Fig. 2). It is worth mentioning that inspite of the steric hindrance at $\mathrm{Zr}$ (IV) metal ion surrounded by seven donor atoms, complex $\mathbf{1}$ could still catalyze indole condensation reaction leading to isolated yields of products up to $82 \%$. 


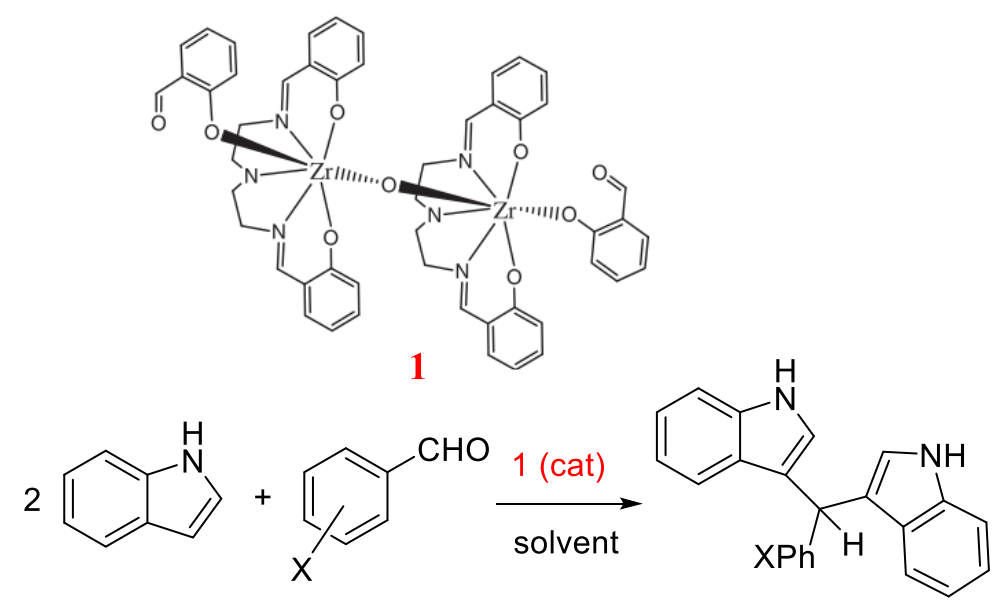

Fig. 2 Condensation of indole with benzaldehyde compounds catalyzed by the $\operatorname{Zr}(\mathrm{IV})$ pentadentate Schiff base complex 1. Reproduced with permission [118]. Copyright 2014 Elsevier B.V.

\subsubsection{Pentadentate Schiff base V complexes}

Oxovanadium(IV) Schiff base complexes derived from amino acids and aromatic $o$ hydroxyaldehydes have gained considerable attention due to their wide use as model systems for the studies of enzymes such as vanadate-dependent haloperoxidases and vanadium nitrogenases, as well as enzyme-catalyzed reactions containing pyridoxal [119-126], thus creating a rich bioinorganic and inorganic medical chemistry of vanadium complexes with potential therapeutic applications that has been very recently reviewed [127]. Vanadium complexes of N,O-donor Schiff base type ligands have also shown good catalytic activity for various organic reactions (e.g. oxygen transfers and C-H activations) [128-130]. In 2013, Maurya's group synthesized an oxidovanadium(V) pentadentate Schiff base complex 2 by the reaction of $\left[\mathrm{V}^{\mathrm{IV}} \mathrm{O}(\mathrm{acac})_{2}\right]$ and a tribasic pentadentate ligand (derived from 2-hydroxyacetophenone and 1,3-diamino-2hydroxypropane) in methanol under aerobic conditions [131]. The vanadium center adopts a distorted octahedral geometry with the $\mathrm{N}_{2} \mathrm{O}_{3}$-pentadentate ligand coordinated through the two Ophenoxy, two N-imine and one Ohydroxyl atoms (Fig. 3). Then, complex 2 has been successfully encapsulated into zeolite Y. The zeolite Y supported V complex 2 exhibits efficient catalytic activities, with a good recycling ability, in the oxidation of styrene, methyl phenyl sulfide and 
diphenyl sulfide with aqueous $\mathrm{H}_{2} \mathrm{O}_{2}$ as an oxidant. In 2015, Back et al. reported on a rare example of dinuclear vanadyl complex with mixed valences. the oxidovanadium (IV/V) compound $\mathbf{3}$ with a $\mathrm{N}_{2} \mathrm{O}_{3}$-pentadentate Schiff base ligand synthesized by reaction of vanadyl(IV) bis-acetylacetonate and the Schiff base formed by direct condensation of triethylenetetramine and pyridoxal [132]. In the dinuclear complex $\mathbf{3}$ the vanadium centers are six-coordinated in a highly distorted octahedral geometry (Fig. 3). Complex 3 was found to be a valence localized species. The mixed oxidation state $\mathrm{VO}^{2+}-\mathrm{VO}^{3+}$ has been confirmed in the solid phase by two different $\mathrm{V}=\mathrm{O}$ bond lengths $(1.902$ and $1.773 \AA$ ) and in solution by electrochemical techniques.
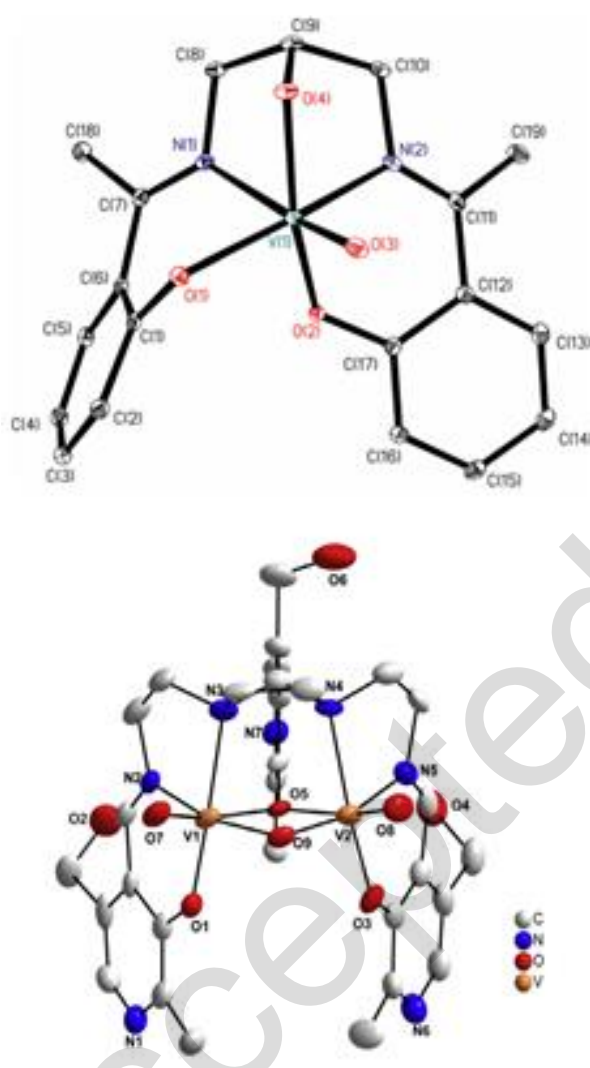

Fig. 3 ORTEP plots of oxidovanadium(V) complex 2 (top) and dinuclear mixed-valence vanadyl complex 3 (bottom). All non-hydrogen atoms are represented by their $30 \%$ probability ellipsoids. Hydrogen atoms and solvates of crystallization for $\mathbf{3}$ are omitted for clarity. Reproduced with permission [131] and [132], respectively. Copyright 2013 and 2015 Elsevier Ltd.

\subsubsection{Pentadentate Schiff base Mo complexes}


Schiff base complexes of oxo-molybdenum, particularly those of the type $c i s-\mathrm{MoO}_{2}(\mathrm{~L})\left(\mathrm{L}^{\prime}\right)$ where L stands for a dianionic tridentate ONO Schiff base ligand and L' for a monodentate ligand or donor solvent molecule, have been synthesised and studied in order to mimic the biological systems since high-valent oxo-molybdenum units are found in the active sites of a majority of molybdenumcontaining enzymes [133]. Several reviews accounting of their synthesis, structure and reactivity are available [134-137]. The applications of such $c i s-\mathrm{MoO}_{2}(\mathrm{ONO})$-type complexes are mostly oxo transfer reactions like epoxidation and sulfoxidation reactions. In 2014, Maurya and co-workers have shown that in the products $\left[\mathrm{MoO}_{2}(\mathrm{ONO}-\mathrm{X})\left(\mathrm{L}^{\prime}\right)\right]$ formed upon reaction between $\mathrm{MoO}_{2}(\mathrm{acac})_{2}$ and the potentially $\mathrm{N}_{2} \mathrm{O}_{3}$-pentadentate Schiff base ligands derived from 1,3-diamino-2hydroxypropane and 5-X-salicylaldehydes $\left(\mathrm{X}=\mathrm{H}, 4\right.$; $\mathrm{Cl}, \mathbf{5} ; \mathrm{Br}, \mathbf{6}, \mathrm{L}^{\prime}=\mathrm{H}_{2} \mathrm{O}$, DMSO), only one set of phenolic oxygen and azomethine nitrogen atoms, along with the alcoholic oxygen atom of the ligands coordinate to the molybdenum center [138]. This dianionic ONO tridentate coordination mode of the pentadentate Schiff base ligand, leaving free from coordination the other set of phenolic oxygen and azomethine nitrogen atoms of the ligand, was established in solution by IR and NMR spectroscopy and in the solid state by X-ray diffraction analysis for the 5-bromo derivative 6 (Fig. 4). Interestingly, the three cis-dioxidomolybdenum(VI) complexes 4-6 catalyze the oxidative bromination of styrene, thus presenting good functional models of haloperoxidases, and are also good catalyst precursors for the oxidation of methyl phenyl sulfide, an activity shown by molybdenum oxotransferases.

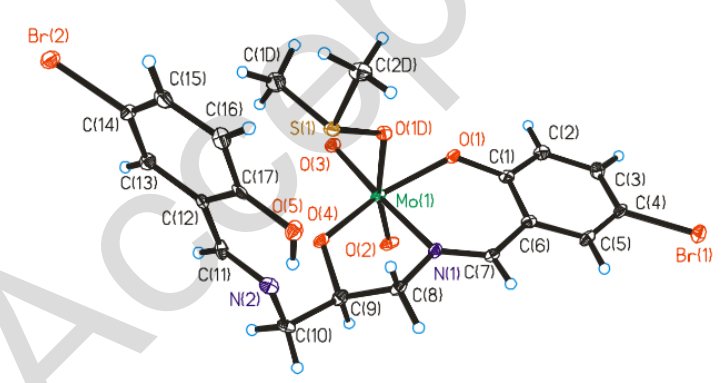

Fig. 4 ORTEP view of the complex $\left.\left[\mathrm{MoO}_{2}\right)(\mathrm{ONO}-\mathrm{Br})(\mathrm{DMSO})\right](6)$. Hydrogen atoms are omitted for clarity. Thermal ellipsoids are drawn at 30\% probability. Reproduced with permission [138]. Copyright 2014 Elsevier Ltd.

Molybdenum complexes with five-coordinate pentadentate Schiff base ligands are scarce. The first 
one $\left[\mathrm{MoCl}_{2}\left(\mathrm{~N}_{3} \mathrm{O}_{2}-\mathrm{SB}\right)\right]$ was briefly reported by Howe and co-workers in 1994 [139], and formulated as a seven-coordinate molybdenum(IV) complex containing the doubly deprotonated pentadentate 2,6-diacetylpyridine-bis(4-methylbenzoylhydrazone) ligand $\left(\mathrm{N}_{3} \mathrm{O}_{2}-\mathrm{SB}\right)$ in the equatorial plane of the complex. in 2017, Mironov et al. [140], prepared a similar heptacoordinated pentagonal bipyramidal Mo(IV) complex 7, expected to be efficient Ising-spin building block for tailoring single-molecule magnets (SMMs) [141-143]. Complex 7 was synthesized by the reaction of $\left(\mathrm{NH}_{4}\right)_{2}\left[\mathrm{MoCl}_{5}\left(\mathrm{H}_{2} \mathrm{O}\right)\right]$ with the pentadentate Schiff-base ligand (1,1'-(pyridine-2,6-diyl)bis(ethan-1yl-1-ylidene))dibenzohydrazine, formed by condensation of 2,6-diacetylpyridine with benzoic acid hydrazide [140]. Complex 7 exhibits a slightly distorted pentagonal bipyramidal geometry with the axial positions being occupied by the chloride ions (Fig. 5). The Schiff base ligand coordinates in a $\mathrm{N}_{3} \mathrm{O}_{2}$-pentadentate fashion in the equatorial plane of the complex and the five donor atoms of the dianionic ligand form an planar pentagon (Fig. 5). Complex 7 is paramagnetic at room temperature ( $\mathrm{S}=1)$ with large positive zero-field splitting $\left(\mathrm{D}=+50 \mathrm{~cm}^{-1}\right)$ and pronounced temperatureindependent paramagnetism. This work paves the way for $4 \mathrm{~d}$ compounds with an odd number of electrons that could present SMM behavior.

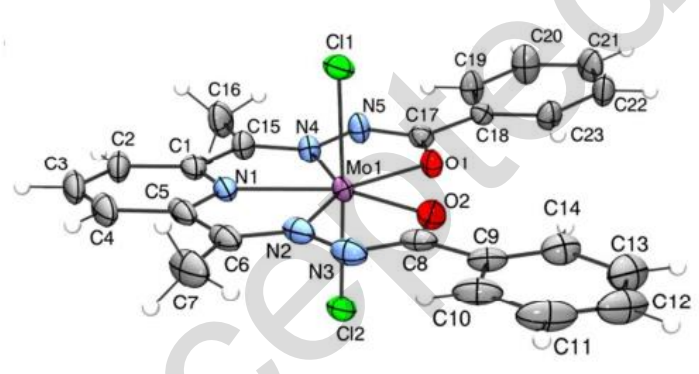

Fig. 5 ORTEP view of the heptacoordinated complex 7. Thermal ellipsoids are drawn at 50\% probability. Reproduced with permission [140]. Copyright 2017 The Royal Society of Chemistry.

\subsubsection{Pentadentate Schiff base Mn(II) complexes}

Manganese is an essential biometal for all organisms, and of unique importance for oxygenic photosynthetic organisms due to their role in the catalysis of water oxidation by photosystem II [144]. High-spin $\mathrm{Mn}$ (II) is also of particular interest as a spin carrier because it contains the highest 
possible number of unpaired electrons for a d transition metal ion [145], and as such has been extensively used in the synthesis of low-dimensional materials that may show long-range cooperative magnetic phenomena [146]. Pentadentate Schiff base ligands based on triazine scaffold reacted with tetrahydrated manganese(II) nitrate to form heptacoordinated cationic $\mathrm{Mn}$ (II) complexes. Complex $\mathbf{8}$ was prepared from the triazine-based ligand with only two hydrazone arms, 2-methoxy-4,6-bis(2-(pyridin-2-ylmethylene)hydrazinyl)-1,3,5-triazine [147], while the azidobridged derivative 9 was obtained from the tricompartmental Schiff base ligand 2,4,6-tris[\{Nmethyl-N'-(pyridine-2-yl)methylidene - hydrazino]-1,3,5-triazine, in the presence of sodium azide [148]. Both compounds 8 and 9 feature a distorted pentagonal bipyramidal metal ion environment (Fig. 6). The equatorial plane is formed by the $\left[\mathrm{Mn}\left(\mathrm{N}_{5}\right)\right]$ set of atoms, one nitrogen of the triazine and four others of the two chelate arms, with various neutral and anionic $\mathrm{O}$ - and $\mathrm{N}$-containing ligands in axial positions. Complex $\mathbf{8}$ showed good antibacterial and antifungal activities, and is recommended to use as antifungal agents against the fungus Candida Albicans. In the binuclear species 9, the magnetic coupling along the $\mu$-1,3-azido bridge was found to be weakly antiferromagnetic $\left(J=-1.72 \mathrm{~cm}^{-1}\right)$, so that such a species can be viewed as a precursor to lowdimensional magnetic materials.
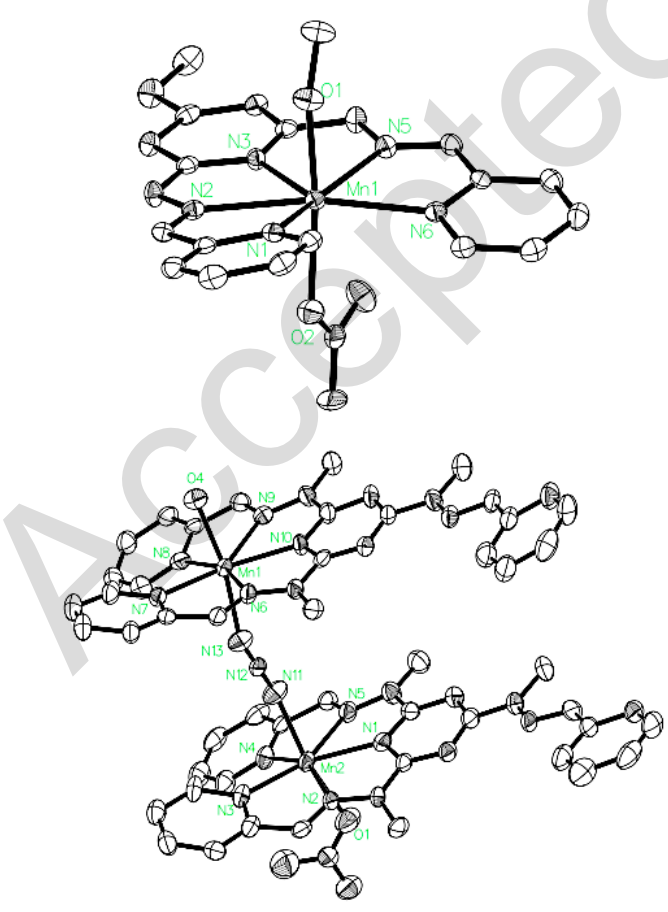

Fig. 6 Molecular structures of cationic parts of $\mathrm{Mn}(\mathrm{II})$ complexes with $\mathrm{N}_{5}$-pentadentate triazinebased Schiff base ligands: mononuclear complex 8 (top) and the azido-bridged bimetallic species 9 
(bottom). Hydrogens, counter anions and solvent crystallization molecules are omitted for clarity. Thermal ellipsoids are drawn at $60 \%$ probability.

\subsubsection{Pentadentate Schiff base Fe(III) complexes}

Since the pionnering work of Cambi et al. in the early 1930s [149-151], who first revealed the unusual magnetic properties of dithiocarbamato iron(III) complexes, a wide variety of $\mathrm{Fe}(\mathrm{III})$ spin crossover systems have been extensively studied and reviewed [101,102,152-155]. In general, the six-coordinate $\mathrm{Fe}(\mathrm{III})$ complexes show spin crossover from the low-spin to high-spin state ( $\mathrm{S}=1 / 2$ to $\mathrm{S}=5 / 2$ ), while five-coordinate $\mathrm{Fe}(\mathrm{III})$ complexes show spin crossover from the intermediate state $(\mathrm{S}=3 / 2$ to $\mathrm{S}=5 / 2)[156,157]$. Moreover, the spin transition can be induced chemically (such as a $\mathrm{pH}$, solvate, ligand change) or physically (such as light irradiation, temperature, pressure) $[152,158$ 164]. A driving force for the exploration of these bistable materials is their potential applications in different domains, such as sensors, visualization devices, data processing and storage, molecular switches, signal amplification, and utilization in medicine as contrast agents [165-169]. Schiff base $\mathrm{Fe}(\mathrm{III})$ complexes, Owing to the cheap synthesis and easy modification of the stereoelectronics of the ligands as well as the facile iron(III) complexation, appeared as an appealing family of coordination compounds to study in depth magnetic behaviour, spin states and spin crossover properties [102-110,159]. For example, Krüger et al. took the advantage of utilizing $\mathrm{N}_{3} \mathrm{O}_{2}$ pentadentate ligands derived from condensation of asymmetric triamines with salicylaldehydes or acetonaphthones to fine-tuning the spin crossover phenomenon in octahedral iron(III) complexes of the type $\left[\mathrm{Fe}\left(\mathrm{N}_{3} \mathrm{O}_{2}\right) \mathrm{X}\right][170,171]$. The labile chloride ligand in the hexacoordinated $\left[\mathrm{Fe}\left(\mathrm{N}_{3} \mathrm{O}_{2}\right) \mathrm{Cl}\right]$ complex 10 (Fig. 7), where $\mathrm{N}_{3} \mathrm{O}_{2}$ stands for the pentadentate ligand obtained by Schiff condensation of 5-bromo-2-hydroxybenzaldehyde with the asymmetric triamine, 1,6-diamino-4-azahexane, $\mathrm{H}_{2} \mathrm{~N}\left(\mathrm{CH}_{2}\right)_{3} \mathrm{NH}\left(\mathrm{CH}_{2}\right)_{2} \mathrm{NH}_{2}$, in the 2:1 ratio, was readily substituted by a simple monodentate pseudohalide ligand $\left(X=\mathrm{N}_{3}, \mathrm{NCO}, \mathrm{NCS}, \mathrm{NCSe}, \mathrm{CN}\right)$. The complexes that contain the thiocyanato or selenocyanato ligand exhibit spin crossover, whereas the cyanido ligand stabilizes the low-spin (LS) state, and the high-spin (HS) state is stabilized by weak-field ligands. 


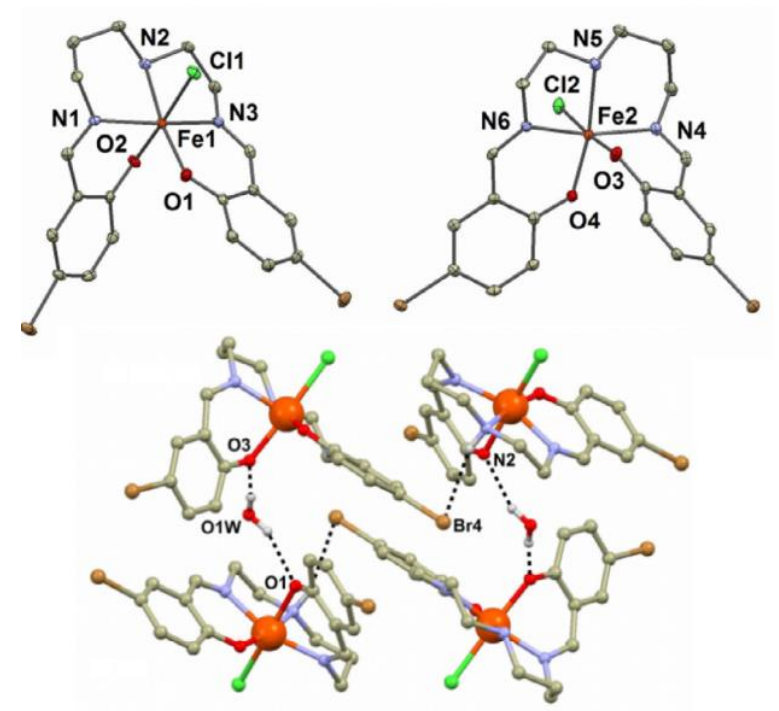

Fig. 7 Molecular structure of the octahedral Fe(III) complex 10 (top), and its crystal packing (bottom). Hydrogen atoms are omitted for clarity except for those involved in the hydrogen bonds (dashed lines). Thermal ellipsoids are drawn at the $50 \%$ probability level. Reproduced with permission [171]. Copyright 2015, Elsevier Ltd

For the Schiff-base dinuclear Fe(III) complexes, Boca's group reported on a series of three ionic compounds $\left[\{\mathrm{Fe}(\text { saldptm })\}_{2}\left(\mu^{2}-\right.\right.$ bpyO $\left.\left._{2}\right)\right]\left(\mathrm{BPh}_{4}\right)_{2}(\mathbf{1 1}),\left[\{\mathrm{Fe}(\mathrm{BuMe}-\mathrm{salpet})\}_{2}\left(\mu^{2}\right.\right.$-bpyO $\left.\left.\mathrm{O}_{2}\right)\right]\left(\mathrm{BPh}_{4}\right)_{2}(\mathbf{1 2})$ and $\left[\{\mathrm{Fe}(\text { saldpt })\}_{2}\left(\mu^{2}-\mathrm{EtbpyO}_{2}\right)\right]\left(\mathrm{BPh}_{4}\right)_{2}(\mathbf{1 3})$, where $\mathrm{H}_{2}$ saldptm $=\mathrm{N}, \mathrm{N}^{\prime}-\left(3,3^{\prime}\right.$ '-dipropylmethylamine)-bis(1-hydroxy-2-benzylidene), $\mathrm{H}_{2}$ BuMe-salpet $=$ N,N'-bis(1-hydroxy-2-benzyliden-3tertbutyl-5methyl)-1,6-diamino-4-azahexane, and $\mathrm{H}_{2}$ saldpt = N,N'-bis(1-hydroxy-2-benzylidene)1,7-diamino-4-azaheptane, whereas $\mathrm{bpyO}_{2}$ and $\mathrm{EtbpyO}_{2}$ abbreviate for the bridging bipyridine Noxide derivates 4,4'-bipyridine-N,N'-dioxide $\left(\mathrm{bpyO}_{2}\right)$ and 4,4'-ethylenedipyridine-N,N'-dioxide EtbpyO $\left._{2}\right)$ [172]. Complexes 11 and $\mathbf{1 3}$ adopt the $\operatorname{trans}(\mathrm{O}, \mathrm{O})$ arrangement while $\mathbf{1 2}$ adopts the $\operatorname{cis}(\mathrm{O}, \mathrm{O})$ arrangement. The molecular structures of $\mathbf{1 2}$ and $\mathbf{1 3}$ are displayed in Fig. 8. The three complexes have been found in high-spin state over the whole temperature region (20-293 K) by Mössbauer spectroscopy [172]. 

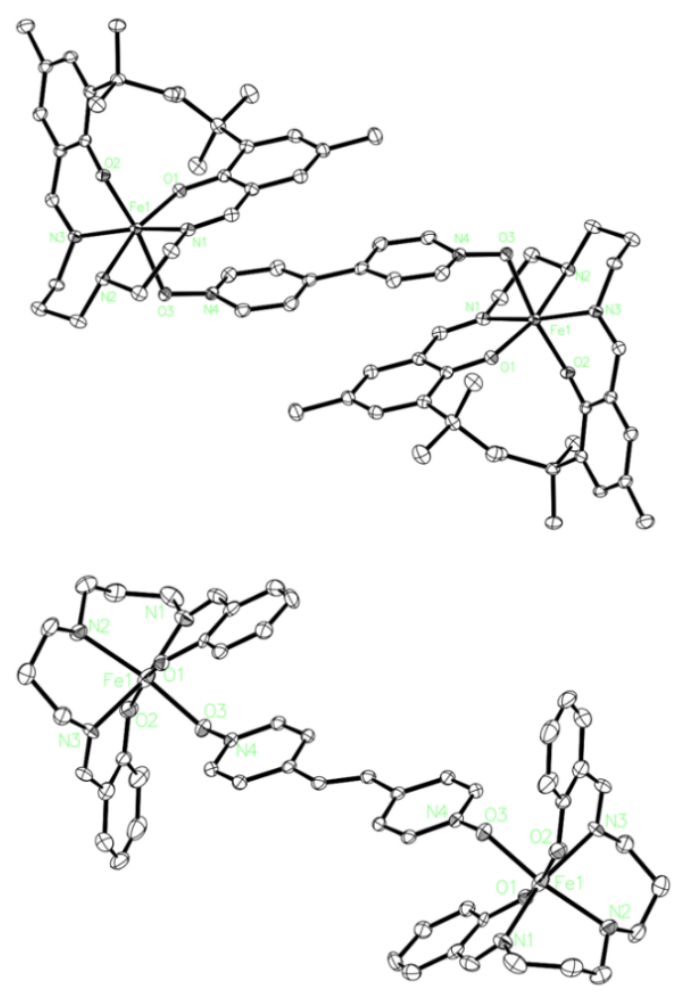

Fig. 8 Molecular structures of the cationic parts of the binuclear complexes $[\{\mathrm{Fe}(\mathrm{BuMe}-$ salpet $)\}_{2}\left(\mu^{2}-\right.$ bpyO 2$\left.)\right]\left(\mathrm{BPh}_{4}\right)_{2}(\mathbf{1 2}$, top $)$ and $\left[\{\mathrm{Fe}(\text { saldpt })\}_{2}\left(\mu^{2}\right.\right.$-EtbpyO $\left.\left.\mathrm{O}_{2}\right)\right]\left(\mathrm{BPh}_{4}\right)_{2}(\mathbf{1 3}$ bottom) showing the heteroatom numbering schemes. Hydrogen atoms, counteranions and crystallization solvents are omitted for clarity. Thermal ellipsoids are drawn at 40\% probability. Half units of complexes $\mathbf{1 2}$ and $\mathbf{1 3}$ were generated by symmetry operations $-\mathrm{x},-\mathrm{y},-\mathrm{z}$.

For the heptanuclear Schiff-base Fe(II)-Fe(III)6 system, Gembicky et al. synthesized a blue homoheptametallic $\left[\mathrm{Fe}^{\mathrm{II}}\left\{(\mathrm{CN}) \mathrm{Fe}^{\mathrm{III}}(\mathrm{L})\right\}_{6}\right] \mathrm{Cl}_{2}$ complex from high-spin $(\mathrm{S}=5 / 2)\left[\mathrm{Fe}^{\mathrm{III}}(\mathrm{L}) \mathrm{Cl}\right]$ complex and $\left[\mathrm{Fe}(\mathrm{CN})_{6}\right]^{4-}$. ( $\mathrm{L}=\mathrm{N}_{3} \mathrm{O}_{2}$ Schif base ligand of N,N'-bis(1-hydroxy-2-benzyliden)-1,7-diamino-4azaheptane). The magnetic susceptibility measurements and Mössbauer spectra have confirmed this system has twelve unpaired electrons $(\mathrm{S}=6)[173]$. Three other cases of heptanuclear $\left[\mathrm{Fe}^{\mathrm{II}}(\mathrm{CN})_{6-}\right.$ $\left.\left\{\mathrm{Fe}^{\mathrm{III}}(\mathrm{L})\right\}_{6}\right] \mathrm{Cl}_{2} \cdot \mathrm{nH}_{2} \mathrm{O}$ complexes have been synthesized by assembling the mononuclear $\mathrm{Fe}(\mathrm{III})$ Schiff base complexes with $\left[\mathrm{Fe}(\mathrm{CN})_{6}\right]^{4-}$ by Šalitros' group [174]. L represents the doubly deprotonated $\mathrm{N}_{3} \mathrm{O}_{2}$-pentadentate Schiff base ligands: N,N'-bis(2-hydroxybenzylidene)-1,5diamino-3-azapentane, N,N'-bis(3-ethoxy-2-hydroxybenzylidene)-1,7-diamino-4-azaheptane, or N,N'-bis(3-methoxy-2-hydroxybenzylidene)-1,6-diamino-3-azahexane. X-ray crystallography 
showed that the complexes adopt a star-like architecture: the $\mathrm{Fe}$ (II) ion is located at the very center, and is linked through cyanide bridges to the six surrounding $\mathrm{Fe}(\mathrm{III})$ fragments. Moreover, all six $\mathrm{Fe}(\mathrm{III})$ coordination sites are high-spin $(\mathrm{S}=5 / 2)$, while the very central Fe(II) site is low-spin ( $\mathrm{S}=$ $0)$.

\subsubsection{Pentadentate Schiff base Co complexes}

Cobalt complexes with pentadentate Schiff base ligands and their structural properties and reactivity have been extensively investigated for their many applications such as oxygen activation, molecular magnets, antifungal, antimicrobial and anticancer agents, and in catalysis $\quad[93,96,100,175-179]$. In 2017, Pogány et al. used the dianionic pentadentate Schiff base ligands of the type N,N'-bis(2hydroxy-3-R-benzylidene)-1,6-diamino-3-azahexane ( $\mathrm{R}=\mathrm{H}, \mathrm{OCH}_{3}, \mathrm{OCH}_{2} \mathrm{CH}_{3}$ ), to synthesize three new cobalt chloride complexes $\left[\mathrm{Co}\left(\mathrm{N}_{3} \mathrm{O}_{2}\right) \mathrm{Cl}\right]$ 14-16 (Fig. 9) [180]. The crystal structure of the three compounds showed a distorted tetragonal bipyramidal environment at the LS Co(III) ion. A reversible $\mathrm{Co}(\mathrm{III}) / \mathrm{Co}$ (II) wave is observed in their cyclic voltammogram. Amirnasr's group also synthesized and characterized two kinds of $\mathrm{Co}(\mathrm{III})$ complexes $\left[\mathrm{Co}\left(\mathrm{L}^{1}\right)(\mathrm{amine})\right] \mathrm{BPh}_{4}$ and $\mathrm{CO}\left(\mathrm{L}^{2}\right)($ amine $\left.)\right] \mathrm{BPh}_{4}$, with $\mathrm{N}_{3} \mathrm{O}_{2}$-pentadentate Schiff base ligands obtained via the condensation of 2-hydroxynaphthaldehyde with diethylenetriamine $\left(\mathrm{L}^{1}\right)$ and dipropylenetriamine $\left(\mathrm{L}^{2}\right)$, respectively [181]. Two of them, $\left[\mathrm{Co}\left(\mathrm{L}^{1}\right)(\text { pyrrolidine })\right]^{+} \quad(\mathbf{1 7})$ and $\left[\mathrm{Co}\left(\mathrm{L}^{2}\right)(3 \text {-methylpyridine })\right]^{+}(\mathbf{1 8})$ were structurally characterized (Fig. 10). Both complexes exhibited distorted octahedral geometry around the Co(III) metal ion, with the three donor $\mathrm{N}$ atoms of the Schiff base ligand facially arranged in $\mathbf{1 7}$ and meridionally in $\mathbf{1 8}$. The authors found the redox potentials of the central $\mathrm{Co}^{3+}$ exhibits a relatively good correlation with the $\sigma$-donor ability of the axial ligands. Furthermore, the spectroscopic and electrochemical properties of these Schiff base $\mathrm{Co}(\mathrm{III})$ complexes are also impacted by the mutual steric hindrance between the ancillary ligands and the pentadentate Schiff base [181]. For the pentadentate Schiff base Co(II) complex, trans-diaqua \{5,5'-[(E,E)-pyridine-2,6diylbis(methylidynenitrilo)]bis-[pyrimidine-2,4(1H,3H)-dione]\} cobalt(II) bis(hexafluorophosphate)dihy- drate complex 19 has been synthesized, and characterized by Koz et al. [182]. The single crystal X-ray diffraction show that $\mathrm{Co}(\mathrm{II})$ is located at the center of the slightly distorted pentagonal-bipyramidal geometry, being seven-coordinated with the two imine $\mathrm{N}$ atoms, 
the pyridine $\mathrm{N}$ atom and two carbonyl $\mathrm{O}$ atoms of the uracil groups located in the equatorial plane, and with the two water O-atoms located in the apical positions (Fig. 11).
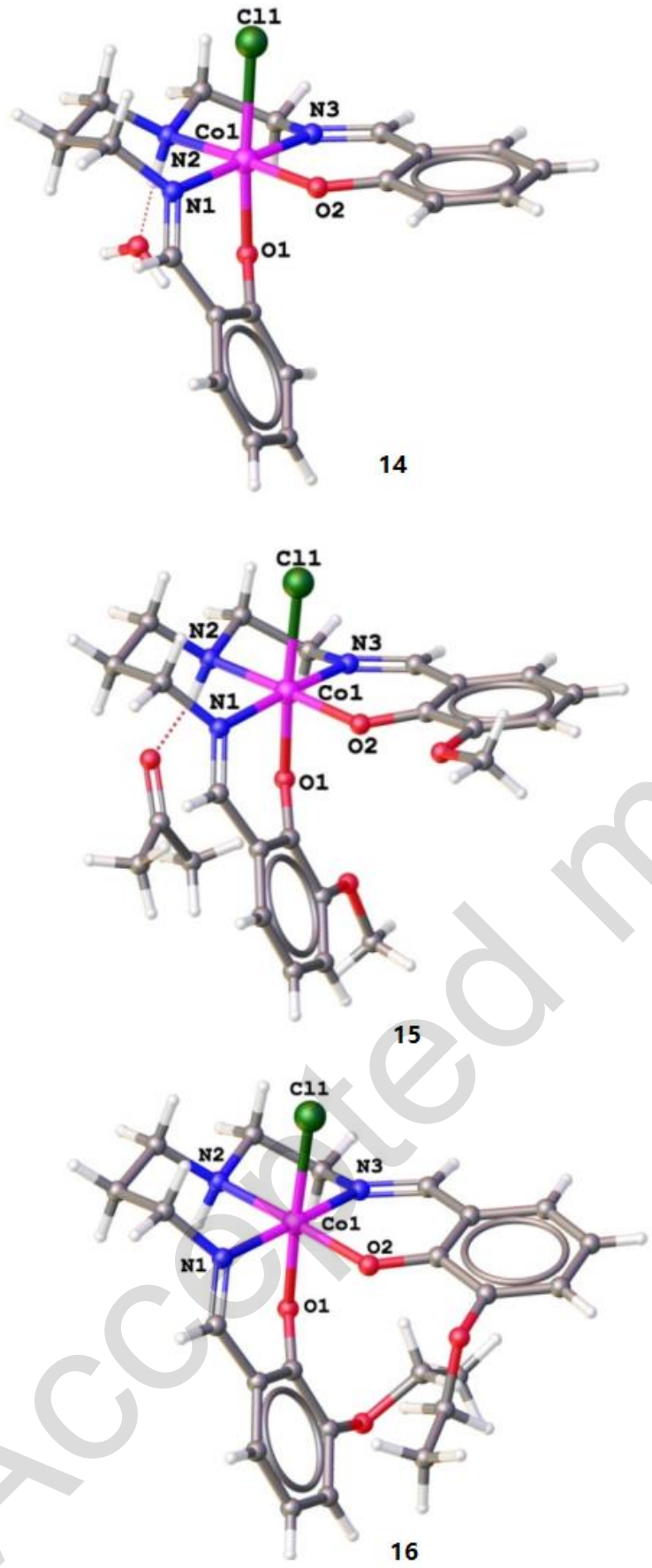

Fig. 9 Schematic representations of $\mathrm{N}_{3} \mathrm{O}_{2}$ pentadentate $\mathrm{Co}$ (III) Shiff base complexes 14 (top), 15 (middle), and 16 (bottom). Reproduced with permission [180] Copyright 2017, Elsevier B.V. 

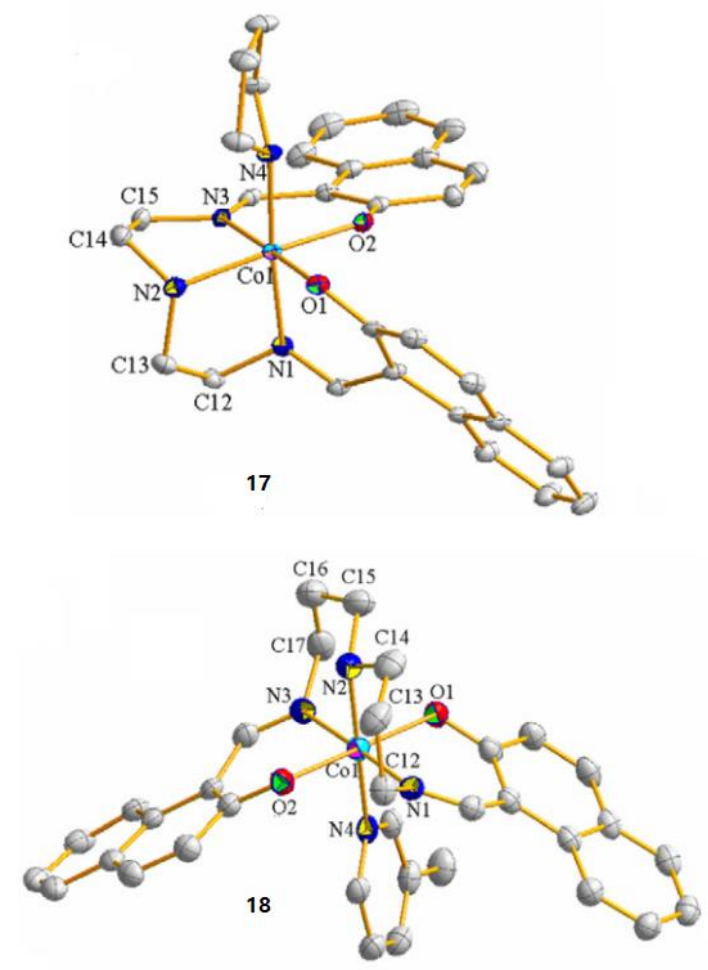

Fig. 10 ORTEP diagrams of complexes 17 (top) and 18 (bottom) with the atom labeling scheme. The displacement ellipsoides are drawn at the $50 \%$ probability level. Reproduced with permission [181]. Copyright 2011, Elsevier B.V.

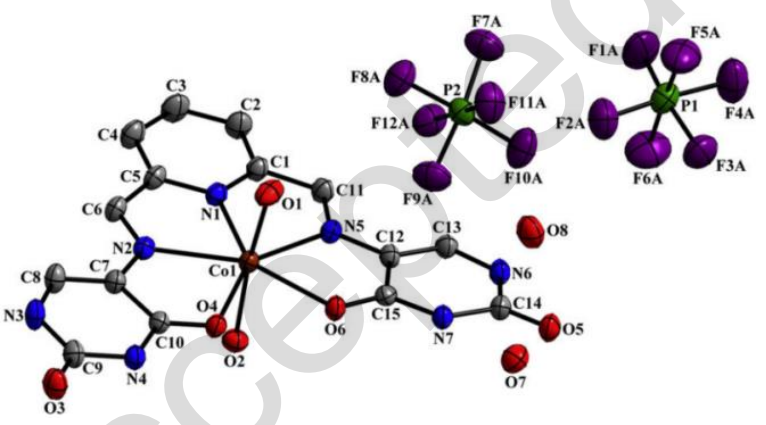

Fig. 11 Molecular structure of 19, shown with $30 \%$ probability displacement ellipsoids and illustrating the atom-numbering scheme. $\mathrm{H}$ atoms have been omitted for clarity and only major parts of disordered fragments are shown. Reproduced with permission [182]. Copyright 2009, Elsevier B.V.

\subsubsection{Pentadentate Schiff base Ni(II) and Cu(II complexes}

Bandyopadhyay and co-workers reported the ionic bimetallic Ni(II) complex 20 containing the $\mu^{1,3}$ 
$\mathrm{N}_{3}$ bridge with a terminal azide [109]. The complex is readily obtained upon reaction of the nickel hydrated perchlorate salts with the $\mathrm{N}_{3} \mathrm{O}_{2}$ pentadentate Schiff base (2-hydroxybenzylidene)-1,7diamino-4-methyl-4- azaheptane in the presence of sodium azide (Fig. 12) [109] [Note of caution: the use of all perchlorate salts is hazardous due to risk of explosion]. In 20, the two $\mathrm{Ni}$ (II) ions adopt a distorted octahedral geometry with $\left[\mathrm{Ni}\left(\mathrm{N}_{4} \mathrm{O}_{2}\right)\right]$ chromophore, and a $\mathrm{d}_{\mathrm{Ni}-\mathrm{Ni}}$ of $5.087 \AA$. Low temperature magnetic measurements established noticeable intradimer ferromagnetic interactions $\left(J=6.5 \mathrm{~cm}^{-1}\right)$. Bandyopadhyay et al. also prepared the mononuclear distorted square-pyramidal $\mathrm{Cu}$ (II) complex 21 of a $\mathrm{N}_{3} \mathrm{O}_{2}$ pentadentate Schiff base ligand (Fig. 12), via a one-pot templated reaction involving the triamine $\mathrm{N}$-(3-aminopropyl)-N-methylpropane-1,3-diamine, hydroxybenzophenone and $\mathrm{Cu}\left(\mathrm{ClO}_{4}\right)_{2} \cdot 2 \mathrm{H}_{2} \mathrm{O}$ in a 1:2:1 molar ratio [183]. In 2015, Charef et al. also synthesized two kinds of nickel(II) Schiff base complex 22 and copper(II) Schiff base complex 23 from 2,2'-(((azanediylbis(propane-3,1-diyl))- bis(azanylylidene))bis(methanylylidene))diphenol and the hydrated acetate salts of nickel(II) and copper(II), respectively [184]. In both complexes, the metal ion attains a five-coordinate distorted trigonal bipyramidal geometry with a stereospecific $\mathrm{N}_{3} \mathrm{O}_{2}$ chromophoric center (Fig. 13). In addition, complex 22 exhibits a high inhibition of the growth of all bacterial strains (8 to $14 \mathrm{~mm}$ inhibition diameters). 

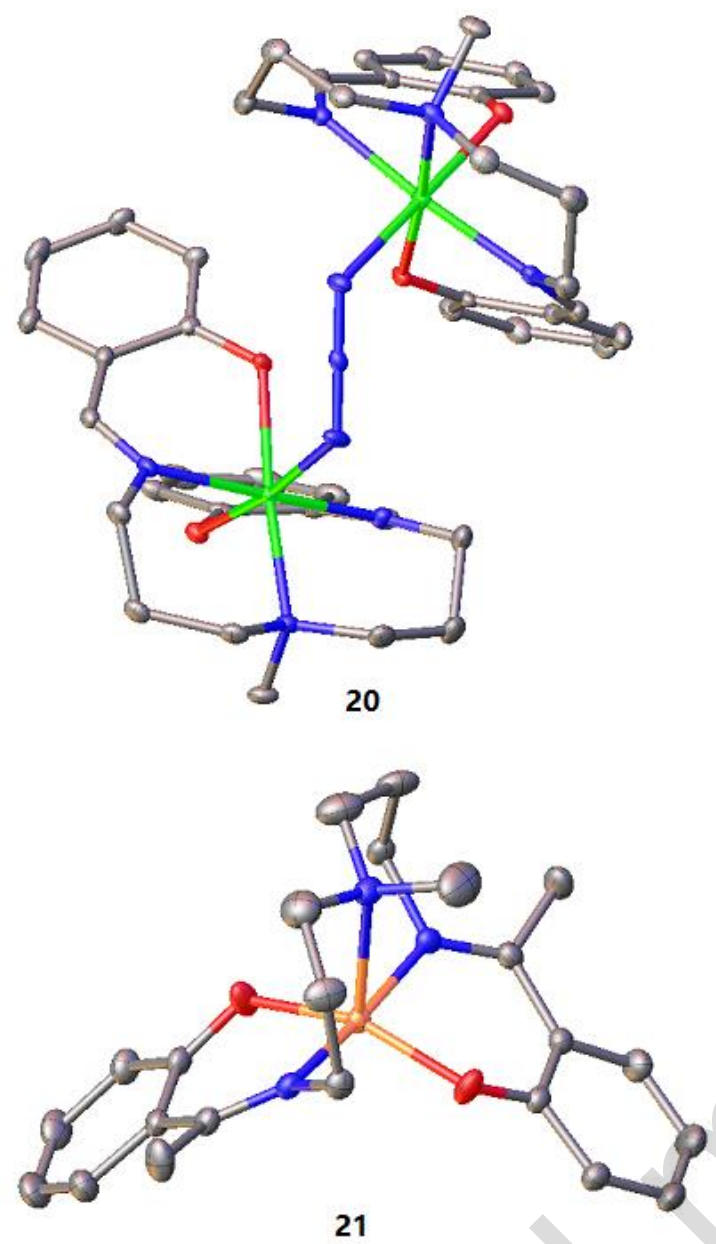

Fig. 12 Molecular structures of the Ni(II) complex 20 (top) and of the $\mathrm{Cu}$ (II) complex 21 (bottom) with their respective atom labeling scheme. Ydrogen atoms are omitted for clarity. Reproduced with permission of refs. [109] and [183], respectively. Copyright 2012 and 2013, Elsevier B.V. 

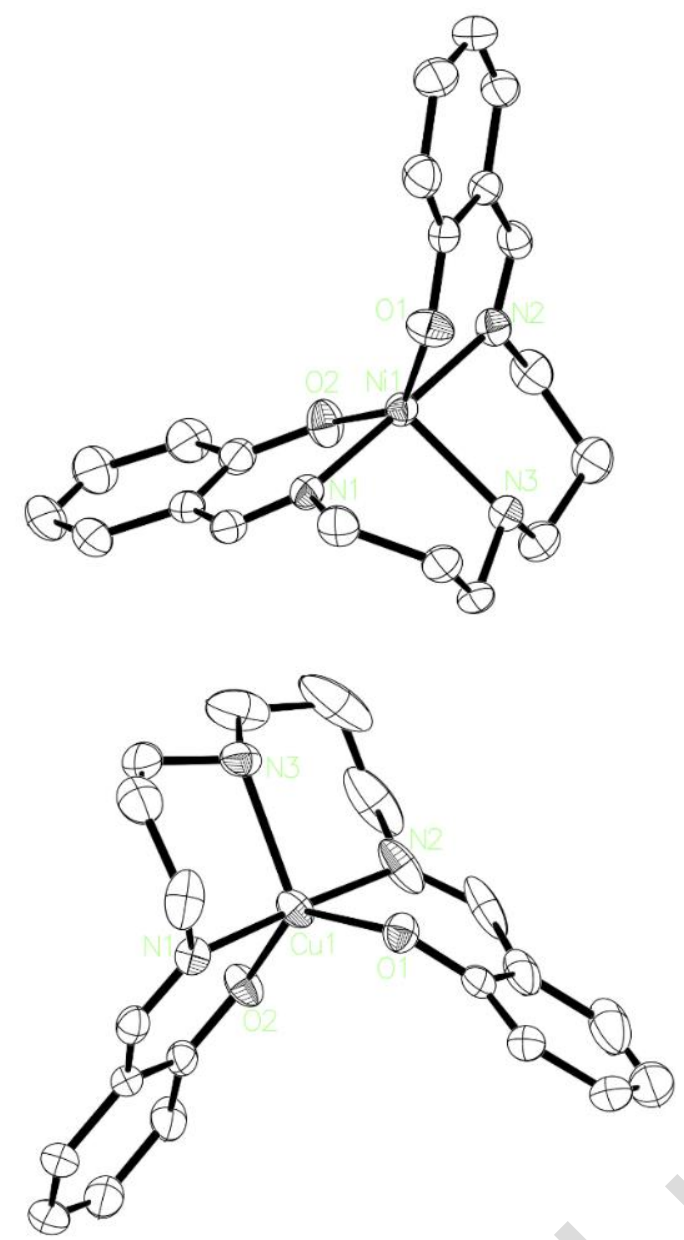

Fig. 13 Molecular structures of $\mathbf{2 2}$ (top) and $\mathbf{2 3}$ (bottom) showing the heteroatom numbering scheme. Hydrogen atoms are omitted for clarity. Thermal ellipsoids are drawn at $20 \%$ probability.

In 2006, Das and co-workers synthesized the tetrametallic complex $\left[\mathrm{Cu}_{4} \mathrm{~L}_{2}\left(\mathrm{CH}_{3} \mathrm{COO}\right)_{4}\right]$ (25) by reaction of copper acetate with the reduced pentadentate asymmetric compartmental ligand $\mathrm{H}_{2} \mathrm{~L}$ containing amino acid side arm 24 (Fig. 14). $\mathrm{H}_{2} \mathrm{~L}$ is obtained by condensation of 5-bromo-2hydroxy-3-(4-methyl-piperazin-1-yl-methyl)-benzaldehyde and L-alanine, followed by in situ reduction of the formed Schiff base with sodium borohydride [185]. The authors confirmed that the tetranuclear complex $\mathbf{2 5}$ was a dimer of dinuclear $\mathrm{Cu}$ (II) subunit by single crystal $\mathrm{X}$-ray analysis, in which the $\mathrm{Cu}$ (II) centers had different geometries and the carboxylate acted as a bridge (Fig. 14). 


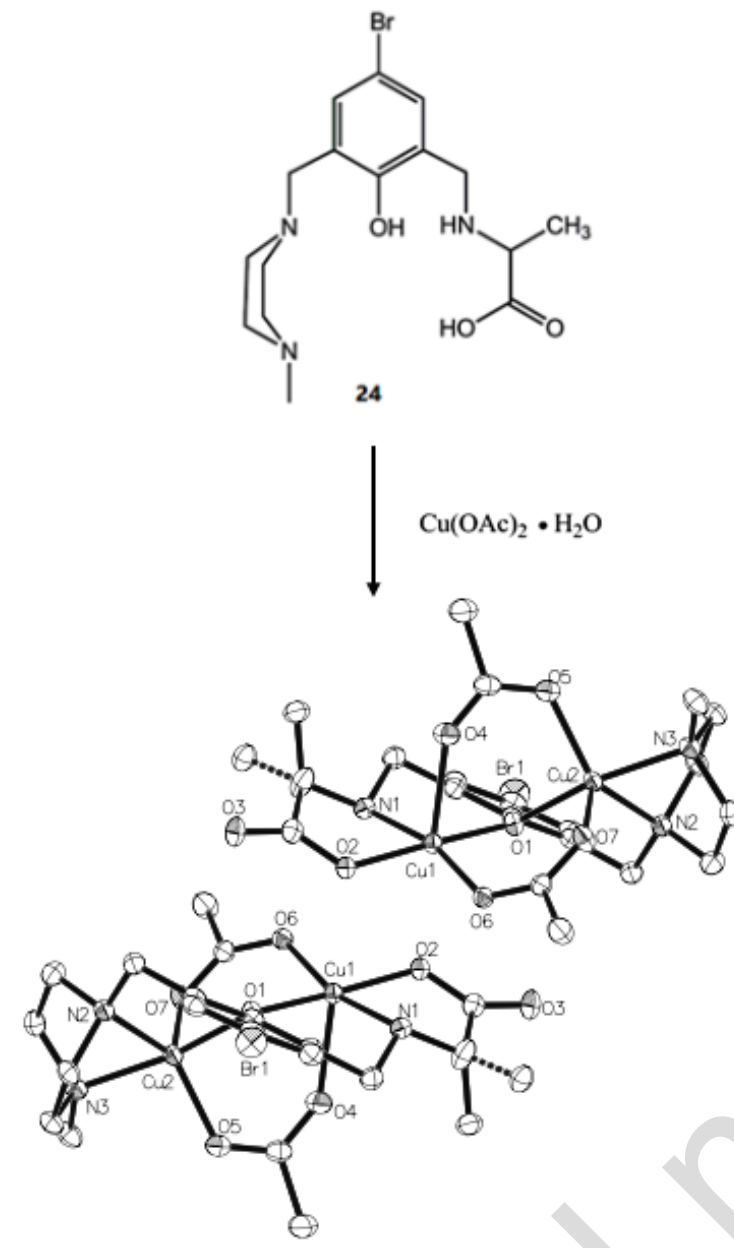

25

Fig. 14 Schematic representation of the reduced Schiff base $\mathbf{2 4}$ and molecular structure of the complex $\left[\mathrm{Cu}_{4} \mathrm{~L}_{2}\left(\mathrm{CH}_{3} \mathrm{COO}\right)_{4}\right](\mathbf{2 5})$. The tetranuclear species was generated by symmetry operation $\mathrm{x},-\mathrm{y},-\mathrm{z}$ expanded the short contact (Thermal ellipsoidal plot at $40 \%$ probability).

Plenty of polymeric copper complexes with Schiff base ligands have been assembled by molecular subunits via $\mathrm{H}-\mathrm{H}$ bonds, metal bonds and $\pi-\pi$ stacking interactions [113,186-189], due to their potential application in the fields of biological activities, metallosupramolecular chemistry and molecular magnetic materials [190,191]. For example, Yardan et al. synthesized and structurally characterized a novel polymeric zig-zag chain copper (II) complex from the monomeric unit $\mathbf{2 6}$ that are linked together via bridging aliphatic oxygen atom of the pentadentate Schiff base ligand N,N'bis(4-methoxy-salyciliden)-2-hydroxy-1,3-diaminopropane (Fig. 15) [192]. They found the polymeric zig-zag $\mathrm{Cu}(\mathrm{II})$ chain forms $2 \mathrm{D}$ networks through hydrogen bonds. Moreover, an 
antiferromagnetic $\mathrm{Cu}-\mathrm{Cu}$ exchange has been found in the dimeric unit via the bridging oxygen atoms $\left(\right.$ Curie constant $=0.49 \mathrm{~cm}^{2} \mathrm{~K} \mathrm{~mol}^{-1}$ and Weiss constant $\left.=-2.76 \mathrm{~K}\right)$.

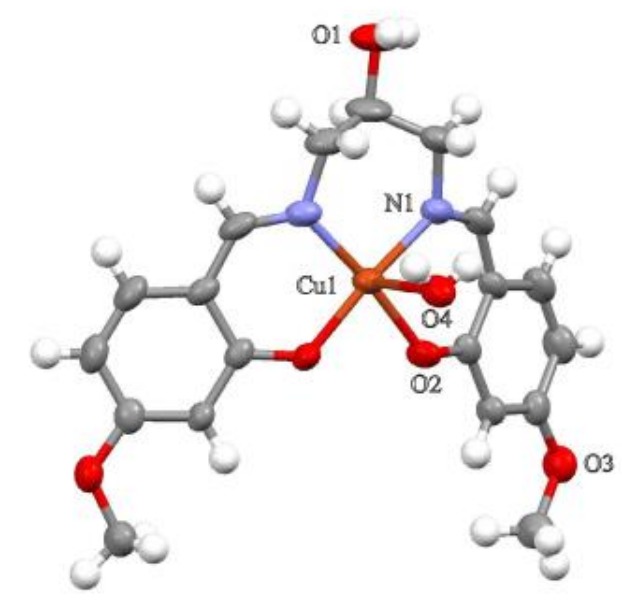

Fig. 15 Molecular structure of monomeric $\mathrm{Cu}(\mathrm{II})$ unit 26. Reproduced with permission [192]. Copyright 2014 Elsevier Ltd.

In 2000, de Castro and co-workers reported on the successful encapsulation of two copper(II) complexes with $\mathrm{N}_{3} \mathrm{O}_{2}$-pentadentate Schiff base ligands in the supercages of zeolite $\mathrm{NaX}$ [193]. Interestingly, the $\mathrm{Cu}$ (II) Schiff base complexes were formed in situ by Schiff condensation of the beforehand adsorbed copper(II) acetylacetonate precursor with the appropriate aliphatic triamine. Four years later, the two $\mathrm{Cu}$ (II) Schiff base complexes were also entrapped into a pillared clay derived from aluminum oxide pillaring oligomer and a Portuguese montmorilonite [194]. As a consequence of the steric effects imposed by the porous structure, in both cases the encapsulated complexes exhibit structural and electronic properties different from those of the free complexes.

\subsubsection{Pentadentate Schiff base Zn(II) complexes}

Pentadentate Schiff base $\mathrm{Zn}(\mathrm{II})$ complexes are of particular importance due to their immense biological properties (anticancer and antimicrobial activity) in human body and biological systems [54,195-200]. For example, Tyula et al. synthesized two new ionic Schiff base Zn(II) complexes, $\left[\mathrm{Zn}\left(\mathrm{H}_{2}\right.\right.$ dapsc) $\left.\left(\mathrm{CH}_{3} \mathrm{OH}\right)_{2}\right]\left[\mathrm{ZnBr}_{2} \mathrm{Cl}_{2}\right](\mathbf{2 7})$ and $\left[\mathrm{Zn}\left(\mathrm{H}_{2}\right.\right.$ dapsc $\left.)\left(\mathrm{CH}_{3} \mathrm{OH}\right) \mathrm{Br}\right] \mathrm{Br} .\left(\mathrm{CH}_{3} \mathrm{OH}\right)(\mathbf{2 8})$ by 1:2 
condensation of 2,6-diacetylpyridine and semicarbazide in the presence of zinc(II) ion as template agent [201]. In both complex cations, the seven-coordinate $\mathrm{Zn}(\mathrm{II})$ center adopts a distorted pentagonal bipyramidal geometry (Fig. 16). Thereinto, the pentadentate $\mathrm{N}_{3} \mathrm{O}_{2}$ semicarbazone ( $\mathrm{H}_{2}$ dapsc) ligands are located at the equatorial plane and two $\mathrm{CH}_{3} \mathrm{OH}$ ligands in $\mathbf{2 7}$, while one $\mathrm{Br}$ and one $\mathrm{CH}_{3} \mathrm{OH}$ ligands in $\mathbf{2 8}$ are located at axial positions. The crystal structure and Hirshfeld surface analysis showed that the Schiff base $\mathrm{Zn}$ (II) complexes $\mathbf{2 7}$ and $\mathbf{2 8}$ are assembled into a 3D supramolecular network by various intermolecular interactions such as $\mathrm{H}-\mathrm{H}, \mathrm{H}-\mathrm{Br}, \mathrm{H}-\mathrm{N}, \mathrm{H}-\mathrm{O}$, and H-C bonds [201].
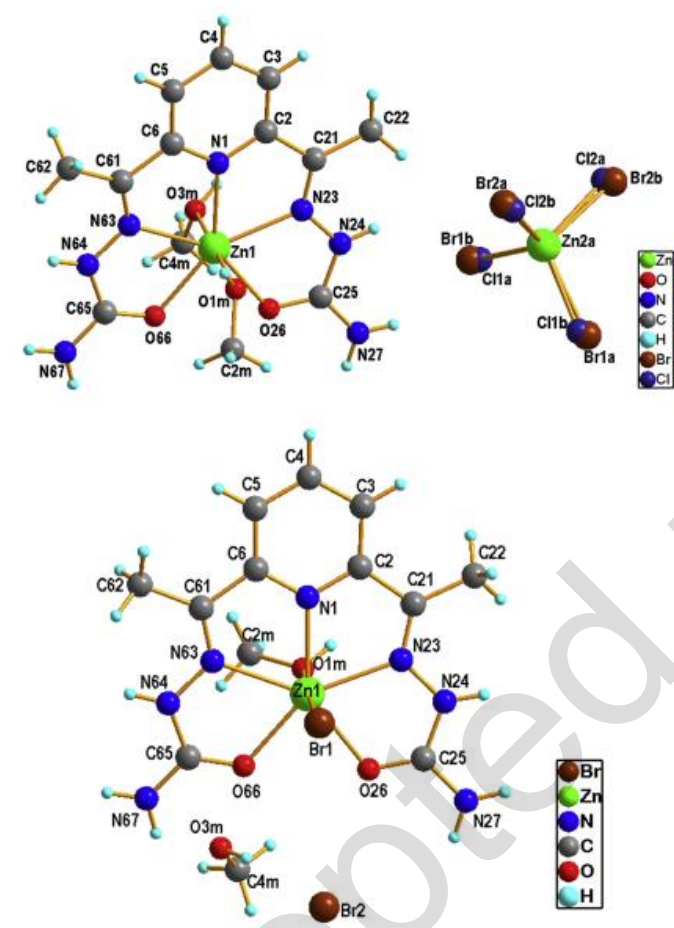

Fig. 16 Molecular structures of $\mathbf{2 7}$ (top) and $\mathbf{2 8}$ (bottom) with the atomic numbering scheme. Reproduced with permission [201]. Copyright 2017 Elsevier B.V.

The neutral $\mathrm{Zn}$ (II) complex 29 with a $\mathrm{N}_{3} \mathrm{O}_{2}$-pentadentate Schiff base ligand has been synthesized by reaction of 2,2'(((azanediylbis(propane-3,1-diyl))bis(azanylylidene))bis(methanylylidene))diphenol with $\mathrm{Zn}(\mathrm{OAc})_{2}$ [202]. From its X-ray diffraction study, the structure of 29 can be viewed as a quasi-square pyramid with the $\mathrm{N}(1)-\mathrm{N}(2)-\mathrm{N}(3)-\mathrm{O}(2)$ base and $\mathrm{O}(1)$ at the apex (Fig. 17). Furthermore, this complex has a strong fluorescence with a broad blue emission 
around $442 \mathrm{~nm}$, suggesting that this $\mathrm{Zn}$ (II) Schiff base complex might be a good model for an efficient light-induced charge-separation process [202].

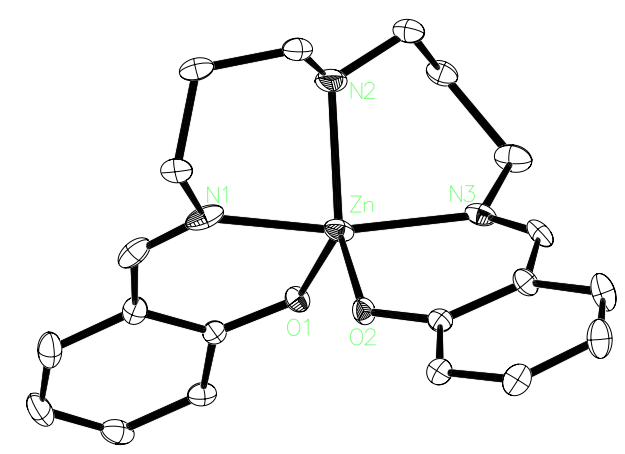

Fig. 17 X-ray crystal structure of $\mathbf{2 9}$ showing the heteroatom numbering scheme. Only one of the two symmetrically identical molecules contained in the unit cell is presented. Hydrogen atoms are omitted for clarity. Thermal ellipsoids are drawn at $40 \%$ probability.

\subsubsection{Pentadentate Schiff base Cd(II) complexes}

Contrary to $\mathrm{Zn}(\mathrm{II})$ ion that plays an important role in biological processes, $\mathrm{Cd}(\mathrm{II})$, on the other hand, is hazardous to human health and environments $[203,204]$. However, Cd(II) complexes of Schiff base ligands have been studied extensively because this second-row transition-metal ion is capable of engaging high coordination numbers (e.g., penta- to octacoordination) owing to its $\mathrm{d}^{10}$ electronic configuration and atomic size. Hence the formed Schiff base compounds that possess frramework rigidity and high thermal stability, make up attractive molecular building blocks for engineering molecular based materials [205-211]. Das et al. synthesized a mononuclear heptacoordinate Cd(II) complex $\left[\mathrm{Cd}(\mathrm{L})\left(\mathrm{H}_{2} \mathrm{O}\right)_{2}\right]\left(\mathrm{ClO}_{4}\right)_{2}(\mathbf{3 0})$, where $\mathrm{L}$ stands for the $\mathrm{N}_{6}$ donor hexadentate Schiff base 2,4bis [2-(pyridine-2-ylmethylidene) hydrazinyl] pyrimidine [212]. This ligand behaves as a neutral pentadentate $\mathrm{N}_{5}$ donor spanning itself in the equatorial plane of a pentagonal bipyramidal arrangement, forming four five-membered chelate rings that encapsulate the divalent metal ion. The two apically coordinated water molecules complete the seven-coordinate geometry (Fig. 18). Neither the ligand nor its $\mathrm{Cd}(\mathrm{II})$ complex are fluorescent. 


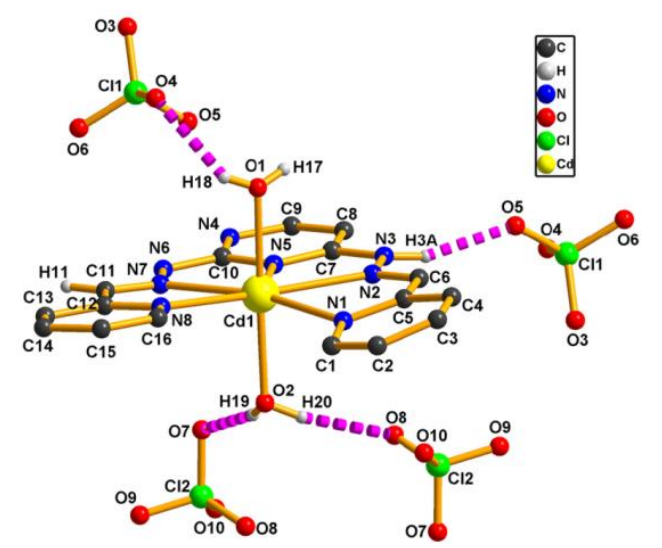

Fig. 18 Molecular structure of complex 30. Reproduced with permission [212]. Copyright 2013 Elsevier B.V.

In 2010, Ghosh's group reported the preparation and characterization of two heptacoordinated 1-D coordination polymers of the type $[\mathrm{Cd}(\mathrm{L})(\mathrm{dca})]_{\mathrm{n}}(\mathrm{X})_{\mathrm{n}} \quad\left[\mathrm{L}=\quad \mathrm{N}, \mathrm{N}^{\prime}\right.$-(bis-(pyridin-2yl)benzylidene)diethylenetriamine; dca = dicyanamide; $\left.\mathrm{X}=\mathrm{ClO}_{4}^{-}(\mathbf{3 1}), \mathrm{PF}_{6}^{-}(32)\right]$ [213]. $\mathrm{X}-\mathrm{ray}$ diffraction study revealed that in both compounds each $\mathrm{Cd}(\mathrm{II})$ center adopts a distorted pentagonal bipyramidal geometry with a $\mathrm{Cd}-\mathrm{N}_{7}$ chromophore made of five $\mathrm{N}$ atoms of the neutral $\mathrm{N}_{5^{-}}$ pentadentate Schiff base ligand and one nitrile $\mathrm{N}$ atom of each $\mu^{1,5}$ bridging dca (Fig. 19). Hydrogen bondings with $\mathrm{ClO}_{4}^{-}$and $\mathrm{PF}_{6}^{-}$counteranions embedded among the polymeric chains resulted in 2-D sheet structures. The coordination polymers have represented the reliability of combination of weak non-covalent interactions and strong covalent bonds in crystal engineering. This contributes to design functional materials at molecular level. In addition, both Cd(II) complexes $\mathbf{3 1}$ and $\mathbf{3 2}$ show intense fluorescence band at 570 and $566 \mathrm{~nm}$, respectively, with lifetimes in the range 2.65-2.70 ns, in DMF solutions at room temperature. 


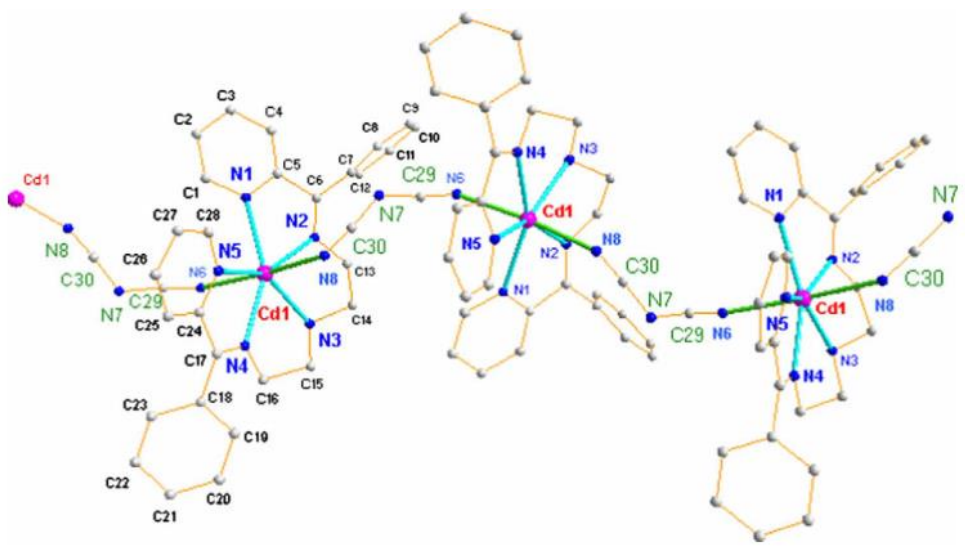

Fig. 19 ORTEP diagram of the cationic chain $[\mathrm{Cd}(\mathrm{L})(\mathrm{dca})]^{\mathrm{nn}+}$ of the coordination polymers $\mathbf{3 1}$ and 32, with atom labeling scheme. Hydrogen atoms are omitted for clarity. Thermal ellipsoids are drawn at 20\% probability. Reproduced with permission [213]. Copyright 2013 Elsevier B.V.

\subsubsection{Pentadentate Schiff base Sn complexes}

Organotin(IV) complexes of Schiff bases are of great interest because they present a wide variety of structural possibilities, catalytic activity, photophysical, non-linear optical and biological properties. Extensive literature on those topics has been compiled in the two comprehensive reviews, focusing upon their chemistry, Thermal behavior and biological applications, published byNath et al. [214,215]. As far as pentadentate Schiff base ligands are concerned here, most of their organotin(IV) compounds have ligands with $\mathrm{N}_{3} \mathrm{O}_{2}$ donor atom set, mainly derived from 2:1 Schiff condensation of salicylaldehyde or substituted salicylaldehydes and diethylenetriamine [216-219]. In such heptacoordinated complexes, the $\mathrm{N}_{3} \mathrm{O}_{2}$-pentadentate Schiff base ligand coordinates to the diorganotin(IV) moiety in the equatorial plane of a pentagonal bipyramid. In 2016, AlvaradoRodríguez and coworkers synthesized two rare examples of dibutyltin(IV) complexes having pentadentate Schiff base ligand containing the $\mathrm{N}_{2} \mathrm{O}_{3}$ donor atom set, $\mathrm{Bu}_{2} \mathrm{SnL}^{1}(\mathbf{3 3})$ and $\mathrm{Bu}_{2} \mathrm{SnL}^{2}$ (34), by condensation of di- $n$-butyltin oxide with $\mathrm{H}_{2} \mathrm{~L}^{1}$ and $\mathrm{H}_{2} \mathrm{~L}^{2}$, respectively [220]. The two ligands that are structural isomers, were prepared by 2:1 Schiff condensation of salicylaldehyde and bis-(2-aminophenyl)ether for $\mathrm{H}_{2} \mathrm{~L}^{1}$, and 2-aminophenol with bis-(2-formylphenyl)ether for $\mathrm{H}_{2} \mathrm{~L}^{2}$. Molecular structures of both complexes $\mathbf{3 3}$ and $\mathbf{3 4}$ (Fig. 20) show a hepta-coordinate Sn(IV) center in a pentagonal bipyramidal geometry, with the $\left[\mathrm{N}_{2} \mathrm{O}_{3}\right]$ core occupying the pentagonal base. The 
Sn-N iminic bond distances are shorter for $\mathrm{Bu}_{2} \mathrm{SnL}^{1}$ where five-membered chelate rings were formed than those observed in $\mathrm{Bu}_{2} \mathrm{SnL}^{2}$ that displayed two six-membered rings.
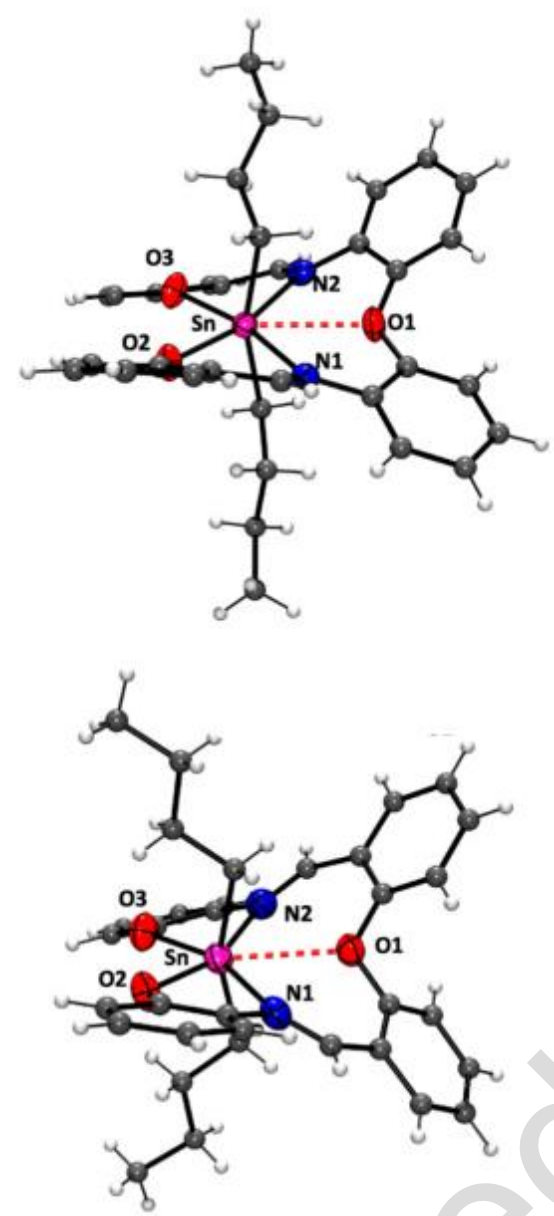

Fig. 20 Molecular structures of the di- $n$-butyltin(IV) complexes 33 (top) and 34 (bottom). Hydrogen atoms and toluene solvent molecule in $\mathbf{3 4}$ have been omitted for clarity. Thermal ellipsoids are drawn at 50\% probability. Reproduced with permission [220] Copyright 2016 Elsevier B.V.

\subsubsection{Pentadentate Schiff base Eu(III) complexes}

Europium(III) complexes of Schiff base ligands have been studied extensively due to their particularly attractive red luminescence derived from energy transfer processes between the Schiff base ligands and $\mathrm{Eu}^{3+}$ ion [221-224]. On the other hand, the excited luminescent $\mathrm{Eu}^{3+}$ center is easily quenched by water. Therefore, it is desirable that the use of suitable antenna can completely saturate the coordination sphere of $\mathrm{Eu}^{3+}$ ion to minimize/avoid non-radiative deactivations caused by water molecules. For example, Two luminescent $\mathrm{Eu}(\mathrm{III})$ complexes of $\mathrm{N}_{3} \mathrm{O}_{2}$-pentadentate Schiff base 
ligands, $\mathrm{Eu}(\mathrm{DAPBH})_{2}\left(\mathrm{NO}_{3}\right)_{3} \cdot 2 \mathrm{H}_{2} \mathrm{O} \quad(\mathbf{3 5})$ and $\mathrm{Eu}(\mathrm{DAPBH})\left(\mathrm{CH}_{3} \mathrm{CH}_{2} \mathrm{OH}\right)(\mathrm{SCN})_{3} \cdot \mathrm{H}_{2} \mathrm{O} \quad$ (36), $\mathrm{DAPBH}=\quad\left(1,1^{\prime}\right.$-(pyridine-2,6-diyl)bis(ethan-1-yl-1-ylidene) $)$ dibenzohydrazide, have been synthesized and structurally characterized by Gao et al. [225]. In complex 35, the molar ratio $\mathrm{Eu}^{3+} / \mathrm{DAPBH}$ is of $1 / 2$ with $\mathrm{NO}_{3}{ }^{-}$not coordinated to $\mathrm{Eu}^{3+}$ ion, while for 36 the molar ratio $\mathrm{Eu}^{3+} / \mathrm{DAPBH}$ is $1 / 1$ with the thiocyanates ligand strongly bounded to $\mathrm{Eu}^{3+}$ center (Fig. 21). Both 35 and $\mathbf{3 6} \mathrm{emit}$ in the red luminescence region of $\mathrm{Eu}^{3+}$ ion, demonstrating that the pentadentate Schiff base ligand is an efficient antenna for $\mathrm{Eu}^{3+}$ emission.

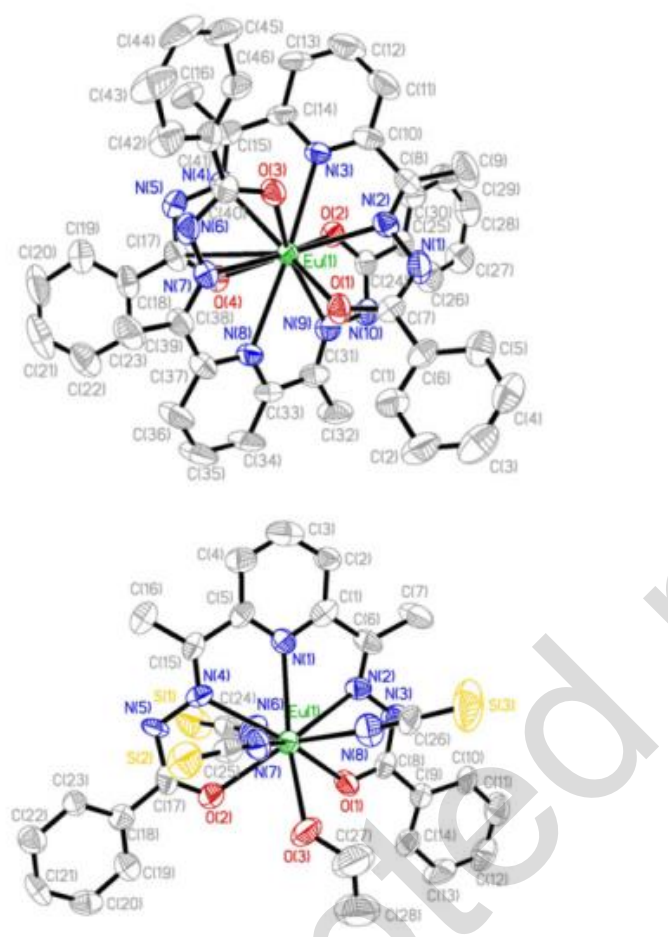

Fig. 21 Molecular structures of the ten-coordinate distorted bicapped tetragonal antiprismatic Eu(III) complex 35 (top) and of the nine-coordinate distorted monocapped tetragonal antiprismatic $\mathrm{Eu}(\mathrm{III})$ complex 36 (bottom). Hydrogen atoms, uncoordinated nitrate ions and lattice water molecules are omitted for clarity. Reproduced with permission [225]. Copyright 2012 Elsevier B.V.

\subsubsection{Pentadentate Schiff base $\mathrm{UO}_{2}$ complexes}

Actinide elements ( +5 or +6 oxidation states) usually form a typical $\mathrm{MO}_{2}{ }^{\mathrm{n}+}$ ion, which is a linear $\mathrm{O}=\mathrm{M}=\mathrm{O}$ structure. The equatorial coordination sites of $\mathrm{MO}_{2}{ }^{\mathrm{n}+}$ varies from 3 to 6 , because additional ligands are only coordinated in the equatorial plane [226-228]. Much of the research dedicated to 
developing a more complete understanding of uranyl, $\mathrm{UO}_{2}(\mathrm{VI})$, the most environmentally available oxidation state of uranium, is the result of an interest in sequestration and waste remediation as they relate to its bioinorganic chemistry [229] and to the nuclear fuel industry [230]. Albeit the pentadentate binding geometry offers a well-suited binding pocket to accommodate the larger atomic radius of uranium, the chemistry of di-oxo uranyl cation $\mathrm{UO}_{2}{ }^{2+}$ complexes of pentadentate Schiff base ligands remained poorly explored. For instance, in 2015, Back's group reported a new dioxo-uranium (VI) complex of a $\mathrm{N}_{3} \mathrm{O}_{2}$-pentadentate Schiff base ligand $\mathbf{3 7}$ formed by reaction of $\mathrm{UO}_{2}\left(\mathrm{NO}_{3}\right)_{2} \cdot 6 \mathrm{H}_{2} \mathrm{O}$ with a Schiff base ligand derived from $2: 1$ condensation reaction of pyridoxal and triethylenetetramine [132]. The imidazolidine ring was found to play an key role in the pentagonal bipyramidal geometry of the $\mathrm{UO}_{2}{ }^{2+}$ cation (Fig. 22).

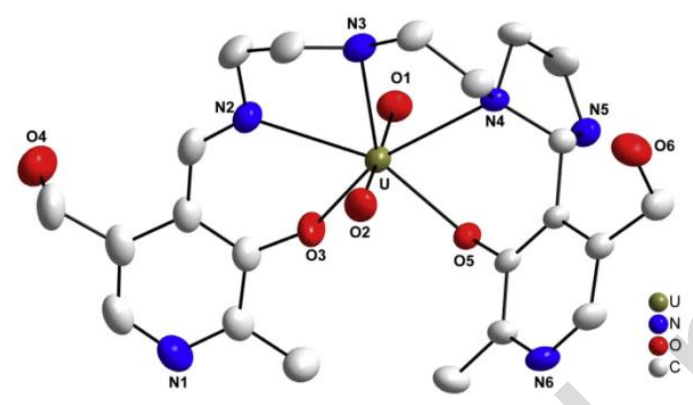

Fig. 22 Structural representation of complex 37. For greater clarity, solvates of crystallization and hydrogen atoms are not shown. Reproduced with permission [132]. Copyright 2015 Elsevier B.V.

In 2016, three new dioxo-uranium complexes of $\mathrm{N}_{3} \mathrm{O}_{2}$-pentadentate s-triazine based Schiff base ligands $\mathrm{UO}_{2}\left(\mathrm{~L}^{1}\right)(\mathbf{3 8}), \mathrm{UO}_{2}\left(\mathrm{~L}^{2}\right)(\mathbf{3 9})$ and $\mathrm{UO}_{2}\left(\mathrm{~L}^{3}\right)(\mathbf{4 0})$, have also been synthesized by reaction of uranyl acetate or nitrate with the appropriate Schiff base proligands $\mathrm{H}_{2} \mathrm{~L}^{1-3}[231] . \mathrm{L}^{1}, \mathrm{~L}^{2}$ and $\mathrm{L}^{3}$ stand for the doubly deprotonated forms of 2,4-Bis(2-hydroxybenzylidenehydrazino)-6-methoxy-striazine, 2,4-Bis(2-hydroxy-3-methoxybenzylidenehydrazino)-6-methoxy-s-triazine and 2,4-Bis(2hydroxy-3-methoxybenzylidenehydrazino)-6-amino-s-triazine, respectively. X-ray diffraction confirmed that the $\mathrm{UO}_{2}{ }^{2+}$ ion is axially positioned and the $\mathrm{U}$ center is coordinated by two phenoxo oxygen atoms and three nitrogen atoms (one from the s-triazine unit and two from the chelate arms) in the equatorial plane to generate a pentagonal bipyramidal coordination environment (Fig. 23). Fluorescence spectra of the three complexes showed maximum emission around $415 \mathrm{~nm}$. 

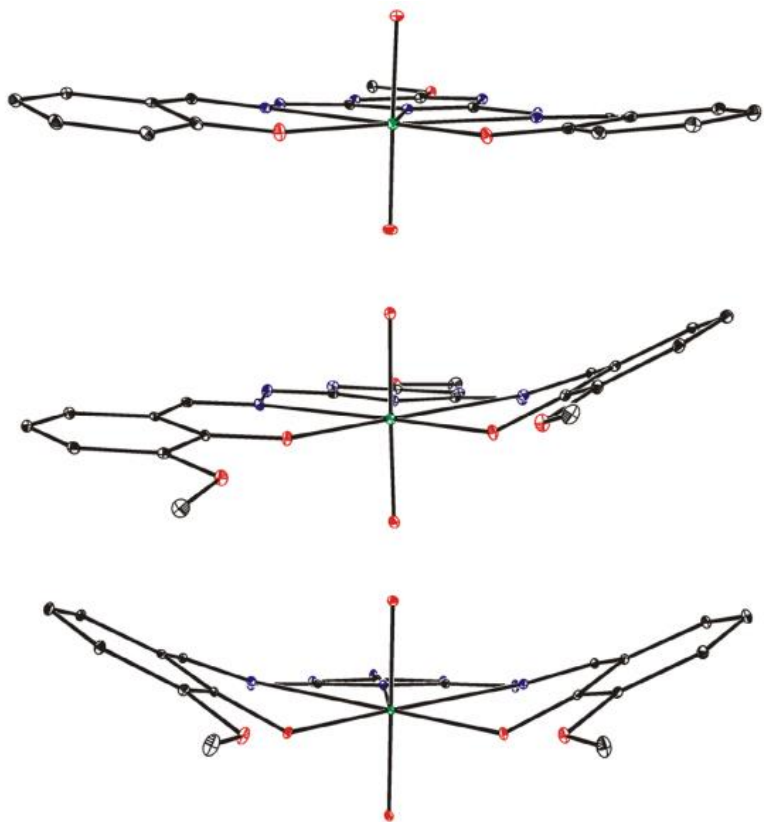

Fig. 23 Conformations of $\mathbf{3 8}, \mathbf{3 9}$ and $\mathbf{4 0}$ (from top). Angles of aromatic ring planes to equatorial coordination planes are $8.3 / 7.8^{\circ}(\mathbf{3 8}), 26.1 / 7.9^{\circ}(\mathbf{3 9})$, and $28.6 / 28.7^{\circ}(\mathbf{4 0})$. Reproduced with permission [231] Copyright 2016 Elsevier Ltd.

In 2017, Gorden and co-workers designed and synthesized, from the commercially available starting material 2,6-pyridinedicarboxylic acid, two new expanded 2,6-bis[1-[(2-hydroxy-aryl)imino]ethyl] pyridine ligands and their corresponding $\mathrm{UO}_{2}(\mathrm{VI})$ complexes (aryl = 3,5-ditertbutylphenyl, 41; napthyl, 42) [232]. The Schiff base ligands fully occupy the equatorial plane with the less strongly coordinating pyridine occupying the fifth site of the pentagon. Consequently, the U(VI) ion adopts, in both cases, a pentagonal bipyramidal coordination geometry (Fig. 24). 


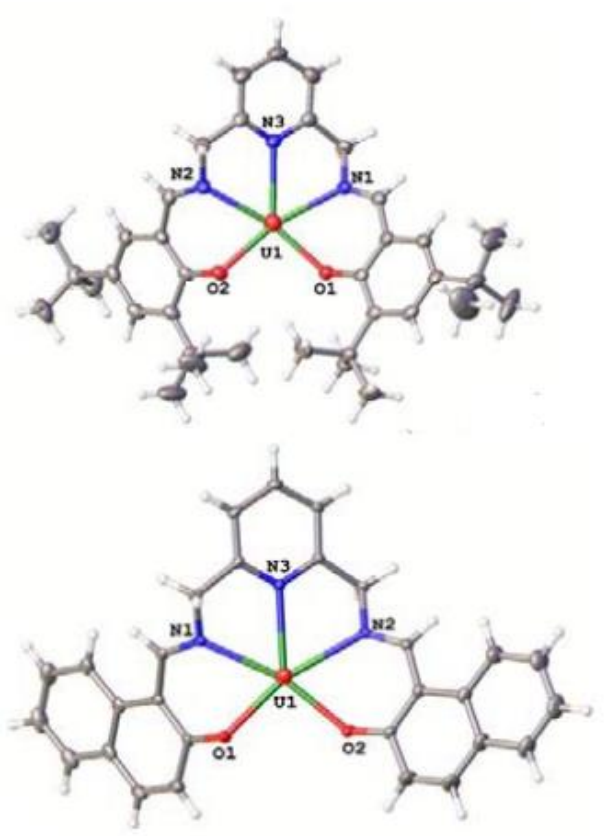

Fig. 24 Conformations of 41 (top) and $\mathbf{4 2}$ (bottom). Reproduced with permission [232] Copyright 2017 The Royal Society of Chemistry.

\subsection{Macrocyclic pentadentate Schiff base ligands and their metal complexes}

The interaction of macrocyclic pentadentate Schiff base ligands with metal ions has been the subject of a range of studies due to their unique coordination and structural properties and their wide application in bioinorganic chemistry as models of biomolecules and in modern chemical techniques such as magnetic resonance imaging [233-241]. For instance, four new macrocyclic pentadentate Schiff base $\mathrm{Ni}(\mathrm{II})$ complexes of the type $\mathrm{NiL}^{1} \mathrm{X}_{2}\left(\mathrm{X}=\mathrm{Cl}, \mathbf{4 3} ; \mathrm{Br}, \mathbf{4 4} ; \mathrm{I}, \mathbf{4 5}, \mathrm{ClO}_{4}, \mathbf{4 6}\right)$ and three of the type $\mathrm{NiL}^{1} \mathrm{X}\left(\mathrm{ClO}_{4}\right)(\mathrm{X}=\mathrm{Cl}, \mathbf{4 7} ; \mathrm{Br}, \mathbf{4 8} ; \mathrm{I}, 49)$ were synthesized by template reactions of dialdehyde 2-[3-(2-formylphenoxy)-2-hydroxypropoxy]benzaldehyde and 1,3-diaminopropane in the presence of $\mathrm{Ni}(\mathrm{II})$ salts by Khandar's group [242]. The 16-membered mixed-donor macrocyclic Schiff base ligand $\mathrm{L}^{1}$ incorporating a pendant alcohol function, 8,9,18,19-tetrahydro-7H,17Hdibenzo[f,o][1,5,9,13] dioxadiazacyclohexadecin-18-ol, acts as a $\mathrm{N}_{2} \mathrm{O}_{3}$-pentadentate Schiff base ligand. The anionic ligand $\mathrm{X}^{-}$occupies the sixth coordination site of the distorted octahedral environment around the nickel center (Fig. 25, top). Later on, the same group prepared a new series of five $\mathrm{Ni}(\mathrm{II})$ complexes of the type $\mathrm{NiL}^{2} \mathrm{X}_{2}\left(\mathrm{X}=\mathrm{Cl}, \mathbf{5 0} ; \mathrm{Br}, \mathbf{5 1} ; \mathrm{I}, \mathbf{5 2} ; \mathrm{NO}_{3}, \mathbf{5 3} ; \mathrm{ClO}_{4}, \mathbf{5 4}\right)$ where $\mathrm{L}^{2}$ is the macrocyclic Schiff base ligand 8,9,18,19-tetrahydro-7H,17Hdibenzo[f,o][1,5,9,13]dioxadiaza 
cyclohexadecine-8,18-diol, obtained by template condensation of 2-[3-(2-formylphenoxy)-2hydroxypropoxy]benzaldehyde and 1,3-diamino-2-propanol in the presence of NIX $_{2}$ hexahydrates [243,244]. In all the five complexes $\mathbf{5 0 - 5 4}$, the potentially $\mathrm{N}_{2} \mathrm{O}_{4}$-hexadentate ligand $\mathrm{L}^{2}$ behaves as a pentadentate ligand, on oxygen of the alcohol function remaining free of coordination. Complexes 50-53 contain nickel(II) in a distorted octahedral environment of $\mathrm{N}_{2} \mathrm{O}_{3} \mathrm{X}$ donor set (Fig. 25, bottom).
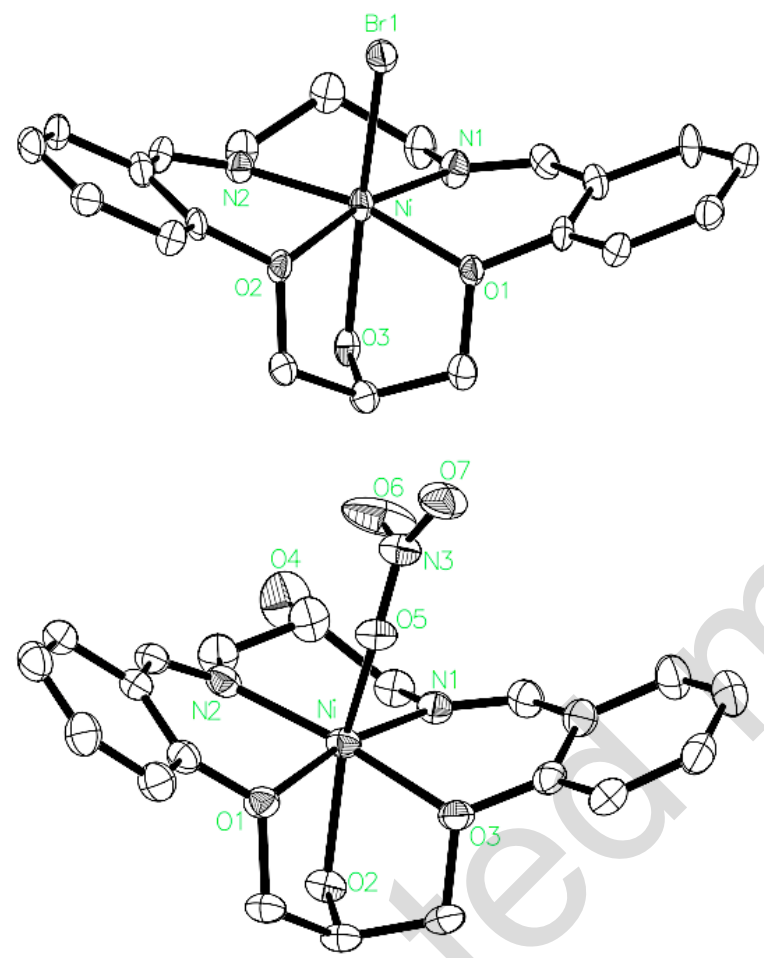

Fig. 25 Molecular structures of the cationic parts of complexes $\mathrm{NiL}^{1} \mathrm{Br}_{2} \cdot \mathrm{CH}_{3} \mathrm{CN}(\mathbf{4 4}$, top) and of $\mathrm{NiL}^{2}\left(\mathrm{NO}_{3}\right)_{2}(\mathbf{5 3}$, bottom). Hydrogen atoms, counteranions, solvent crystallization molecules are omitted for clarity. Thermal ellipsoids are drawn at $40 \%$ and $20 \%$ probability for $\mathbf{4 4}$ and $\mathbf{5 3}$, respectively.

In the field of macrocyclic pentadentate Schiff base Mn(II) complexes, Decurtins and co-workers synthesized the precursor $\left[\mathrm{Mn}^{\mathrm{II}}(\mathrm{L}) \mathrm{Cl}_{2}\right]$ where $\mathrm{L}$ stands for the $\mathrm{N}_{3} \mathrm{O}_{2}$-pentadentate macrocyclic Schiff base ligand resulting from the 1:1 cyclocondensation of 2,6-Diacetylpyridine and 3,6-dioxaoctano1,8 diamine, and used it as building block to react with metallocyanide derivatives $\left[\mathrm{M}(\mathrm{CN})_{\mathrm{n}}\right]^{\mathrm{m}-}(\mathrm{M}$ 
$=\mathrm{Cr}, \mathrm{Fe}, \mathrm{Ni}, \mathrm{Pd}, \mathrm{Pt})$. As a result, eight cyano-bridged molecular assemblies, all containing the $\left[\mathrm{Mn}^{\mathrm{II}}(\mathrm{L})(\mathrm{CN})_{2}\right]^{2+}$ unit (55) (Fig. 26), have been obtained with a variety of structural topologies [245]. In 2016, A series of mononuclear Mn(II) complexes of the macrocyclic pentadentate Schiff base (15-pyN ${ }_{3} \mathrm{O}_{2}(3,12,18$-triaza-6,9-dioxabicyclo- [12.3.1] octadeca-1(18),14,16-triene)) with two axially coordinated halido-/ pseudohalido coligands $(\mathrm{X})$, of the thype $\left[\mathrm{Mn}\left(15-\mathrm{pyN}_{3} \mathrm{O}_{2}\right) \mathrm{X}_{2}\right](\mathrm{X}=\mathrm{I}$, 56; $\mathrm{N}_{3}, \mathbf{5 7} ; \mathrm{NCS}, \mathbf{5 8}$ ) have been synthesized by Drahos et al. [246]. The single crystal X-ray analysis of $\mathbf{5 6}, \mathbf{5 7}$ and $\mathbf{5 8}$ demonstrated that all of them have a distorted pentagonal-bipyramidal geometry (Fig. 27). Furthermore, these complexes have potential ability to form supramolecular 1D chains due to hydrogen bonds, non-covalent contacts and $\pi$ - $\pi$ stacking interactions [246].

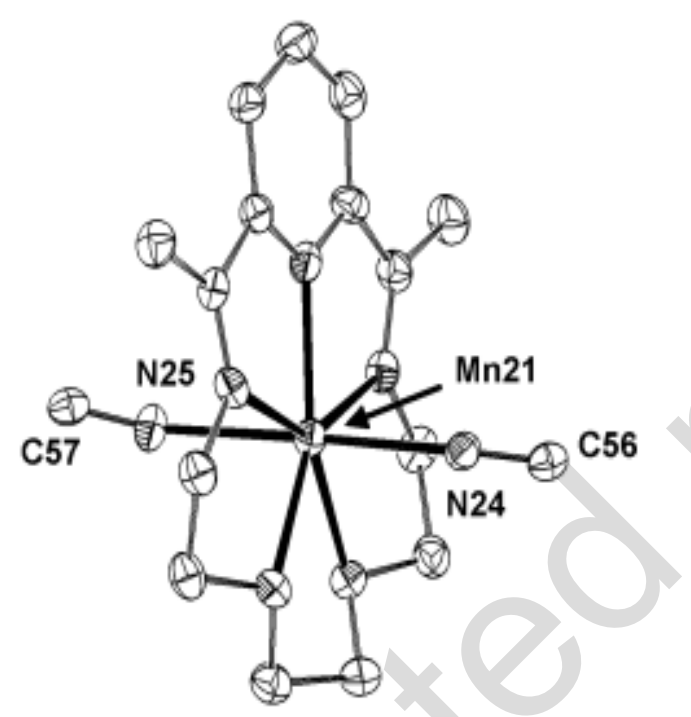

Fig. 26 ORTEP representation (ellipsoids at 50\% probability) of the molecular structure of the $\left[\mathrm{Mn}(\mathrm{L})(\mathrm{CN})_{2}\right]^{2+}$ unit (55). Reproduced with permission [245]. Copyright 2005 American Chemical Society. 

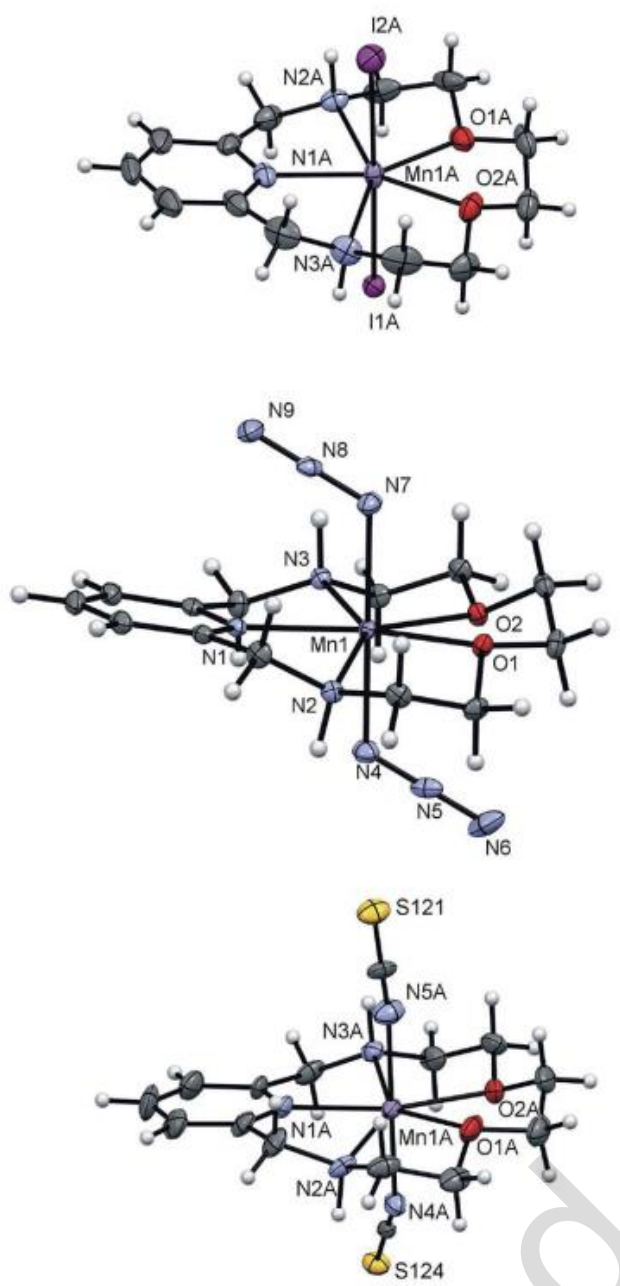

Fig. 27 Molecular structures of $\left[\mathrm{Mn}\left(15-\mathrm{pyN}_{3} \mathrm{O}_{2}\right) \mathrm{I}_{2}\right]\left(\mathbf{5 6}\right.$, top), $\left[\mathrm{Mn}\left(15-\mathrm{pyN}_{3} \mathrm{O}_{2}\right)\left(\mathrm{N}_{3}\right)_{2}\right](\mathbf{5 7}$, middle), and $\left[\mathrm{Mn}\left(15-\mathrm{pyN}_{3} \mathrm{O}_{2}\right)(\mathrm{NCS})_{2}\right](\mathbf{5 8}$, bottom). Non-hydrogen atoms are drawn with thermal ellipsoids at the 50\% probability level. Only one of two (for 56) and three (for 58) crystallographically independent molecules are shown for clarity. Reproduced with permission [246]. Copyright 2016 The Royal Society of Chemistry.

In 2017, Keypour and co-workers synthesized and structurally characterized the $\mathrm{Mn}$ (II) (59) and $\mathrm{Zn}(\mathrm{II})(\mathbf{6 0})$ macrocyclic Schiff-base complexes by templated 1:1 cyclocondensation reaction of 2,2'(piperazine-1,4-diylbis(methylene))dianiline and 2,6-pyridinedicarbaldehyde in the presence of $\mathrm{Mn}(\mathrm{II})$ and $\mathrm{Zn}(\mathrm{II})$ perchlorate salts, respectively [247]. In both complexes $\mathbf{5 9}$ and $\mathbf{6 0}$, the metal(II) ions are in a seven-coordinate, distorted pentagonal planar environment, surrounded by five nitrogen 
atoms from the macrocyclic ligand, with two monodentate perchlorate anions (in 59) and two water molecules (in 60) occupying the axial positions (Fig. 28). The results of antibacterial studies indicate that complex $\mathbf{5 9}$ has more activity than Tobramycin and Tetracycline (as standards) against $B$. thuringiensis, $S$. saprophyticus and Pectobacterium sp bacteria. Complex $\mathbf{6 0}$ exhibits more cytotoxic activity than doxorubicin as standard in U87 MG cell line [247]. The crystal structure of a sixcoordinate $\mathrm{Zn}$ (II) complex $\mathbf{6 1}$ based on the 16-, membered pentaaza macrocycle derived from 1:1 cyclocondensation of 2,6-diacetylpyridine and $\mathrm{N}, \mathrm{N}$ '-bis(3-aminopropyl)piperazine in the presence of $\mathrm{ZnBr}_{2}$, was also reported by the same group [248]. In this case, the hexacoordinated metal center adopts a slightly distorted pentagonal pyramidal geometry (Fig. 29).
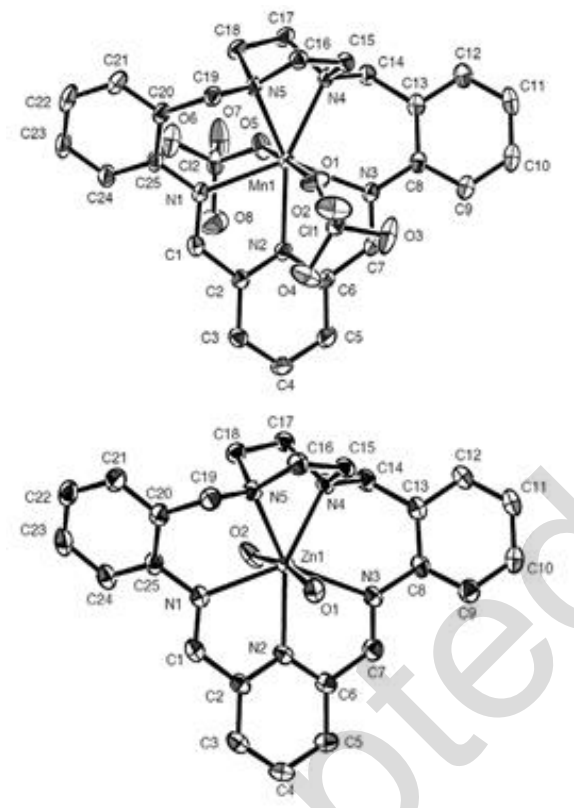

Fig. 28 ORTEP representations of $\left[\mathrm{MnL}\left(\mathrm{ClO}_{4}\right)_{2}\right]\left(\mathbf{5 9}\right.$, top) and $\left[\mathrm{ZnL}\left(\mathrm{H}_{2} \mathrm{O}\right)_{2}\right]\left(\mathrm{ClO}_{4}\right)_{2}(\mathbf{6 0}$, bottom). Displacement ellipsoids are drawn at the $50 \%$ probability level. The $\mathrm{H}$ atoms and counter ions $\left(\mathrm{ClO}_{4}^{-}\right)$ for $\mathbf{6 0}$ are omitted for clarity. Reproduced with permission [247]. Copyright 2017 Elsevier Ltd. 


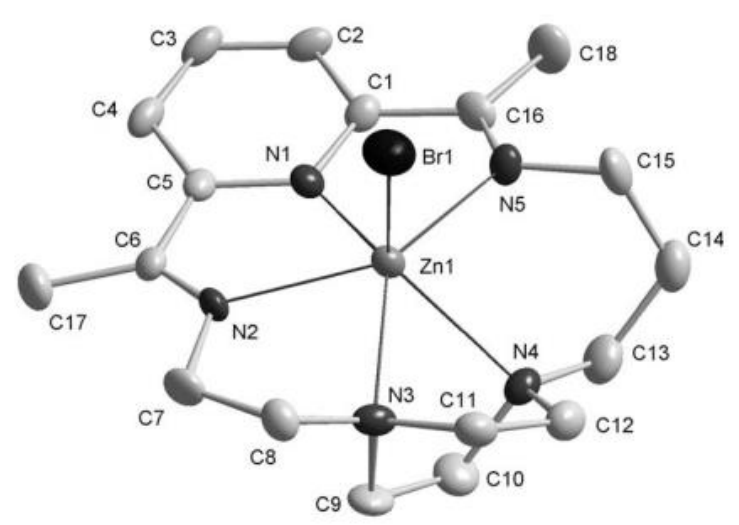

Fig. 29 Crystal structure of the cationic part of complex $[\mathrm{ZnLBr}] \mathrm{ClO}_{4}(\mathbf{6 1})$ with atom numbering scheme. All H atoms and the counter ion are omitted for clarity. Displacement ellipsoids are shown at 30\% probability level. Reproduced with permission [248]. Copyright 2009 Elsevier Ltd

\subsection{P-containing pentadentate Schiff base Re complexes}

Phosphorus-containing pentadentate Schiff base ligands are easily synthesized from the readily available formylphosphines of the composition $\mathrm{Ph}_{3-\mathrm{n}} \mathrm{P}\left(2-\mathrm{C}_{6} \mathrm{H}_{4} \mathrm{CHO}\right)_{n}(\mathrm{n}=1-3)$. As a result, these Schiff base ligands usually contain additional donor atoms $[249,250]$. Despite the fact that Pcontaining pentadentate ligand systems are perfectly suitable for the stabilization of $\left[\operatorname{Re}^{\mathrm{V} N}\right]^{2+}$, $\left[\mathrm{Re}^{\mathrm{V}} \mathrm{NPh}\right]^{3+}$ or $\left[\mathrm{Re}^{\mathrm{v}} \mathrm{O}\right]^{3+}$ cores, the corresponding Re complexes have wide applications in nuclearmedical therapy with the $\beta$ - emitting isotopes ${ }^{186} \mathrm{Re}$ and ${ }^{188} \mathrm{Re}$, there are only a few examples of structurally well-characterized complexes [251-253]. For example, Abram's group synthesized two novel pentadentate Schiff base Re complexes 62 and 63 by reactions of $\operatorname{PhP}\left\{\mathrm{C}_{6} \mathrm{H}_{4}-2-\left(\mathrm{CH}_{2}-\right.\right.$ $\left.\left.\mathrm{NH}\left(\mathrm{C}_{6} \mathrm{H}_{4}-2-\mathrm{OH}\right)\right)\right\}_{2}\left(\mathrm{H}_{2} \mathrm{~L}\right)$ with $\left[\mathrm{NBu}_{4}\right]\left[\mathrm{ReOCl}_{4}\right]$ (Fig. 30) [254].

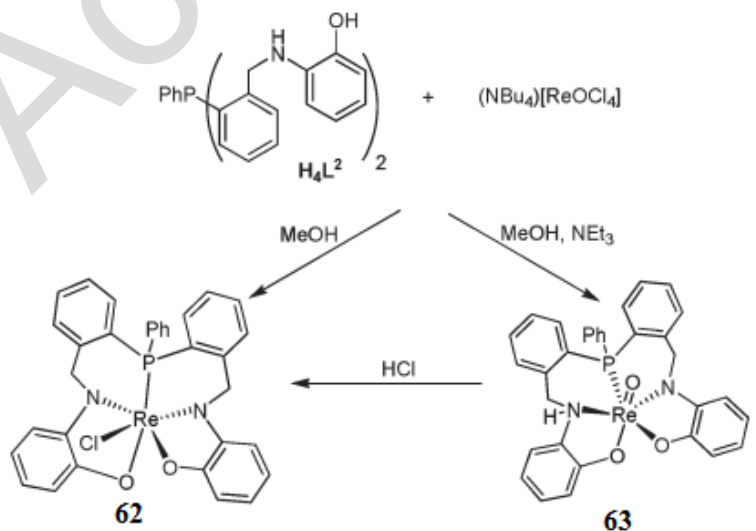


Fig. 30 Synthesis of $[\operatorname{ReCl}(\mathrm{L})](\mathbf{6 2}$, left) and $[\mathrm{ReO}(\mathrm{HL})](\mathbf{6 3}$, right). Reproduced with permission [254]. Copyright 2009 American Chemical Society.

\subsection{S-containing pentadentate Schiff base ligand and their metal complexes}

Sulfur-containing Schiff base ligand and their metal complexes, where sulfur is a soft donor atom in the backbone, have been the subject of a great deal of studies, mainly due to their interesting physical and chemical properties, and wide application in bioinorganic and medicinal chemistry [255-274]. In 2013, Dieng et al. synthesized two new polynuclear nickel(II) complexes $\left[\left(\mathrm{NiL}^{1}\right)_{2}\right] \cdot \mathrm{CH}_{3} \mathrm{OH} \cdot 4 \mathrm{H}_{2} \mathrm{O}$ (64) and $\left[\mathrm{Ni}_{3}\left(\mathrm{H}_{2} \mathrm{~L}^{2}\right)_{2}\left(\mathrm{NO}_{3}\right)_{2}\right] \quad(65)$ by reaction of pentadentate salicylaldimine acyclic Schiff base ligand 2-((2-(2-(2-hydroxybenzylideneamino)ethylthio)ethylimino)methyl)phenol $\left(\mathrm{H}_{2} \mathrm{~L}^{1}\right)$ and its related hydrogenated derivative 2-((2-(2-(2hydroxybenzylamino)ethylthio)ethylamino)methyl)phenol $\left(\mathrm{H}_{4} \mathrm{~L} 2\right)$ with hydrated nitrate and perchlorate nickel(II) salts [275]. The geometry around the two metal ion of the dimer $\mathbf{6 4}$ and the two peripheral $\mathrm{Ni}(\mathrm{II})$ ions of the trimetallic species $\mathbf{6 5}$ can be described as slightly distorted octahedral in a $\mathrm{N}_{2} \mathrm{SO}_{3}$ donor set environment . In both complexes, the nickel atoms are linked by two bridging phenolate oxygens (Fig. 31). The magnetic data shows there is a moderate antiferromagnetic interaction in complexes $64\left(J=-66.4 \pm 0.6 \mathrm{~cm}^{-1}\right)$ and $65(J=-11.12 \pm 0.3$ $\mathrm{cm}^{-1}$ ) via the phenoxo bridge. The dimeric double helical nickel(II) complex 66 has been synthesized from the reaction of 2,6-diacetylpyridine Schiff base of S-methyldithiocarbazate and nickel(II) acetate tetrahydrate by Mirza et al. [276]. Interestingly, the pyridine nitrogen atom acts as an unusual bridging donor atom leading to six-coordinate $\mathrm{Ni}$ (II) centers with a $\mathrm{N}_{4} \mathrm{~S}_{2}$ coordination cores (Fig. 32). On the other hand, in the same paper the authors showed that the helical dimeric copper(II) complex 67, obtained by reaction of copper acetate and 2,6-diacetylpyridine Schiff base of Sbenzyldithiocarbazate, does not contain any shared donor atoms [276]. Consequently, each $\mathrm{Cu}$ ( II) ion in dimer 67 is five-coordinate, approximately square-pyramidal, sitting in an $\mathrm{N}_{3} \mathrm{~S}_{2}$ donor environment (Fig. 32). 

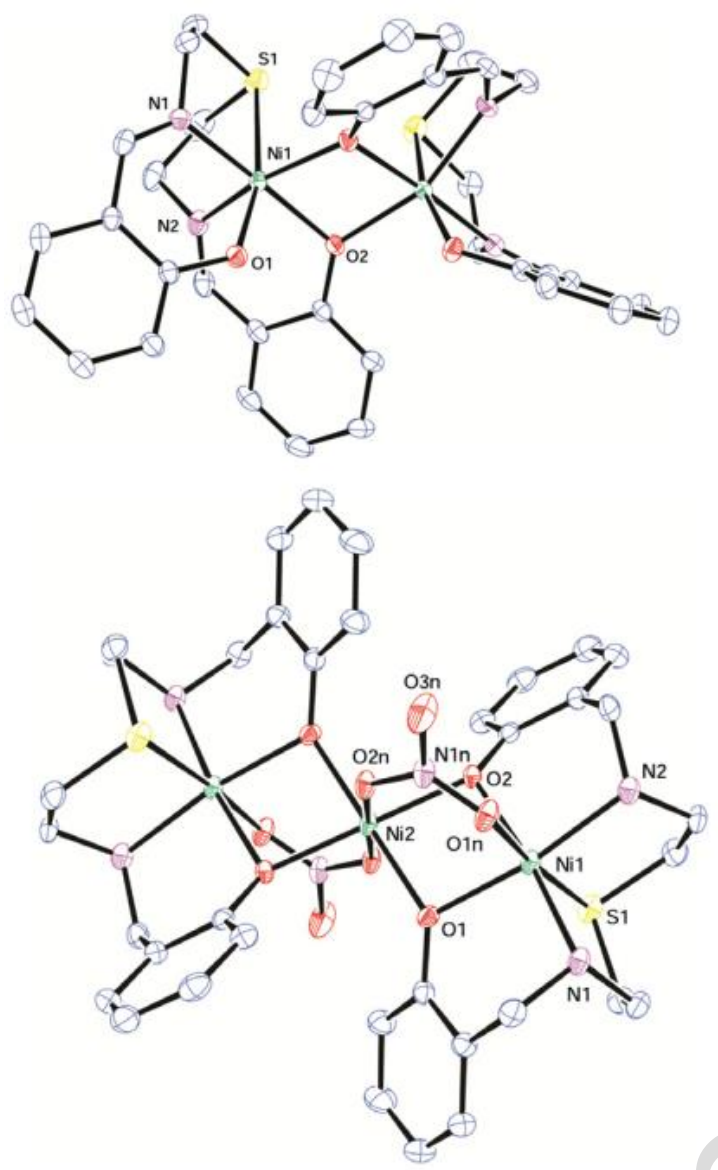

Fig. 31 Crystal structures of $\left[\left(\mathrm{NiL}^{1}\right)_{2}\right] \cdot \mathrm{CH}_{3} \mathrm{OH} \cdot 4 \mathrm{H}_{2} \mathrm{O}(64$, top $)$ and $\left[\mathrm{Ni}_{3}\left(\mathrm{H}_{2} \mathrm{~L}^{2}\right)_{2}\left(\mathrm{NO}_{3}\right)_{2}\right](65$, bottom). Reproduced with permission [275]. Copyright 2012 Elsevier B.V.
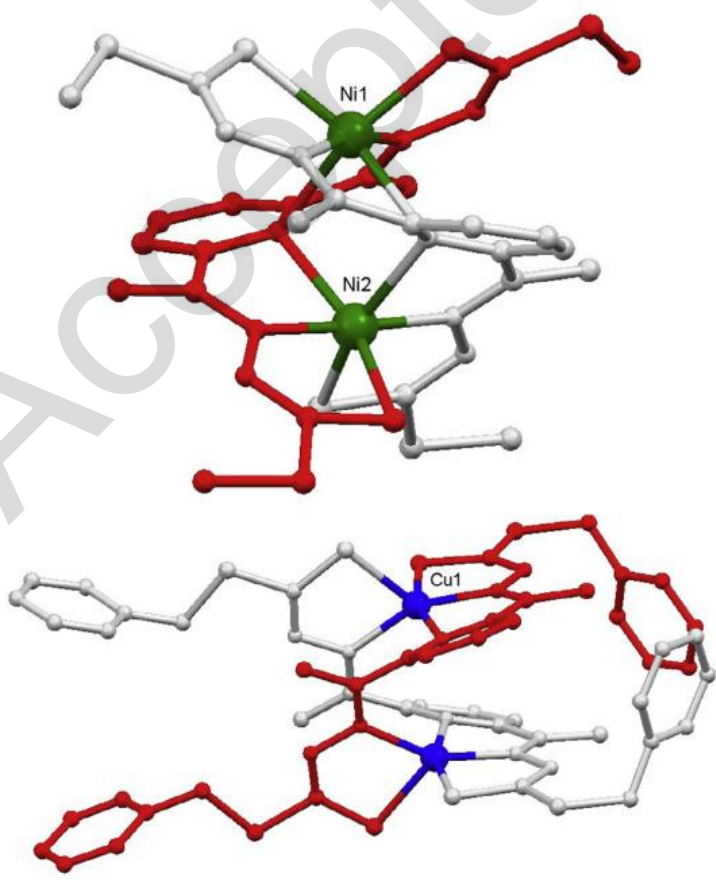
Fig. 32 Ball-and-stick view of the dimeric double helical Ni(II) complex 66 (top) and of the dimeric helical $\mathrm{Cu}$ (II) complex 67 (bottom), where the two symmetry related ligands are differently coloured. The twofold axis is aligned horizontally and the $\mathrm{Cu}$ ions are crystallographically identical. Reproduced with permission [276]. Copyright 2014 Elsevier Ltd

The first pentacoordinate $\mathrm{Pb}(\mathrm{II})$ complex with a pentagonal geometry, $\left[\mathrm{Pb}\left(\mathrm{H}_{2} \mathrm{DAPTsz}-\mathrm{Me}\right)\right](\mathbf{6 8})$, has been synthesized by reaction of the $\mathrm{N}_{3} \mathrm{~S}_{2}$-pentadentate Schiff base proligand bis(4-Nmethylthiosemicarbazone) 2,6-diacetylpyridine ( $\left.\mathrm{H}_{4} \mathrm{DAPTsz}-\mathrm{Me}\right)$ with lead anode in an electrochemical cell, by Bermejo's group [277]. The five donor atoms of $\mathrm{N}_{3} \mathrm{~S}_{2}$ ligand coordinate exclusively to $\mathrm{Pb}$ (II) ion center due to inert pair effect (Fig. 33). Furthermore, using the same methodology with the appropriate metal anode, they also prepared the heptacoordinated [ $\left.\mathrm{Mn}\left(\mathrm{H}_{2} \mathrm{DAPTsz}-\mathrm{Me}\right)(\mathrm{EtOH})_{2}\right]$ complex 69 and the dimeric $\left[\mathrm{Zn}\left(\mathrm{H}_{2} \mathrm{DAPTsz}-\mathrm{Me}\right)\right]_{2} \cdot \mathrm{EtOH} \cdot 2 \mathrm{H}_{2} \mathrm{O}$ complex 70 [278]. The heptacoordinated $\mathrm{Mn}$ (II) complex $\mathbf{6 9}$ shows a pentagonal bipyramidal structure, while the helical zinc dimer $\mathbf{7 0}$ shows octahedral and tetrahedral environments for the metal centers (Fig. 33). 

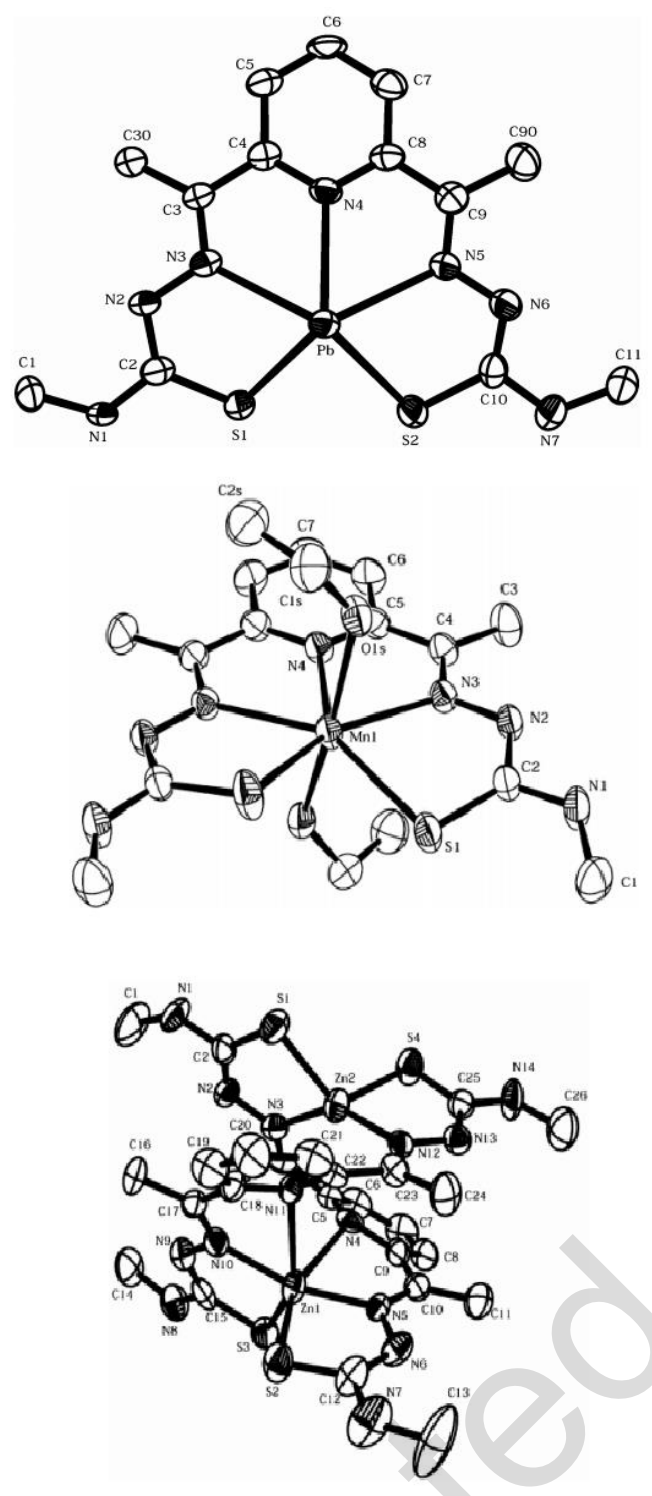

Fig. 33 Molecular structures of $\left[\mathrm{Pb}\left(\mathrm{H}_{2} \mathrm{DAPTsz}-\mathrm{Me}\right)\right](\mathbf{6 8}, \mathrm{top}),\left[\mathrm{Mn}\left(\mathrm{H}_{2} \mathrm{DAPTsz}-\mathrm{Me}\right)(\mathrm{EtOH})_{2}\right](\mathbf{6 9}$, middle), and $\left[\mathrm{Zn}\left(\mathrm{H}_{2} \mathrm{DAPTsz}-\mathrm{Me}\right)\right]_{2} \cdot \mathrm{EtOH} .2 \mathrm{H}_{2} \mathrm{O}$ (70, bottom), showing the atomic numbering scheme. Thermal ellipsoids are drawn at the 50\% probability level. Hydrogen atoms as well as lattice $\mathrm{EtOH}$ and $\mathrm{H}_{2} \mathrm{O}$ for $\mathbf{7 0}$ are omitted for clarity. Reproduced with permission [277]. Copyright 2005 The Royal Society of Chemistry.

Using the same kind of $\mathrm{N}_{3} \mathrm{~S}_{2}$-pentadentate Schiff bases, de Sousa's group prepared three sevencoordinate diorganotin(IV) complexes $\mathbf{7 1 - 7 3}$ by the reaction of 2,6-diacetylpyridine bis(Smethyldithiocarbazate)] ( $\mathrm{H}_{2}$ dapmdtc) and 2,6-diacetylpyridine bis(S-benzyldithiocarbazate)] ( $\mathrm{H}_{2}$ dapbdtc) with $\mathrm{Me}_{2} \mathrm{SnCl}_{2}$ or $\mathrm{Ph}_{2} \mathrm{SnCl}_{2}$ [278]. The X-ray structures demonstrated these complexes 
exhibit a distorted pentagonal bipyramidal geometry, with organic groups in the apical positions and the $\mathrm{N}_{3} \mathrm{~S}_{2}$-pentadentate Schiff bases donor atoms occupying the equatorial plane (Fig. 34). Homologous cationic zinc(II) and cadmium(II), and neutral diorgano- and dihalogeno-tin(IV) pentagonal bipyramidal complexes of $\mathrm{N}_{3} \mathrm{~S}_{2}$-pentadentate $\mathrm{Schiff}$ base ligand have alsos been reported by Ali and co-workers [279].
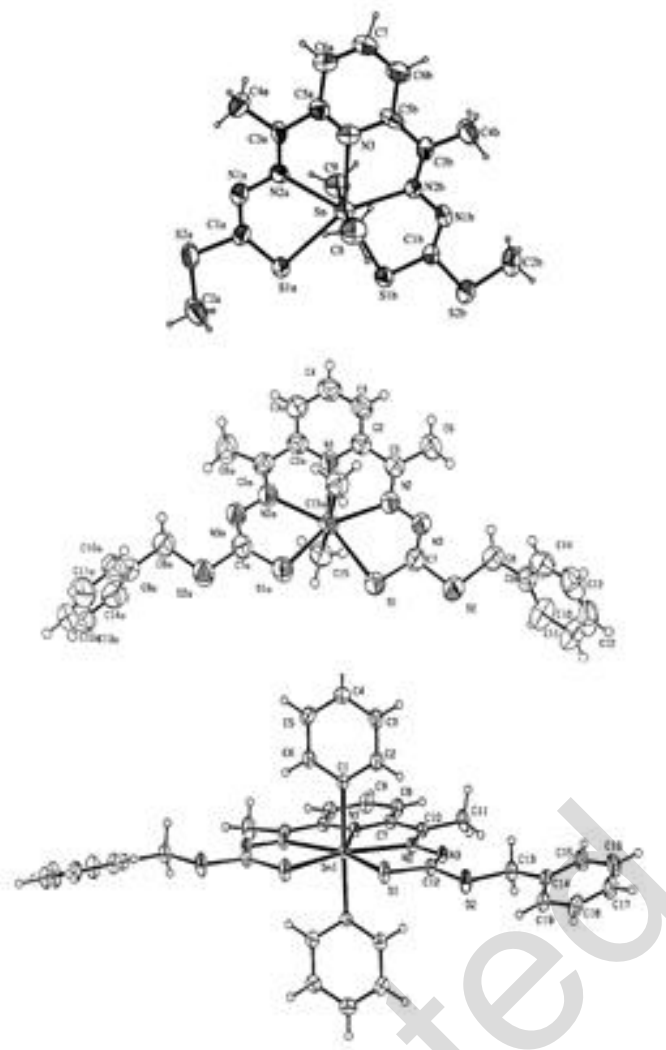

Fig. 34 Perspective views of $\left[\mathrm{Me}_{2} \mathrm{Sn}\right.$ (dapmdtc)] (71, top), $\left[\mathrm{Me}_{2} \mathrm{Sn}\right.$ (dapbdtc)] (72, middle), and $\left[\mathrm{Ph}_{2} \mathrm{Sn}\right.$ (dapbdtc)] (73, bottom), showing the atom numbering scheme. Reproduced with permission [278]. Copyright 2006 Springer.

In 2015, Nguyen et al. reported the syntheses of novel $\mathrm{N}_{2} \mathrm{O}_{2} \mathrm{~S}$-pentadentate dialkylamino(thiocarbonyl)- benzamidine proligands $\left(\mathrm{H}_{3} \mathrm{~L}, \mathrm{H}_{3} \mathrm{~L}-\mathrm{CO}_{2} \mathrm{Et}\right.$ and $\left.\mathrm{H}_{3} \mathrm{~L}-\mathrm{CO}_{2} \mathrm{H}\right)$ and their reaction with $\left[\mathrm{NBu}_{4}\right]\left[\mathrm{MOCl}_{4}\right]$ to form the corresponding rhenium(v) and technetium(V) complexes $[\mathrm{ReO}(\mathrm{L})](\mathbf{7 4}),[\mathrm{TcO}(\mathrm{L})](\mathbf{7 5}),\left[\mathrm{ReO}\left(\mathrm{L}-\mathrm{CO}_{2} \mathrm{Et}\right)\right](\mathbf{7 6}),\left[\mathrm{TcO}\left(\mathrm{L}-\mathrm{CO}_{2} \mathrm{Et}\right)\right](\mathbf{7 7}),\left[\mathrm{ReO}\left(\mathrm{L}-\mathrm{CO}_{2} \mathrm{H}\right)\right](\mathbf{7 8})$ and $\left[\mathrm{ReO}\left(\mathrm{L}-\mathrm{CO}_{2}-\mathrm{TG}\right)\right](79)$ [280]. The X-ray Structures have confirmed that the ligands are triply deprotonated and fully occupy the remaining five coordination positions of the $\{\mathrm{MO}\}^{3+}$ cores in all 
the complexes with the same $\mathrm{N}_{2} \mathrm{O}_{2} \mathrm{~S}$ donor atom constellation (Fig. 35). In a "proof-of-principle" reaction for possible bioconjugations, the complex $\mathbf{7 9}$ has been obtained from the reaction of $\mathbf{7 8}$, having the $-\mathrm{CO}_{2} \mathrm{H}$ anchor group in its periphery, and triglycine ethyl ester (TG) in the presence of N,N'-dicyclohexylcarbodiimide (DCC) and N-hydroxybenzotriazole (HOBT) in dry DMF at room temperature. Imido rhenium(V) complexes of similar pentadentate dialkylamino(thiocarbonyl)benzamidines $\left(\left(\mathrm{H}_{3} \mathrm{~L}-\mathrm{Morph}, \mathrm{H}_{3} \mathrm{~L}-\mathrm{Et}\right)\right.$, are also accessible [281]. The molecular structure of $[\operatorname{Re}(\mathrm{NPh})(\mathrm{L}-\mathrm{Morph})](\mathbf{8 0})$ is presented in Fig. 35. On the other hand, the ruthenium(III) complexes of cystamine-based disulfide pentadentate Schiff base ligands (L) displaying the same mixed N,O,S donor set and derived from cystamine and 2-hydroxy-substituted aromatic aldehydes, of the type $[\mathrm{RuX}(\mathrm{L})](\mathrm{X}=\mathrm{Cl}, \mathrm{Br})$, exhibited efficient catalytic activities in the transfer hydrogenation and $\mathrm{N}$-alkylation of $o$-substituted anilines [282].
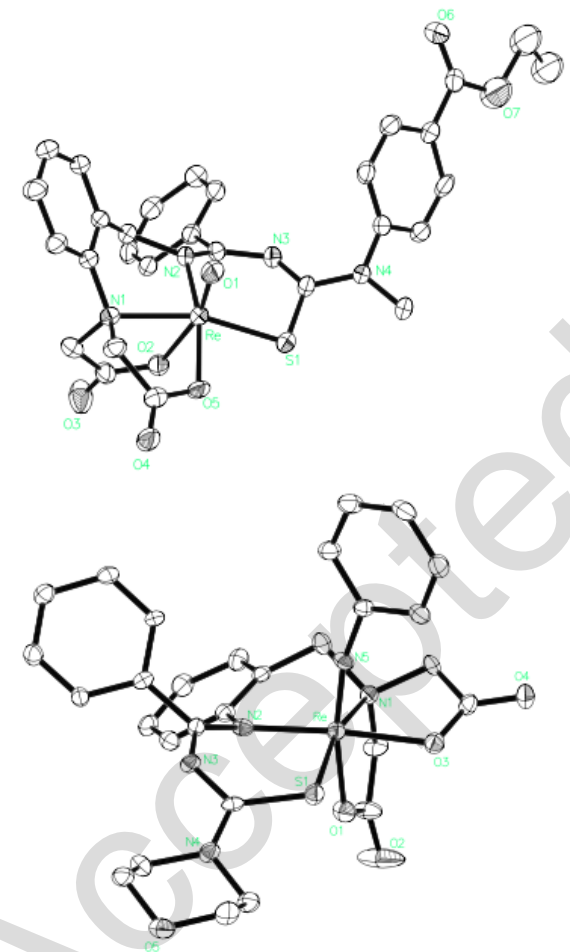

Fig. 35 Molecular structures of the oxo- $\operatorname{Re}(\mathrm{V})$ complex 76 (top) And of the phenylimido$\mathrm{Re}(\mathrm{V})$ complex 80 (bottom). Hydrogen atoms and the $\mathrm{MeOH}$ crystallization solvent for $\mathbf{7 6}$ are omitted for clarity. Thermal ellipsoids are drawn at 30\% and 20\% probability for $\mathbf{7 6}$ and $\mathbf{8 0}$, respectively. 
Pentadentate Schiff base ligands containing both soft and hard donor atoms are a versatile class of ligands, which are well-suited for the formation of stable complexes with many main group elements and transition metals in various oxidation states. Mixing $\mathrm{N}, \mathrm{O}$ and $\mathrm{S}$, donors into Schiff base compounds alters their steric and electronic properties, thus increasing their ability to form complexes with a variety of metal ions as neutral, singly, doubly or triply deprotonated chelating ligands, yielding both mono- and dinuclear complexes with interesting structural features. thermodynamically stable and/or kinetically inert complexes of pentadentate ligand systems should be of great interest for the development of new radiopharmaceuticals.

\section{Hexadentate Schiff base ligands and their metal complexes.}

Recent interests in the design, synthesis and characterization of hexadentate Schiff base ligands have focused on the asymmetric property. Their metal complexes are expected to be applied in asymmetric catalysis. For example, Constable et al. synthesized the enantiopure hexadentate ligands (S)-81 and (R)-81 by the condensation of enantiopure (S)-(-)-1,1'-binaphthyl- 2,2'-diamine or (R)(+)-1,1'-binaphthyl-2,2'-diamine with two equivalents of 2,2'-bipyridine-6- carbaldehyde in dry toluene [283]. In the presence of $\mathrm{MeOH}$, the ligand (S,S,S)-82 has been obtained by diastereoselective addition of (S)-81 and $\mathrm{MeOH}$ (Fig. 36), but this reaction is reversible and (S,S,S)$\mathbf{8 2}$ is reverted to (S)-81 by eliminating $\mathrm{MeOH}$, when dissolved in $\mathrm{CH}_{2} \mathrm{Cl}_{2}, \mathrm{CHCl}_{3}$ or $\mathrm{CH}_{3} \mathrm{CN}$.

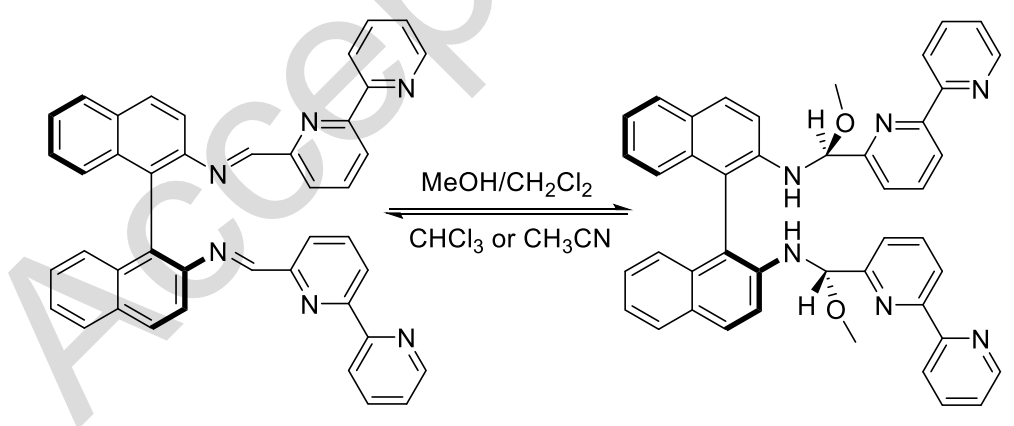

Fig. 36 The synthesis of $\mathbf{8 2}$.

\subsection{Hexadentate Schiff base Mn(II), Zn (II) and Cd(II) complexes}


Hexadentate Schiff base manganese(III) complexes have attracted wide attention due to their highspin (HS) state and elongated octahedral geometry. They are also widely used for building molecular magnets [284-288], or in extended assemblies [289], since the lengthened $\mathrm{Mn}$ (III) units show favorable magnetic anisotropy, with a $\mathrm{D}<0$ parameter for the zero-field-splitting Hamiltonian. For example, Four six-coordinate mononuclear manganese(III) Schiff base complex [Mn(5-MeO-sal$\mathrm{N}-1,5,8,12)] \mathrm{Y}\left(\mathrm{Y}=\mathrm{ClO}_{4}^{-}, \mathbf{8 3 a} ; \mathrm{BF}_{4}^{-}, \mathbf{8 3 b} ; \mathrm{NO}_{3}^{-}, \mathbf{8 3} \mathbf{c} ; \mathrm{CF}_{3} \mathrm{SO}_{3}^{-}, \mathbf{8 3 d}\right){ }^{\prime}$ where $\quad 5-\mathrm{MeO}-\mathrm{sal}-\mathrm{N}-1,5,8,12$ stands for the doubly deprotonated $\mathrm{N}_{4} \mathrm{O}_{2}$-hexadentate Schiff base ligand obtained by $2: 1$ condensation of 5-methoxysalicylaldehyde and N,N'-bis(3-aminopropyl)ethylenediamine, have been reported and investigated to determine the intramolecular ligand distortion, impact of counter anion effects and intermolecular supramolecular structures on the spin crossover behavior by Wang et al. (Fig. 37) [290].

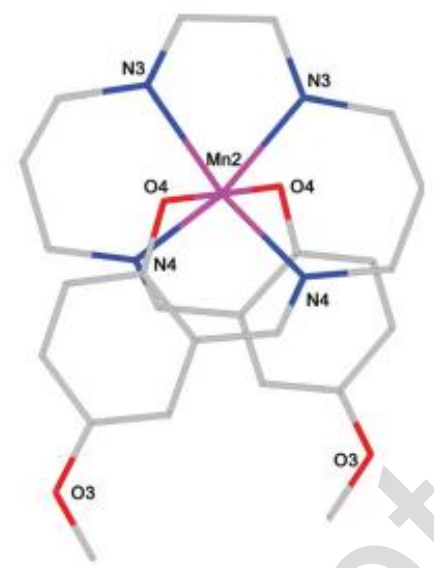

Fig. 37 Molecular structure of the complex cation $[\mathrm{Mn}(5-\mathrm{MeO}-\mathrm{sal}-\mathrm{N}-1,5,8,12)]^{+}$of $\mathbf{8 3 a}$ at $100 \mathrm{~K}$. Hydrogen atoms have been omitted for clarity. Reproduced with permission [290]. Copyright 2016 The Royal Society of Chemistry.

In 2008, Salehzadeh and co-workers first synthesized and characterized two new complexes, $\left[\mathrm{CdL}_{22 \mathrm{pyfp}}\left(\mathrm{NO}_{3}\right)\right]\left[\mathrm{ClO}_{4}\right](\mathbf{8 4})$ and $\left[\mathrm{MnL}_{22 \mathrm{pyfp}} \mathrm{Cl}\right]\left[\mathrm{ClO}_{4}\right](\mathbf{8 5})$ that are mononuclear $\mathrm{Cd}(\mathrm{II})$ and $\mathrm{Mn}(\mathrm{II})$ complexes supported by the $\mathrm{N}_{6}$-hexadentate unsymmetrically-substituted Schiff base ligand $\mathrm{L}_{22 \mathrm{pyp}} \mathrm{Cl}$ (Fig. 38) [291]. These complexes were synthesized through the condensation of the asymmetric tripodal tetraamine $\mathrm{L}_{22 \mathrm{py}}$ with 2-pyridinecarboxaldehyde in the presence of 
$\mathrm{Cd}\left(\mathrm{NO}_{3}\right)_{2} \cdot 4 \mathrm{H}_{2} \mathrm{O}$ and $\mathrm{MnCl}_{2} \cdot 4 \mathrm{H}_{2} \mathrm{O}$, respectively, in the ratios 1:1:1 and 2 equiv. of $\mathrm{NaClO}_{4}$. Interestingly, single crystal X-ray diffraction showed that complex $\mathbf{8 4}$ is formed as a distorted dodecahedron eight-coordinate $\mathrm{Cd}(\mathrm{II})$ ion, whereas $\mathbf{8 5}$ is a seven-coordinate compound in which the Mn(II) metal ion adopts a distorted pentagonal bipyramidal geometry. Their electronic spectra have been explained on the basis of TD-DFT calculations.

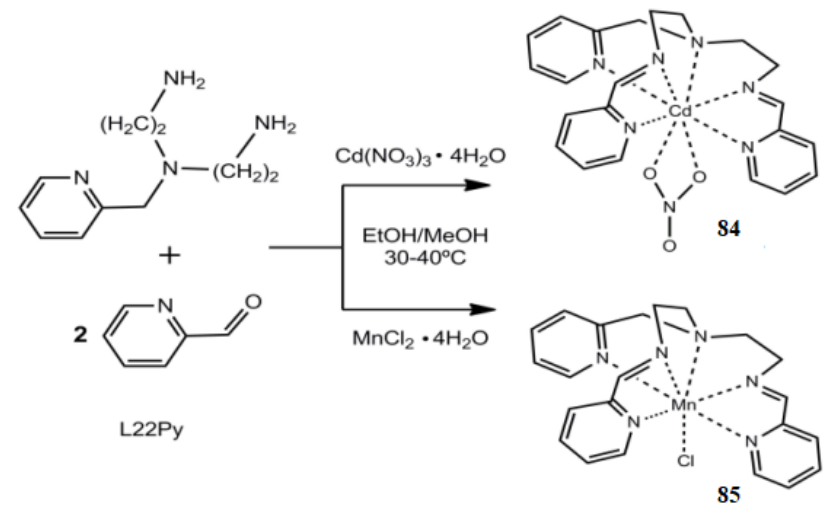

Fig. 38 Synthesis of the cadmium(II) $(\mathbf{8 4}$, top) and manganese(II) (85, bottom) complexes supported by the hexadentate Schiff base ligand $\mathrm{L}_{22 \mathrm{pyfp}} \mathrm{Cl}$.

The same year, neutral $\left[\mathrm{Mn}\left(\mathrm{H}_{2} \mathrm{~L}\right)\right](\mathbf{8 6}),\left[\mathrm{Cd}\left(\mathrm{H}_{2} \mathrm{~L}\right)\right](\mathbf{8 7})$ and $\left[\mathrm{Ni}\left(\mathrm{H}_{2} \mathrm{~L}\right)\right](\mathbf{8 8})$ complexes have been synthesized by the reaction of a new symmetrical $\mathrm{N}_{4} \mathrm{O}_{2}$-hexadentate Schiff base ligand, 1,8-N-bis(3carboxy)disalicylidene-3,6-diazaoctane-1,8-diamine $\left(\mathrm{H}_{4} \mathrm{~L}\right)$ with the corresponding metal acetate salt, by Sarkar et al. [292]. These complexes are all pseudo-octahedral with some variations in their configurations, confirmed by both theoretical calculations and X-ray crystal structure studies (Fig. 39). Moreover, these complexes are facilely engaged into the 1-D, 2-D and 3-D supramolecular coordination networks by the $\pi-\pi$ stacking, $\mathrm{C}-\mathrm{H} . . . \pi$ interactions and unusual $\mathrm{H}$-bonding interactions. In addition, the optical band gap ( $\left.\mathrm{E}_{\mathrm{gd}}\right)$ values of complexes $\mathbf{8 6}$ and $\mathbf{8 7}$ are of 2.30 and $2.57 \mathrm{eV}$, respectively. 

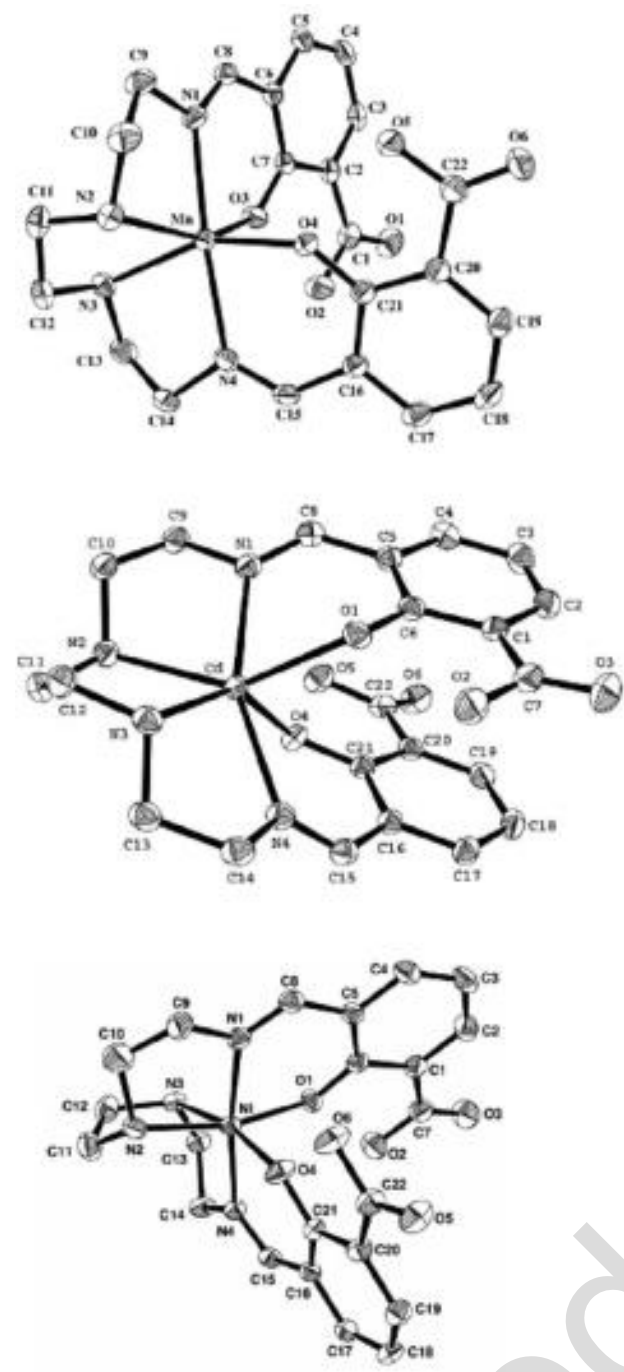

Fig. 39 ORTEP views of the $\mathrm{Mn}(\mathbf{8 6}$, top),Cd (87, middle), and $\mathrm{Ni}(\mathbf{8 8}$, bottom) complexes with ellipsoids drawn at the 50\% probability level. Reproduced with permission [292]. Copyright 2008 Elsevier Ltd.

In 2014, Golbedaghi et al. synthesized and characterized two new $\mathrm{N}_{2} \mathrm{O}_{4}$-hexadentate Schiff base ligands and their four corresponding complexes: $\left[\mathrm{Cd}\left(\mathrm{H}_{2} \mathrm{~L}^{1}\right)\left(\mathrm{NO}_{3}\right)\right] \mathrm{ClO}_{4}(\mathbf{8 9}),\left[\mathrm{Cd}\left(\mathrm{H}_{2} \mathrm{~L}^{2}\right)\left(\mathrm{NO}_{3}\right)\right] \mathrm{ClO}_{4}$ (90), $\left[\mathrm{Zn}\left(\mathrm{H}_{2} \mathrm{~L}^{1}\right)\right]\left(\mathrm{ClO}_{4}\right)_{2}(\mathbf{9 1})$ and $\left[\mathrm{Zn}\left(\mathrm{H}_{2} \mathrm{~L}^{2}\right)\right]\left(\mathrm{ClO}_{4}\right)_{2}(\mathbf{9 2})$, where $\mathrm{H}_{2} \mathrm{~L}^{1}$ and $\mathrm{H}_{2} \mathrm{~L}^{2}$ stand for the Schiff bases derived from 1:1 condensation of ethanol amine with 2-[2-(2-formyl phenoxy)ethoxy] benzaldehyde and 2-[2-(3-formyl phenoxy)ethoxy] benzaldehyde, respectively [293]. The X-ray crystal structure of complex $\mathbf{8 9}$ shows that it adopts a distorted dodecahedron geometry due to the coordination of the $\mathrm{N}_{2} \mathrm{O}_{4}$ donor set of the Schiff base ligand and two oxygen atoms of the nitrate 
anion to the eigth-coordinate $\mathrm{Cd}(\mathrm{II})$ metal ion (Fig. 40).

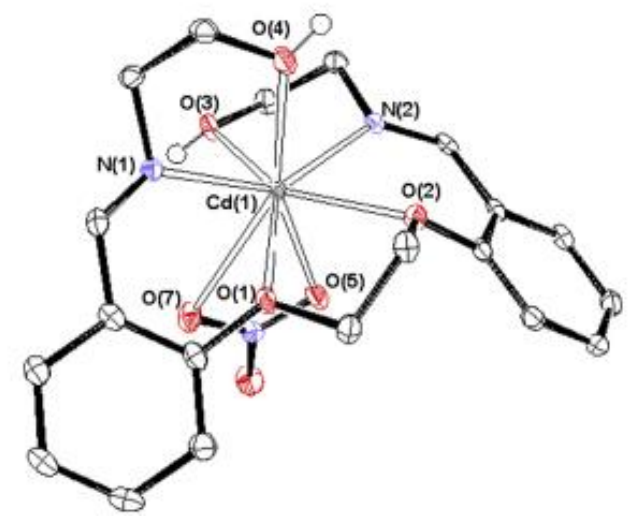

Fig. 40 Molecular structure of $\left[\mathrm{Cd}\left(\mathrm{H}_{2} \mathrm{~L}^{1}\right)\left(\mathrm{NO}_{3}\right)\right] \mathrm{ClO}_{4}(\mathbf{8 9})$. Hydrogen atoms and the perchlorate anion are omitted for clarity. Reproduced with permission [293]. Copyright 2004 Elsevier B.V

Two neutral zinc complexes with $\mathrm{N}_{4} \mathrm{O}_{2}$-hexadentate Schiff base ligand, $\mathrm{ZnL}^{1}$ (93) and $\mathrm{ZnL}^{2}$ (94) have been prepared in a one-pot procedure by the reaction between triethylenetetramine, salicylaldehyde or $o$-vanillin (3-methoxysalicylaldehyde), and zinc acetate by Chantarasiri et al. [294]. X-ray analysis show that in $\mathbf{9 3}$ and $\mathbf{9 4}$, the six-coordinate $\mathrm{Zn}$ (II) metal ion is coordinated by for amine ligands and two phenolic oxygen atoms to form a distorted $\mathrm{ZnN}_{4} \mathrm{O}_{2}$ octahedron, and that both complexes have a bent-shaped conformation with the slope-plane moieties that contain aromatic rings (Fig. 41).

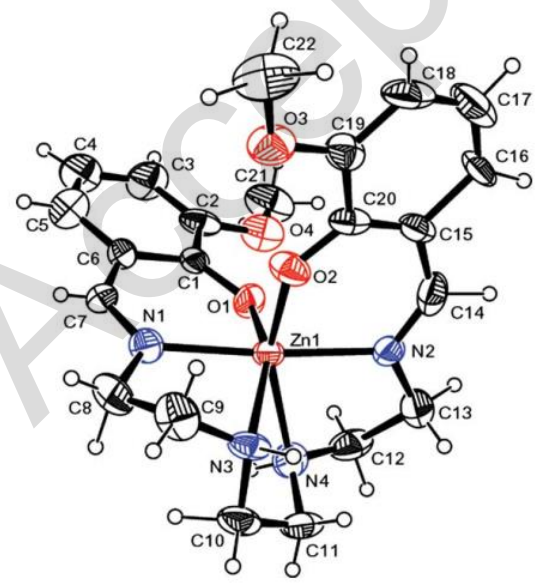

Fig. 41 ORTEP diagram of $\mathrm{ZnL}^{2}(\mathbf{9 4})$. Ellipsoids are drawn at 50\% probability level. Reproduced with permission [294]. Copyright 2004 Elsevier B.V. 


\subsection{Hexadentate Schiff base Al(III) complexes}

In 2017, Xu et al. successfully synthesized the hexadentate Schiff base $\mathrm{Al}(\mathrm{III})$ complex 95 by the reaction of aluminum alkyls with $\mathrm{N}, \mathrm{N}^{\prime}$-bis(3,5-di-tert-butylsalicylidene)-2,2'-(ethylenedioxy)dianiline $\left(\mathrm{H}_{2} \mathrm{~L}\right)$ [295]. The authors also proposed a formation mechanism (Fig.42). Firstly, an aluminum ethyl complex [AlEtL] was formed by the reaction of $\mathrm{AlEt}_{3}$ with 1 equiv. of $\mathrm{H}_{2} \mathrm{~L}$ via elimination of ethane, subsequently the intermediate aluminum hydride [AlHL] was obtained by the ethylene elimination [296], and then the final product 95 was formed by the intramolecular nucleophilic attack of intermediate [AlHL]'s Al-H at hexadentate Schiff base ligand's imine carbon atoms [297]. In addition, complex 95 shows excellent catalytic activity in the cycloaddition reaction of $\mathrm{CO}_{2}$ and various functionalized terminal epoxides (Eq. 1) [298].

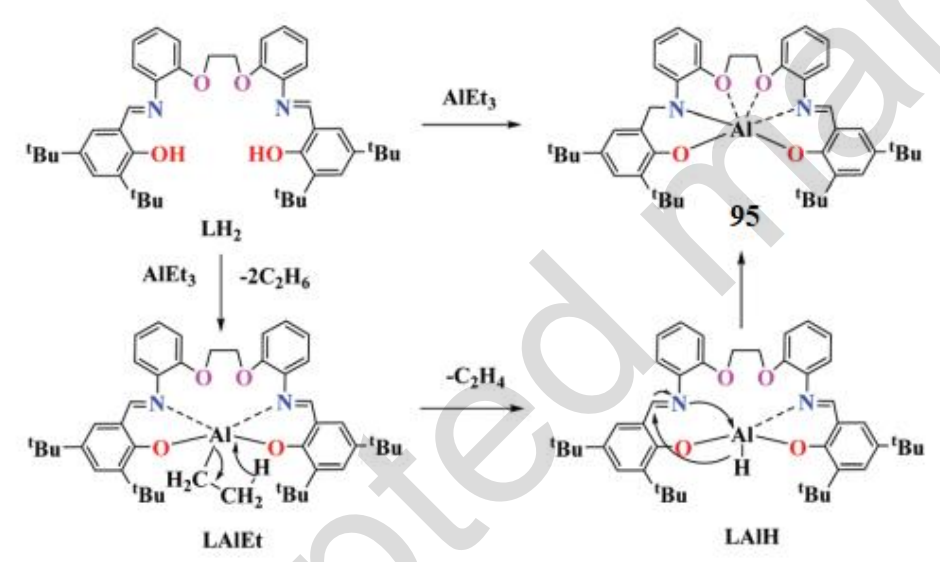

Fig. 42 Possible formation mechanism of complex 95. Reproduced with permission [295]. Copyright 2017 The Royal Society of Chemistry.

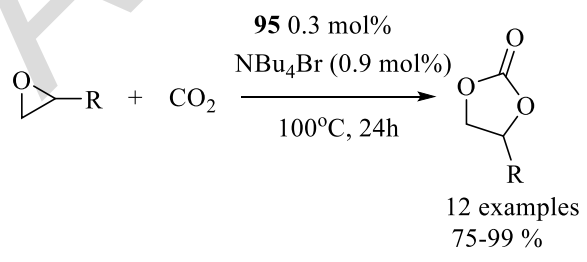

Eq. 1

\subsection{Hexadentate Schiff base lanthanide(III) complexes}

Schiff base lanthanide complexes have attracted wide attention due to their applications in 
luminescent probes, magnetic resonance imaging and magnetic materials [299-303]. For example, Ghosh and co-workers synthesized a family of isostructural and isomorphous nonacoordinated lanthanide(III) complexes of type $\left[\mathrm{Ln}(\mathrm{L})(\mathrm{NCS})_{3}\right](\mathrm{Ln}=\mathrm{La}, 96 ; \mathrm{Gd}, 97 ; \mathrm{Tb}, 98$; $\mathrm{Dy}, 99)$ by the reaction of $\mathrm{N}$-(1-pyridin-2-yl-phenylidene)-N'-[2-(\{2-[(1-pyridin-2-yl-phenylidene)amino]ethyl \}amino)ethyl]ethane-1,2-diamine (L), lanthanide nitrates and ammonium thiocyanate in the 1:1:3 molar ratio [304]. Single crystal X-ray crystallography reveals all the complexes 96-99 have a tricapped trigonal prismatic structure with a $\mathrm{LnN}_{9}$ chromophore (Fig. 43). Following the Curie Law, VT magnetic susceptibility measurements are in agreement with $4 f^{7}, 4 f^{8}$ and $4 f^{9}$ configurations, respectively, expected for an isolated, mononuclear $\mathrm{Ln}(\mathrm{III})$ ion.

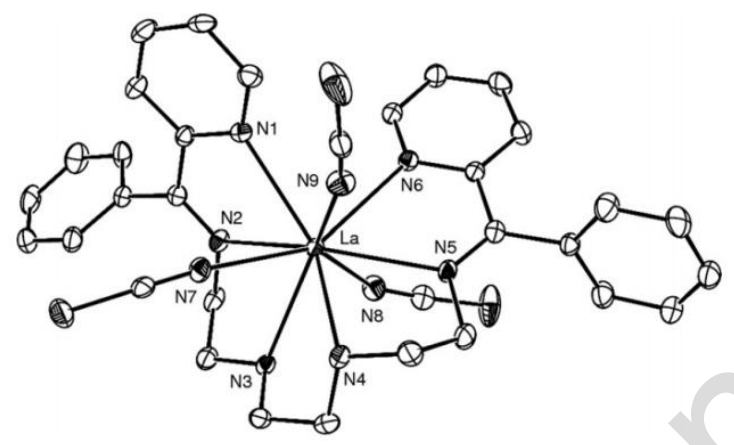

Fig. $4320 \%$ Thermal ellipsoid plot of [ $\left.\mathrm{La}(\mathrm{L})(\mathrm{NCS})_{3}\right]$ (96). Reproduced with permission [304]. Copyright 2010 Elsevier Ltd.

Owing to their great flexibility and multiple chelating points in the ligand framework, hexadentate Schiff base ligands are also well suited tools to synthezise polynuclear metal complexes with potential applications in various fields such as magnetic materials $[305,306]$ or in the development of novel chemotherapeutic Schiff bases and their metal complexes [307,308].

\section{Heptadentate Schiff base ligands and their metal complexes}

Over the two last decades, heptadentate Schiff base ligands and their metal complexes, such as heptaaza Schiff base macrocyclic bis(pendant donor) manganese(II) complexes, were found to have a lot of specific applications such as synthetic ionophores [309,310], cyclic antibiotics [311-313], 
anion receptors [314-316], and therapeutic reagents in chelation therapy [317,318]. They also can be used in host-guest interactions [319]. For instance, Khanmohammadi et al. reported a new manganese(II) complex of an unsymmetrical heptaaza Schiff base macrocyclic ligand 100 (Fig. 44) that has been prepared by template condensation between 2,6-diacetylpyridine and N, N, N', N'tetrakis-(2-aminoethyl)propane-1,2- diamine in the presence of $\mathrm{Mn}$ (II) ion in EtOH [320]. It was also reported that complex $\mathbf{1 0 0}$ and its familiar symmetrical derivatives had more remarkable inhibition zone on the culture of Escherichia coli and Staphylococcus aureus than standard drugs.<smiles>CC(=O)c1cccc(C(C)=O)n1</smiles><smiles>C[C@H](CN(CCN)CCN)N(CCN)CCN</smiles>

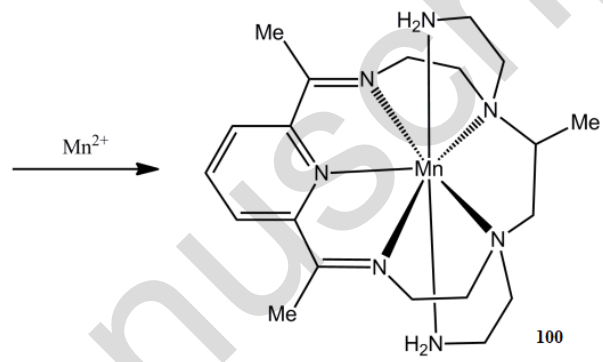

Fig. 44 Template synthesis of the heptadentate Schiff base Mn(II) complex 100 [320].

In 2009, Salehzadeh et al. reported an unexpected chelate-assisted C-C bond-forming reaction during template condensation of the asymmetric bis(3-aminopropyl)-(2-aminoethyl) amine derivative and 2-pyridinecarboxaldehyde in methanol solution, in the presence of $\mathrm{Cd}\left(\mathrm{ClO}_{4}\right)_{2}$ [321]. Two products were formed during this reaction: the expected condensation one 101, and $\mathbf{1 0 2}$ in which the methylene group adjacent to the imine bond in the ethylene arm of the ligand has reacted with an additional equivalent of 2-pyridinecarboxaldehyde. The presence of a rigid five-membered chelate ring has been shown to be necessary to make this reaction to occur. Both compounds $\mathbf{1 0 1}$ and 102 have been structurally characterized by X-ray diffraction (Fig. 45). On the other hand, Marshall-Roth and Brown synthesized an oxo-free $\mathrm{N}_{4} \mathrm{O}_{3}$-heptadentate Mo compound [Mo(MeClamp)] (103), by the reaction of tris(2-(3',5'-di-tert-butyl-2'-hydroxyphenyl)amino-4methylphenyl)amine $\left(\mathrm{MeClampH}_{6}\right)$ and dioxomolybdenum(VI) bis(acetylacetonate) [322]. From its X-ray diffraction study, the seven-coordinate molybdenum(VI), adopts a C3-symmetric, capped octahedral structure with the triarylamine nitrogen supplying the capping ligand (Fig. 46). 

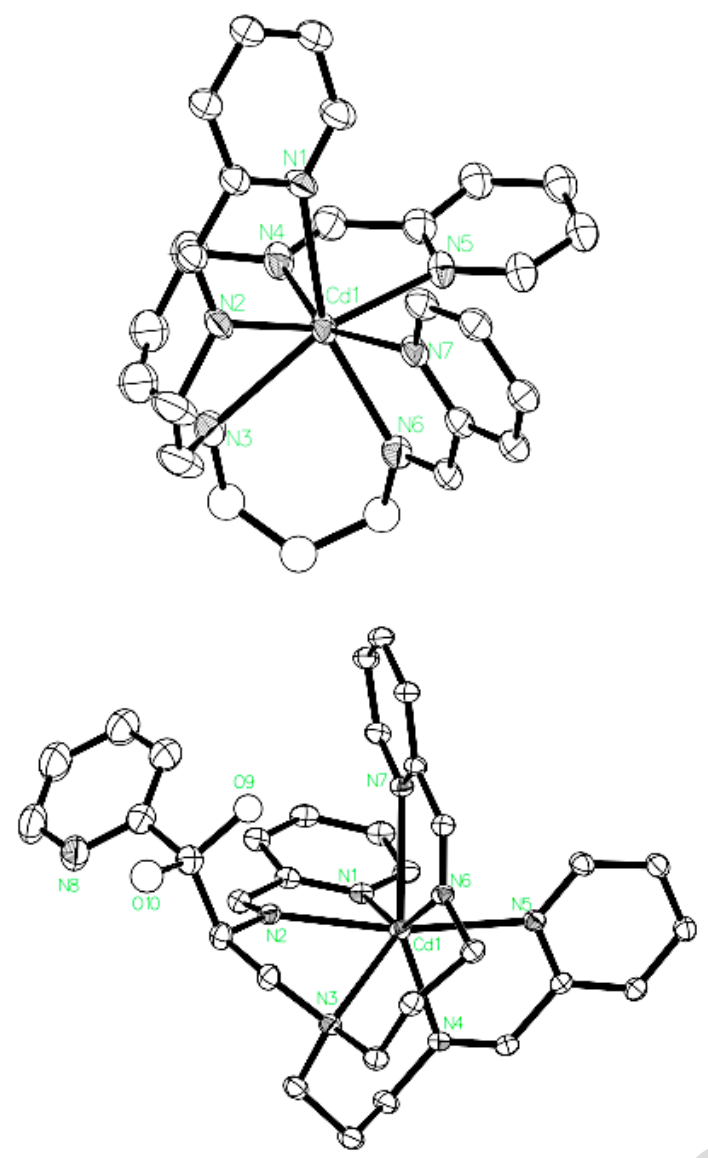

Fig. 45 Molecular structures of unsymmetrically-substituted $\mathrm{N}_{7}$-heptadentate tripodal Schiff base $\mathrm{Cd}(\mathrm{II})$ complexes 101 (top) and 102 (bottom). Hydrogen atoms and perchlorate counterions are omitted for clarity. Thermal elipsoids are drawn at $30 \%$ and $20 \%$ probability, respectively.

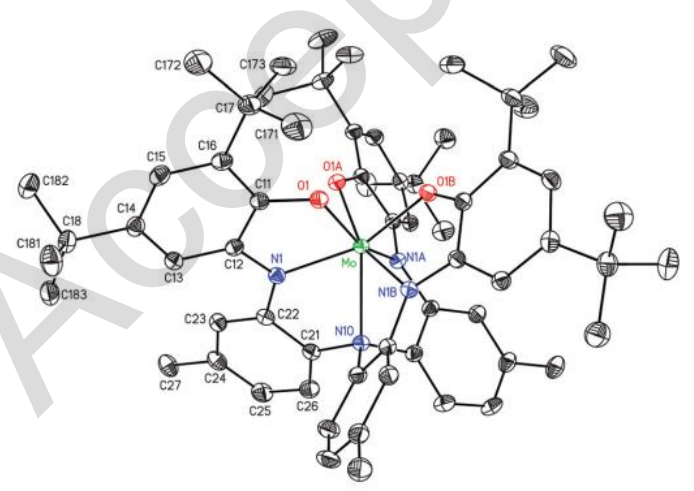

Fig. $46 \mathbf{5 0 \%}$ thermal ellipsoid plot of the seven-coordinate Mo(VI) complex $[\mathrm{Mo}(\mathrm{MeClamp})] .3 \mathrm{C}_{6} \mathrm{H}_{6}(\mathbf{1 0 3})$. Hydrogen atoms are omitted for clarity. Reproduced with permission [322]. Copyright 2015 The Royal Society of Chemistry. 
In fact, most heptadentate Schiff base metal complexes are lanthanides Ln(III) complexes, due to lanthanide atom's large size requiring large coordination numbers and predominantly ionic bonding. Therefore, Ln(III) complexes have been successfully applied for constructing various selfassembled structures, in catalysis, for ion exchange, magnetism, gas adsorption and luminescence [323-341]. For example, Blakemore et al. recently synthesized a series of f-block metal complexes $(\mathrm{Ln}=\mathrm{Ce}, 104 ; \mathrm{Nd}, 105 ; \mathrm{Eu}, 106$ and $\mathrm{Sm}, 107)$ by the reaction of a tripodal ligand featuring three appended pyrene moieties scaffold and $\mathrm{Ln}\left(\mathrm{N}\left(\mathrm{SiMe}_{3}\right)_{2}\right)_{3}$ in $\mathrm{THF}$ (Fig. 47) [342]. The lanthanide(III) ions are encapsulated within a heptadentate coordination environment. Moreover, these compounds were readily immobilized on graphitic electrodes through the pyrene moieties. On the other hand, a new heptadentate Schiff base Th(IV) complex $\left[\mathrm{Th}\left(\mathrm{H}_{3} \mathrm{~L}\right)\left(\mathrm{NO}_{3}\right)(\mathrm{MeO})\right] .2 \mathrm{NO}_{3}(\mathbf{1 0 8})$ has been reported by Zhang et al. (Fig. 48) [343]. Deprotonation of imidazole nitrogen donors allows to form either discrete heterometallic cages or supramolecular assemblies containing the tetravalent actinide ion.
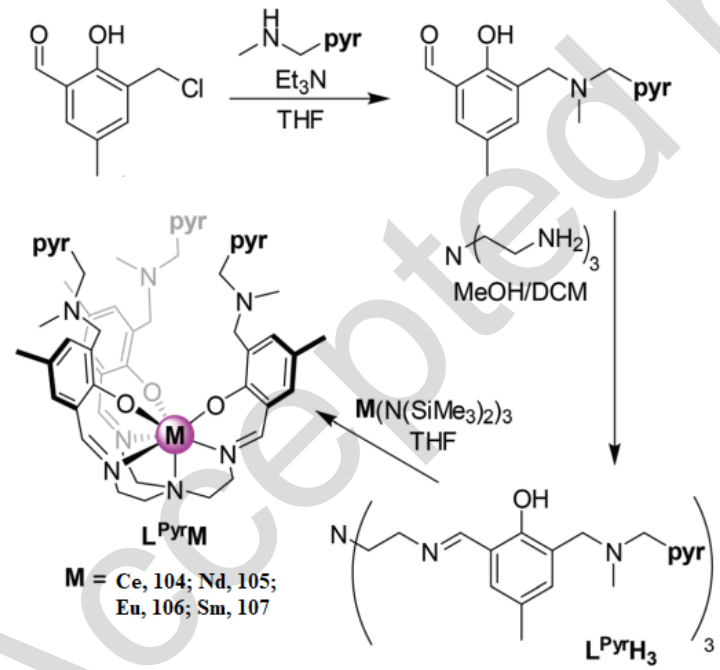

Fig. 47 Synthesis of pyrene-decorated heptadentate ligand $\mathrm{LPyrH}_{3}$ of f-block element complexes $L^{\text {Pyr }} \operatorname{Ln}($ 104-107) for surface immobilization studies. Reproduced with permission [342]. Copyright 2017 The Royal Society of Chemistry. 


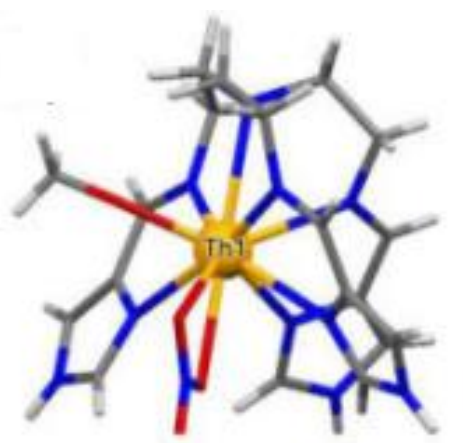

Fig. 48 Formation of Th(IV) metaloligands 108. Reproduced with permission ${ }^{[343] .}$ Copyright 2017 Elsevier Ltd.

\section{Summary and outlook}

The synthesis and structure of multidentate Schiff bases and their metal complexes is fascinating, because it reveals a great richness of structural, physico-chemical and catalytic properties, as well as playing an important role in the bioinorganic chemistry. Given the simplicity and ease of access to multidentate Schiff bases and their metal complexes with multiple properties, the investigation of multidentate Schiff base metal complexes is essential to precise and understand structureproperty relationships in order to optimize and improve their use in a wide range of applications. This review focused on some background and recent progress in the synthesis of multidentate Schiff bases and their mono-nuclear metal complexes, structural and physico-chemical properties (such as spin crossover, catalysis etc). Some typical examples are discussed in detail, like pentadentate, hexadentate, heptadentate and macrocyclic Schiff base ligands and their complexes of transition metals, main group elements, lanthanides and actinides. Transition metals preferentially make complexes with penta- and hexadentate Schiff base ligands, while most heptadentate Schiff base metal complexes are lanthanide and actinide based complexes, owing to seven donor atoms and enough of flexibility of ligand frameworks to comply with the steric demands of the metal coordination. The synthesis of mononuclear metal complexes with octadentate Schiff base ligands still remains a difficult challenge. The octadentate Schiff base ligands are, indeed, much more suited to construct di-and multinuclear metal complexes [344-359]. This class of compounds that represents a broad area of research has not been discussed in this review. Nevertheless, synergistic 
substrate activation brought about by two or more adjacent metals in a complex in the course of a reaction, especially catalytic reactions, is a difficult problem that continuously requires considerable research efforts.

\section{Acknowledgements}

We express our deepest gratitude to Dr N. Novoa (UdeC, Concepción, Chile) for helpful discussion and assistance with graphical representations. P. Hamon (ISCR, Rennes) is also thanked for his help in literature search. We also acknowledge financial support from the National Natural Science Foundation of China (Grant No. 21805166), The 111 Project of Hubei Province (Grant No. 201819-1), China Three Gorges University, the Université de Rennes 1 and the Centre National de la Recherche Scientifique (CNRS).

\section{References}

[1] H. Schiff, Ann. Chem. Suppl. 3 (1864) 343-349.

[2] H. Schiff, Justus Liebigs Ann. Chem. 131 (1864) 118-119.

[3] R.B. Moffett, In N. Rabjohn (Ed), Organic syntheses, vol. 4. New York (USA): John Wiley \& Sons, Inc.; 1963. pp. 605-608.

[4] M.J. O’DONNELL, Acc. Chem. Res. 37 (2004) 506-517 and references cited therein.

[5] X. Ye, Y. Chen, C. Ling, R. Ding, X. Wang, X. Zhang, S. Chen, Dalton Trans. 47 (2018) $10915-$ 10924.

[6] S.Y. Ding, J. Gao, Q. Wang, Y. Zhang, W.G. Song, C.Y. Su, W. Wang, J. Am. Chem. Soc. 133 (2011) 19816-19822.

[7] Z.A. De los Santos, R.S. Ding, C. Wolf, Org. Biomol. Chem. 14 (2016) 1934-1939.

[8] N. Mohan, S.S. Sreejith, P.M. Sabura Begum, M.R. Prathapachandra Kurup, New J. Chem. 42 (2018) 13114-13121. 
[9] Y. Fu, Y. Tu, $\quad$ C. Fan, $\quad$ C. Zheng, $\quad$ G. Liu, S. Pu, New J. Chem. 40 (2016) 85798586.

[10] A.B. Pradhan, S.K. Mandal, S. Banerjee, A. Mukherjee, S. Das, A.R. Khuda Bukhsh, A. Saha, Polyhedron 94 (2015) 75-82.

[11] B.J. Vasanthi, L. Ravikumar, Eur. Polym. J. 43 (2007) 4325-4331.

[12] M.W. Sabaa, R.R. Mohamed, E.H. Oraby, Eur. Polym. J. 45 (2009) 3072-3080.

[13] D.S. Ahmed, G.A. El-Hiti, A.S. Hameed, E. Yousif, A. Ahmed, Molecules 22 (2017) 1506; doi:10.3390.

[14] I. Bravo, M. Revenga-Parra, F. Pariente, E. Lorenzo, Sensors 17 (2017) 144; doi:10.3390/s17010144.

[15] C. Demitri, V. Maria De Benedictis, M. Madaghiele, C. Esposito Corcione, A. Maffezzoli, Measurement 90 (2016) 418-423.

[16] O.A.G. Wahba, A.M. Hassan, A.M. Naser, A.M. Hanafi, Egypt. $\quad$ J. Chem. 60 (2017) 25-40.

[17] Y. Liu, L. Mao, S. Yang, M. Liu, H. Huang, Y. Wen, F. Deng, Y. Li, X. Zhang, Y. Wei, Dyes Pigments, 158 (2018) 79-87.

[18] D. Şenol, J. Biol. Chem. 45 (2017) 67-80.

[19] J.J. Kaylor, T. Xu, N.T. Ingram, A. Tsan, H. Hakobyan, G.L. Fain, G.H. Travis, NAT. COMMUN. 8: 16 (2017) DOI: 10.1038/s41467-017-00018-4.

[20] V.L. Mooney, I. Szundi, J.W. Lewis, E.C.Y. Yan, D.S. Kliger, Biochemistry 51 (2012) 26302637.

[21] O.A.G. Wahba, A.M. Hassan, A.M. Naser, A. Mohy-Eldin Gabr, Pigment Resin Technol. 46 (2017) 286-295

[22] H.-W. Ou, K.-H. Lo, W.-T. Du, W.-Y. Lu, W.-J. Chuang, B.-H. Huang, H.-Y. Chen, C.-C. Lin, Inorg. Chem. 55 (2016) 1423-1432.

[23] W. Al Zoubi, Y.G. Ko, j. Organomet. Chem. 822 (2016) 173-188. 
[24]D.N. Dhar, C.L. Taploo, J. Sci. Ind. Res. 41 (1982) 501-506.

[25]P. Przybylski, A. Huczynski, K. Pyta, B. Brzezinski, F. Bartl, Curr. Org. Chem. 13 (2009) 124148.

[26]P. Alreja, N. Kaur, Inorg. Chim. Acta 480 (2018) 127-131.

[27]C.M. da Silva, D.L. da Silva, L.V. Modolo, R.B. Alves, M.A. de Resende, C.V.B. Martins, A^ de Fatima, J. Adv. Res. 2 (2011) 1-8.

[28] K. Sztanke, A. Maziarka, A. Osinka, M. Sztanke, Bioorg. Med. Chem. 21 (2013) 3648-3666.

[29] D. Utreja, S. Singh, M. Kaur, Curr. Bioact. Compd. 11 (2015) 215-230.

[30] L.H. Abdel-Rahman, A.M. Abu-Dief, M.O. Aboelez, A.A. Hassan Abdel-Mawgoud, J. Photochem. Photobiol. B 170 (2017) 271-285.

[31]G. Bringmann, M. Dreyer, J.H. Faber, P.W. Dalsgaard, D. Staerk, J.W. Jaroszewski, H. Ndangalasi, F. Mbago, R. Brun, S.B. Christensen, J. Nat. Prod. 67 (2004) 743-748.

[32]A.O. de Souza, F.C.S. Galetti, C.L. Silva, B. Bicalho, M.M. Parma, S.F. Fonseca, A.J. Marsaioli, A.C.L.B. Trindade, R.P. Freitas Gil, F.S. Bezerra, M. Andrade-Neto, M.C.F. de Oliveira, Quim. Nova 30 (2007) 1563-1566.

[33]Z. Guo, R. Xing, S. Liu, Z. Zhong, X. Ji, L. Wang, P. Li, Carbohydr. Res. 342 (2007) 13291332.

[34]F. Giordanetto, C. Tyrchan, J. Ulander, ACS Med. Chem. Lett. 8 (2017) 139-142.

[35]A. Carreno, C. Zuniga, D. Paez-Hernandez, M. Gacitua, R. Polanco, C. Otero, R. Arratia-Perez, J.A. Fuentes, New J. Chem. 42 (2018) 8851-8863.

[36] Y. Jia, J. Li, Chem. Rev. 115 (2015) 1597-1621.

[37] J.L. Segura, M.J. Manchenoa, F. Zamora, Chem. Soc. Rev. 45 (2016) 5635-5671.

[38] P.A. Vigato, S. Tamburini, Coord. Chem. Rev. 248 (2004) 1717-2128.

[39] R.M. Clarke, T. Storr, Dalton Trans. 43 (2014) 9380-9391. 
[40] R.M. Clarke, K. Herasymchuk, T. Storr, Coord. Chem. Rev. 352 (2017) 67-82.

[41] T.J. Boyle, J.M. Sears, J.A. Greathouse, D. Perales, R. Cramer, O. Staples, A.L. Rheingold, E.N. Coker, T.M. Roper, R.A. Kemp, Inorg. Chem. 57 (2018) 2402-2415.

[42] T.J. Boyle, D. Perales, J.M. Rimsza, T.M. Alam, D.M. Boye, J.M. Sears, J.A. Greathouse, R.A. Kemp, Dalton Trans. 47 (2018) 4162-4174.

[43] A. Erxleben, Inorg. Chim. Acta 472 (2018) 40-57.

[44] M.T. Kaczmarek, M. Zabiszak, M. Nowak, R. Jastrzab, Coord. Chem. Rev. 370 (2018) 42-54.

[45] M.C. Heffern, V. Reichova, J.L. Coomes, A.S. Harney, E.A. Bajema, T.J. Meade, Inorg. Chem. 54 (2015) 9066-9074 and related references 7-19 cited therein.

[46] A. Combes, C. R. Acad. Sci. 108 (1889) 1252-1255.

[47] L.M. Manus, R.J. Holbrook, T.A. Atesin, M.C. Heffern, A.S. Harney, A.L. Eckermann, T.J. Meade, Inorg. Chem. 52 (2013) 1069-1076.

[48] M.D. Peterson, R.J. Holbrook, T.J. Meade, E.A. Weiss, J. Am. Chem. Soc. 135 (2013) 1316213167.

[49] R.J. Holbrook, D.J. Weinberg, M.D. Peterson, E.A. Weiss, T.J. Meade, J. Am. Chem. Soc. 137 $(2015) 3379-$,3385 .

[50] L. Zhou, C.C. Kwok, G. Cheng, H. Zhang, C.M. Che, Opt. Lett. 38 (2013) 2373-2375.

[51] M. Hajrezaie, M. Paydar, C.Y. Looi, S.Z. Moghadamtousi, P. Hassandarvish, M.S. Salga, H. Karimian, K. Shams, M. Zahedifard, N.A. Majid, H.M. Ali, M.A. Abdulla, Sci. Rep. 5 (2015) 9097. [52] A. Hematpoor, M. Paydar, S.Y. Liew, Y. Sivasothy, N. Mohebali, C.Y. Looi, W.F. Wong, M.S. Azirun, K. Awang, Chem. Biol. Interact. 279 (2018) 210-218.

[53] M. Zahedifard, F.L. Faraj, M. Paydar, C.Y. Looi, M. Hajrezaei, M. Hasanpourghadi, B. Kamalidehghan, N.A. Majid, H.M. Ali, M.A. Abdulla, Sci. Rep. 5 (2015) 11544.

[54] A. de Fátima, C. de Paula Pereira, C. Raquel Said Dau Gonçalves Olímpio, B. Germano de Freitas Oliveira, L. Lopardi Franco, P. Henrique Corrêa da Silva, J. Adv. Res. 13 (2018) 113-126. 
[55] C.R. Nayar, R. Ravikumar, J. Coord. Chem. 67 (2014) 1-16.

[56] J. Jia, Y. Li, J. Gao, Dyes Pigments 137 (2017) 342-351.

[57] S. Di Bella, A. Colombo, C. Dragonetti, S. Righetto, D. Roberto, Inorganics 6 (2018) 133; doi:10.3390/inorganics6040133, and references cited therein.

[58] Z. Li, H. Yan, G. Chang, M. Hong, J. Dou, M. Niu, J. Photochem. Photobiol. B 163 (2016) 403-412.

[59] K. Dhara, P. Roy, J. Ratha, M. Manassero, P. Banerjee, Polyhedron 26 (2007) 4509-4517.

[60] S. Mondal, M. Chakraborty, A. Mondal, B. Pakhira, A.J. Blake, E. Sinn, S.K. Chattopadhyay, New J. Chem. 42 (2018) 9588-9597.

[61] H.-Y. Yin, J. Tang, J.-L. Zhang, Eur. J. Inorg. Chem. 2017, 5085-5093.

[62] S.H. Li, F.R. Chen, Y.F. Zhou, J.N. Wang, H. Zhang, J.G. Xu, Chem. Commun. (2009) 41794181.

[63] A. Ganguly, B.K. Paul, S. Ghosh, S. Kar, N. Guchhait, Analyst 138 (2013) 6532-6541.

[64] A. Enríquez-Cabrera, A. Vega-Peñaloza, V. Álvarez-Venicio, M. Romero-Ávila, P.G. Lacroix, G. Ramos-Ortiz, R. Santillan, N. Farfán, J. Organomet. Chem. 855 (2018) 51-58.

[65] S. Ramezani, M. Pordel*, A. Davoodnia, Inorg. Chim. Acta 484 (2019) 450-456.

[66] Y. Xin, J. Yuan, Polym. Chem. 3 (2012) 3045-3055.

[67] A.A. El-Bindary, A.Z. El-Sonbati, M.A. Diab, M.M. Ghoneim, L.S. Serag, J. Mol. Liq. 216 (2016) $318-329$.

[68] W. Al Zoubi, N. Al Mohanna, Spectrochim. Acta Part A: Mol. Biomol. Spectrosc. 132 (2014) 854-870.

[69] A.W. Jeevadason, K.K. Murugavel, M.A. Neelakantan, Renew. Sustain. Energy Rev. 36 (2014) 220-227.

[70] J. Zhang, L. Xu, W.-Y. Wong, Coord. Chem. Rev. 355 (2018) 180-198. 
[71] J.E. Baumeister, K.M. Reinig, C.L. Barnes, S.P. Kelley, S.S. Jurisson, Inorg. Chem. 57 (2018) 12920-12933.

[72] R. Golbedaghi, R. Fausto, Polyhedron 155 (2018) 1-12.

[73] W.A. Zoubi, Y.G. Ko, J. Organomet. Chem. 822 (2016) 173-188.

[74] P. Das, W. Linert, Coord. Chem. Rev. 311 (2016) 1-23.

[75] W.L. Man, W.W.Y. Lam, T.C. Lau, Acc. Chem. Res. 47 (2014) 427-439.

[76] K.R. Balinge, A.i. Ganesh Khiratkar, P.n. Rambhau Bhagat, J. Organomet. Chem. 854 (2018) $131-139$

[77] A. Ouraria, B. Ketfia, S.I.R. Malhaa, A. Amine, J. Electroanal. Chem. 797 (2017) 31-36.

[78] A.E. Sorochinsky, J.L. Acen, H. Moriwaki, T. Sato, V.A. Soloshonok, Amino Acids 45 (2013) 691-718.

[79]A.E. Sorochinsky, J.L. Acen, H. Moriwaki, T. Sato, V.A. Soloshonok, Amino Acids 45 (2013) 1017-1033.

[80] C.P. Pradeep, S.K. Das, Coord. Chem. Rev. 257 (2013) 1699-1715.

[81] J.L. Acena, A.E. Sorochinsky, H. Moriwaki, T. Sato, V.A. Soloshonok, J. Fluorine Chem. 155 (2013) 21-38.

[82] B. Agrahari, S. Layek, A. Rakesh Ganguly, D.D. Pathak, Inorg. Chim. Acta 471 (2018) 345354.

[83] I. Araki, K. Fukui, H. Fujii, Inorg. Chem. 57 (2018) 1685-1688.

[84] N. Devi, K. Sarma, R. Rahaman, P. Barman, Dalton Trans. 47 (2018) 4583-4595.

[85] B. Babaei, A. Bezaatpour, M. Amiri, S. Szunerits, R. Boukherroub, Chem. Select 3 (2018) 2877-2881.

[86] M. Cozzolino, V. Leo, C. Tedesco, M. Mazzeo, M. Lamberti, Dalton Trans. 47 (2018) 1322913238 .

[87] A. Gualandi, C.M. Wilson, P.G. Cozzi, CHIMIA Int. J. Chem. 71 (2017) 562-567. 
[88] H.C. Kolb, M.G. Finn, K.B. Sharpless, Angew. Chem. Int. Ed. 40 (2001) 2004-2021.

[89] L. Liang, D. Astruc, Coord. Chem. Rev. 255 (2011) 2933-2945.

[90] C. Wang, D. Ikhlef, S. Kahlal, J.-Y. Saillard, D. Astruc, Coord. Chem. Rev. 316 (2016) 1-20.

[91] X. Liu, N. Novoa, C. Manzur, D. Carrillo, J.-R. Hamon, New J. Chem. 40 (2016) 3308-3313.

[92] T.P. Yoon, E.N. Jacobsen, Science 299 (2003) 1691-1693.

[93] P.G. Cozzi, Chem. Soc. Rev. 33 (2004) 410-421.

[94] M. Rezaeivala, H. Keypour, Coord. Chem. Rev. 280 (2014) 203-253.

[95] E.L. Gavey, M. Pilkington, Coord. Chem. Rev. 296 (2015) 125-152.

[96] K.C. Gupta, A.K. Sutar, Coord. Chem. Rev. 252 (2008) 1420-1450.

[97] R. KATWAL, H. KAURa, B. KISHORE KAPUR, Sci. Revs. Chem. Commun. 3 (2013) 1-15.

[98] X. Liu, C. Manzur, N. Novoa, S. Celedón, D. Carrillo, J.-R. Hamon, Coord. Chem. Rev. 357 (2018) 144-172.

[99] R. Hernandez-Molina, A. Mederos, Acyclic and Macrocyclic Schiff Base Ligands, in: J.A. McCleverty, T.J. Meyer (Eds.), Comprehensive Coordination Chemistry II, Elsevier Pergamon, Oxford, 2004, vol. 1, pp. 411-458.

[100] R. Pedrido, M.R. Bermejo, A.M. García-Deibe, A.M. González-Noya, M. Maneiro, M. Vázquez, Eur. J. Inorg. Chem. (2003) 3193-3200.

[101] Spin crossover phenomenon / Phénomène de transition de spin, A. Bousseksou (Ed.), C. R. Chimie 21 (2018) 1055-1300.

[102] D. J. Harding, P. Harding, W. Phonsri, Coord. Chem. Rev. 313 (2016) 38-61.

[103] P. Gütlich, Y. Garcia, H.A. Goodwin, Chem. Soc. Rev. 29 (2000) 419-427.

[104] R. Boča, I. Nemec, I. Šalitroš, J. Pavlik, R. Herchel, F. Renz, Pure Appl. Chem. 81 (2009) 1357-1383.

[105] M. Wolff, C. Krüger, P. Homenya, L. Heyer, R. Saadat, B. Dreyer, D. Unruh, T. Meyer, G. 
Klingelhoefer, L. Rissing, R. Sindelar, Y. Ichiyanagi, F. Renz, Hyperfine Interact. 226 (2014) 237241.

[106] L. Pogny, B. Brachnakov, J. Moncol, J. Pavlik, I. Nemec, Z. Trvncek, M. Mazfflr, L. Bucinsky, L. Suchnek, I. Salitros, Chem. Eur. J. 24 (2018) 5191-5203.

[107] I. Salitros`, R. Boc`a, L. Dlhán`, M. Gembický, J. Kožíšek, J. Linares, J. Moncol, I. Nemec, L. Perašínová, F. Renz, I. Svoboda, H. Fuess, Eur. J. Inorg. Chem. (2009)3141-3154.

[108] S. Gupta, A. Mukherjee, M. Nethaji, A.R. Chakravarty, Polyhedron 24 (2005) 1922-1928.

[109] M. Layek , M. Ghosh, S. Sain , M. Fleck , P.T. Muthiah, S.J. Jenniefer, J. Ribas, D. Bandyopadhyay, J. Mol. Struc. 1036 (2013) 422-426.

[110] I. Nemec, R. Herchel, R. Bo`ca, Z. Travnı`cek, I. Svoboda, H. Fuessd, W. Linert, Dalton Trans. 40 (2011) 10090-10099.

[111] W. Radecka-Paryzek, V. Patroniak, J. Lisowski, Coord. Chem. Rev. 249 (2005) 2156-2175.

[112] X.-S. Gao, C.a.-C. Ni, X.-M. Ren, Polyhedron 138 (2017) 225-231.

[113] P. Mahapatra, S. Giri, M.G.B. Drew, A. Ghosh, Dalton Trans. 47 (2018) 3568-3579.

[114] S. Bhattacharyya, S.B. Kumar, S.K. Dutta, E.R.T. Tiekink, M. Chaudhury, Inorg. Chem. 35 (1996) 1967-1973.

[115] V.D. Sasnovskaya, V.A. Kopotkov, A.V. Kazakova, A.D. Talantsev, R.B. Morgunov, S.V. Simonov, L.V. Zorina, V.S. Mironov, E.B. Yagubskii, New J. Chem. 42 (2018) 14883-14893.

[116] P.K. Mishra, V. Chakravortty, K.C. Dash, Trans. Met. Chem. 16 (1991) 73-75.

[117] M. Jafarpour, A. Rezaeifard, S. Gazkar, M. Danehchin, Trans. Met. Chem. 36 (2011) 685-690 .

[118] N.T.S. Khomami, F. Heshmatpour, B. Neumüller, Inorg. Chem. Commun. 41 (2014) 14-18.

[119] D. Rehder, J. Inorg. Biochem. 80 (2000) 133-136.

[120] R.R. Eady, in H. Sigel, A. Sigel (Eds.), Metal Ions in Biological Systems, vol. 31, Marcel Dekker, New York (1995). 
[121] A. Butler, in J. Reedijk, E. Boiwman (Eds.), Bioinorganic Catalysis, second ed., Marcel Dekker, New York (1999).

[122] D. Rehder, Bioinorganic Vanadium Chemistry, John Wiley \& Sons, New York (2008) p. 115.

[123] M.R. Maurya, A. Kumar, M. Ebel, D. Rehder, Inorg. Chem. 45 (2006) 5924-5937.

[124] L. Canali, D.C. Sherrington, Chem. Soc. Rev. 28 (1999) 85-93.

[125] H. Gröger, Chem. Rev. 103 (2003) 2795-2828.

[126] R. Ando, S. Mori, M. Hayashi, T. Yagyu, M. Maeda, Inorg. Chim. Acta 357 (2004) 1177-1184.

[127] E. Del Carpio, L. Hernández, C. Ciangherotti, V. Villalobos Coa, L. Jiménez, V. Lubes, G. Lubes, Coord. Chem. Rev. 372 (2018) 117-140.

[128] M.R. Maurya, J. Costa Pessoa, J. Organomet. Chem. 696 (2011) 244-254.

[129] P. Adão, J. Costa Pessoa, R.T. Henriques, M.L. Kuznetsov, F. Avecilla, M.R. Maurya, U. Kumar, I. Correia, Inorg. Chem. 48 (2009) 3542-3561.

[130] M.R. Maurya, A. Kumar, J. Costa Pessoa, Coord. Chem. Rev. 255 (2011) 2315-2344.

[131] M.R. Maurya, M. Bisht, N. Chaudhary, F. Avecilla, U. Kumar, H.-F. Hsu, Polyhedron 54 (2013) 180-188.

[132] D.F. Back, G.M. de Oliveira, L.A. Fontana, A. Neves, B.A. Iglesias, T.P. Camargo, P.T. Campos, J.P. Vargas, Inorg. Chim. Acta 428 (2015) 163-169.

[133] R. Hille, Chem. Rev. 1996, 96, 2757-2816.

[134] A. Syamal, M.R. Maurya Coord. Chem. Rev. 1989, 95, 183-238.

[135] K. Jeyakumar, D.K. Chand, J. Chem. Sci. 121 (2009) 111-123.

[136] R. Sanz, M.R. Pedrosa, Curr. Org. Synth. 2009, 6, 239-263.

[137] R.D. Chakravarthy, D.K. Chand, J. Chem. Sci. 123 (2011) 187-199 and references cited therein.

[138] M.R. Maurya, S. Dhaka, F. Avecilla, Polyhedron 67 (2014) 145-159. 
[139] A.S.M. Al-Shihri, J.R. Dilworth, S.D. Howe, J. Silver, R.M. Thompson, J. Davies, D.C. Povey, Polyhedron 12 (1993) 2297-2305.

[140] V.S. Mironov, T.A. Bazhenova, Y.V. Manakin, K.A. Lyssenko, A.D. Talantsev, E.B. Yagubskii, Dalton Trans. 46 (2017) 14083-14087.

[141] X.-Y. Wang, C. Avendaño, K.R. Dunbar, Chem. Soc. Rev. 40 (2011) 3213-3238.

[142] Q.-L. Wang, H. Southerland, J.-R. Li, A. V. Prosvirin, H. Zhao, K.R. Dunbar, Angew. Chem. Int. Ed. 51 (2012) 9321-9324.

[143] D.-Q. Wu, D. Kempe, Y. Zhou, L.-D. Deng, D. Shao, X.-Q. Wei, L. Shi, K. R. Dunbar, X.-Y. Wang, Inorg. Chem. 56 (2017) 7182-7189.

[144] C.S. Mullins, V.L. Pecoraro, Coord. Chem. Rev. 252 (2008) 416-443.

[145] F.A. Cotton, G. Wilkinson, C.A. Murillo, M. Bochmann, Advanced Inorganic Chemistry (6th ed.), Wiley-Interscience (1999).

[146] D. Gatteschi, R. Sessoli, Angew. Chem. Int. Ed. 42 (2003) 2-33, and references cited therein.

[147] S.M. Soliman, A. El-Faham, S.E. Elsilk, M. Farooq, Inorg. Chim. Acta 479 (2018) 275-285.

[148] A. Das, S. Demeshko, S. Dechert, F. Meyer, Eur. J. Inorg. Chem. (2011) 1240-1248.

[149] L. Cambi, L. Szegö, Ber. Dtsch. Chem. Ges. (A and B Series) 64 (1931) 2591-2598.

[150] L. Cambi, L. Szegö, Ber. Dtsch. Chem. Ges. (A and B Series) 66 (1933) 656-661.

[151] L. Cambi, L. Malatesta, Ber. Dtsch. Chem. Ges. (A and B Series) 70 (1937) 2067-2078.

[152] Spin Crossover in Transition Metal Compounds, P. Gütlich, H.A. Goodwin, Eds., Top. Curr. Chem. Springer-Verlag, Berlin, 233-235 (2004).

[153] Spin-Crossover Materials: Properties and Applications, M.A. Halcrow Ed., John Wiley \& Sons, Chichester, UK (2013).

[154] C. Atmani, F. El Hajj, S. Benmansour, M. Marchivie, S. Triki, F. Conan, V. Patinec, H. Handel, G. Dupouy, C.J. Gómez-García, Coord. Chem. Rev. 254 (2010) 1559-1569. 
[155] M.A. Halcrow, Chem. Soc. Rev. 40 (2011) 4119-4142.

[156] S. Mossin, B.L. Tran, D. Adhikari, M. Pink, F.W. Heinemann, J. Sutter, R.K. Szilagyi, K. Meyer, D.J. Mindiola, J. Am. Chem. Soc. 134 (2012) 13651-13661.

[157] P. Gütlich, Eur. J. Inorg. Chem. (2013) 581-591.

[158] P. Masarova, P. Zoufaly, J. Moncol, I. Nemec, J. Pavlik, M. Gembicky, Z. Travnıcek, R. Bocad, I. Salitros, New J. Chem. 39 (2015) 508-519.

[159] L. Pogany, J. Moncol, J. Pavlik, I. Salitros, New J. Chem. 41 (2017) 5904-5915.

[160] E. König, Struct. Bonding 76 (1991) 51-152.

[161] P. Gütlich, A. Hauser, H. Spiering, Angew. Chem. Int. Ed. Engl. 33 (1994) 2024-2054.

[162] A. Hauser, J. Jeftic, H. Romstedt, R. Hinek, H. Spering, Coord. Chem. Rev. 190-192 (1999) 471-491.

[163] P. Gütlich, P. van Koningsbruggen, F. Renz, Struct. Bonding 107 (2004) 27-265.

[164] M. Nihei, T. Shiga, Y. Maeda, H. Oshio, Coord. Chem. Rev. 251 (2007) 2606-2621.

[165] J. Linares, E. Codjovi, Y. Garcia, Sensors 12 (2012) 4479-4492.

[166] O. Kahn, C.J. Martinez, Science 279 (1998) 44-48.

[167] A. Bousseksou, G. Molnar, L. Salmon, W. Nicolazzi, Chem. Soc. Rev. 40 (2011) 3313-3335.

[168] J.A. Real, A.B. Gaspar, M.C. Muñoz, Dalton Trans. (2005) 2062-2079.

[169] R.N. Meller, E.L. Vander, S. Laurent, J. Am. Chem. Soc. 125 (2003) 8405 - 8407.

[170] C. Krüger, P. Augustín, I. Nemec, Z. Trávnícek, H. Oshio, R. Boca, F. Renz, Eur. J. Inorg. Chem. (2013) 902-915.

[171] C. Krüger, P. Augustin, L. Dlhan, J. Pavlik, J. Moncol, I. Nemec, R. Boca, F. Renz, Polyhedron 87 (2015) 194-201. 
[172] I. Nemec, R. Boca, M. Gembicky, L. Dlhána, R. Herchel, F. Renz, Inorg. Chim. Acta 362 (2009) 4754-4759.

[173] M. Gembicky, R.Boca, F. Renz, Inorg. Chem. Commun. 3 (2000) 662-665.

[174] I. Salitros, R. Boca, R. Herchel, J. Moncol, I. Nemec, M. Ruben, F. Renz, Inorg. Chem. 51 ( 2012) 12755-12767.

[175] R.H. Niswander, L.T. Taylor, J. Am. Chem. Soc. 99 (1977) 5935-5939.

[176] R. Herchel, R. Boča, Dalton Trans. (2005) 1352-1353.

[177] L.M. Brines, J. Shearer, J.K. Fender, D. Schweitzer, S.C. Shoner, D. Barnhart, W. Kaminsky, S. Lovell, J.A. Kovacs, Inorg. Chem. 46 (2007) 9267.

[178] A. Banerjee, S. Chattopadhyay,Polyhedron 159 (2019) 1-11.

[179] C.R. Munteanua, K. Suntharalingam, Dalton Trans. 44 (2015) 13796-13808.

[180] L. Pogány, J. Moncol, M. Gál, I. Šalitroš, R. Boca, Inorg. Chim. Acta 462 (2017) 23-29.

[181] M. Amirnasr, F. Fadaee, K. Mereiter, Inorg. Chim. Acta 371 (2011) 6-12.

[182] G. Koz, N. Özdemir, D. Astley, M. Dinçer, S.T. Astley, J. Mol. Struct. 966 (2010) 39-47.

[183] S. Sain, R. Saha, G. Mostafa, M. Fleck, D. Bandyopadhyay, Polyhedron 31 (2012) 82-88.

[184] N. Charef, F. Sebti, L. Arrar, M. Djarmouni, N. Boussoualim, A. Baghiani, S. Khennouf, A. Ourari, M.A. AlDamen, M.S. Mubarak, D.G. Peters, Polyhedron 85 (2015) 450-456.

[185] C.P. Pradeep, P.S. Zacharias, S.K. Das, Inorg. Chem. Commun. 9 (2006) 1071-1074.

[186] T. Taguchi, W. Wernsdorfer, K.A. Abboud, G. Christou, Inorg. Chem. 49 (2010) 10579-10589.

[187] P.-K. Chen, X.-Q. Shen, C.-Y. Ge, J.-F. Kou, H.-Y. Zhang, H.-W. Hou, Y. Zhu, X.-F. Zheng, H.Q. Zhang, Syn. React. Inorg. Met. Org. Chem. 36 (2006) 603-607.

[188] D. Matoga, J. Szklarzewicz, W. Nitek, Polyhedron 36 (2012) 120-126.

[189] V.T. Yilmaza, I. Degirmencioglu, O.Andaca, S. Karabocek, A.M.Z. Slawin, J. Mol. Struct. 
654 (2003) 125-129.

[190] E. Gungor, H. Kara, Inorg. Chim. Acta 384 (2012) 137-142.

[191] E. Gungor, H. Kara, Spectrochim. Acta, Part A 82 (2011) 217-220.

[192] A. Yardan, Y. Yahsi, H. Kara, A. Karahan, S. Durmus, R. Kurtaran, Inorg. Chim. Acta 413 (2014) 55-59.

[193] R. Ferreira, M. Silva, C. Freire, B. de Castro, J.L. Figueiredo, Micropor. Mesopor. Mat. 38 (2000) 391-401.

[194] A.P. Carvalho, C. Castanheira, B. Cardoso, J. Pires, A.R. Silva, C. Freire, B. de Castro, M.B. de Carvalho, J. Mater. Chem. 14 (2004) 374-379.

[195] G. Parkin, Chem. Commun. (2000) 1971-1985.

[196] R.S. Brown, J. Huguet, N.J. Curtis, in H. Sigel (Ed.), Role of Metal Ions in Biological Systems vol. 15, Marcel Dekker, New York (1983).

[197] Z. Wang, Y.-Q. Fan, L. Shi, Y.-G. Xu, J. Coord. Chem. 66 (2013) 2032-2038.

[198] C.J. Whiteoak, G. Salassaa, A.W. Kleij, Chem. Soc. Rev. 41 (2012) 622-631.

[199] J.R. Anacona, V. Rangel, M. Lorono, J. Camus, Spectrochim. Acta, Part A 149 (2015) 23-29.

[200] M.E. Germain, M.J. Knapp, J. Am. Chem. Soc. 130 (2008) 5422-5423.

[201] Y.A. Tyula, A. Zabardasti, H. Goudarziafshar, M.S. Roudsari, M. Dusek, V. Eigner, J. Mol. Struct. 1150 (2017) 383-394.

[202] M.A. AlDamen, N. Charef, H.K. Juwhari, K. Sweidan, M.S. Mubarak, D.G. Peters, J. Chem. Crystallogr. 46 (2016) 411-420.

[203] L.G. Marzilli, T.J. Kistenmacher, G.L. Eichhorn, in T.G. Spiro (Ed.), Metal Ions in Biology, vol. 1, Wiley, New York (1980) p. 179.

[204] H. Strasdeit, W. Saak, S. Pohl, W.L. Driessen, J. Reedijk, Inorg. Chem. 27 (1988) 1557-1563.

[205] P.A. Vigato, S. Tamburini,L. Bertolo, Coord. Chem. Rev. 251 (2007) 1311-1492. 
[206] J.-C. Dai, X.-T. Wu, Z.-Y. Fu, C.-P. Cui, S.-M. Hu, W.-X. Du, L.-M. Wu, H.-H. Zhang, R.-Q. Sun, Inorg. Chem. 41 (2002) 1391-1396.

[207] Y.-H. Liu, Y.-L. Lu, H.-C. Wu, J.-C. Wang, K.-L. Lu, Inorg. Chem. 41 (2002) 2592-2597.

[208] B.N. Sarkar, S. Choubey, K. Bhar, S. Chattopadhyay, P. Mitra, B.K. Ghosh, J. Mol. Struct. 994 (2011) 306-312.

[209] J. Chakraborty, S. Thakurta, B. samanta, A. Ray, G. Pilet, S.R. Batten, P. Jensen, S. Mitra, Polyhedron 26 (2007) 5139-5149.

[210] C. Janiak, Dalton Trans. (2003) 2781-2804.

[211] S. Le Gac, L. Fusaro, V. Dorcet, B. Boitrel, Chem. Eur. J. 19 (2013) 13376-13386.

[212] K. Das, A. Jana, S. Konar, S. Chatterjee, T.K.Mondal, A.K. Barik, S.K. Kar, J. Mol. Struct.1048 (2013) 98-107.

[213] B.N. Sarkar, K. Bhar, S. Chattopadhyay, S. Das, P. Mitra, B.K. Ghosh, J. Mol. Struct. 963 (2010) 35-40.

[214] M. Nath, S. Goyal, Main Group Met. Chem. 19 (1995) 75-102.

[215] M. Nath, P.K. Saini, Dalton Trans. 40 (2011) 7077-7121.

[216] R. Luna-García, B.M. Damián-Murillo, V. Barba, H. Höpfl, H.I. Beltrán, L.S. ZamudioRivera, Chem. Commun. (2005) 5527-5529.

[217] R. Luna-García, B.M. Damián-Murillo, V. Barba, H. Höpfl, H.I. Beltrán, L.S. ZamudioRivera, J. Organomet. Chem. 694 (2009) 3965-3972.

[218] A. González, E. Gómez, A. Cortés-Lozada, S. Hernández, T. Ramírez-Apan, A. NietoCamacho, Chem. Pharm. Bull. 57 (2009) 5-15.

[219] A. Cortes-Lozada, E. Gomez, S. Hernandez, Synth. React. Inorg., Met.-Org., Nano-Met. Chem. 42 (2012) 1143-1153.

[220] J. Pérez-Pérez, J.G. Alvarado-Rodríguez, N. Andrade-López, J.C. Borbolla, D. MartínezOtero, J.M. Vásquez-Pérez, Inorg. Chem. Commun. 70 (2016) 75-78. 
[221] S. Sato, M. Wada, Bull. Chem. Soc. Jpn. 43 (1970) 1955-1962.

[222] M. Latva, H. Takalo, V.M. Mukkala, C. Matachescu, J.C. Rodriguez-Ubis, J. Kankare, J. Lumin, 75 (1997) 149-169.

[223] M.H. Ha-Thi, J.A. Delaire, V. Michelet, I. Leray, J. Phys. Chem. A 114 (2010) 3264-3269.

[224] I. Pospieszna-Markiewicz, W. Radecka-Paryzek, M. Kubicki, Z. Hnatejko, Inorg. Chim. Acta 453 (2016) 409-414.

[225] X.-S. Gao, J.-T. Wang, Inorg. Chim. Acta 386 (2012) 1-7.

[226] J.J. Katz, G.T. Seaborg, L.R. Morss, The Chemistry of the Actinide Elements, 2nd ed., Chapman and Hall, London (1986).

[227] S. Cotton, Lanthanide and Actinide Chemistry, John Wiley \& Sons Ltd, West Sussex, England (2006).

[228] K. Takao, M. Kato, S. Takao, A. Nagasawa, G. Bernhard, C. Hennig, Y. Ikeda, Inorg. Chem. 49 (2010) 2349-2359.

[229] J.D. Van Horn, H. Huang, Coord. Chem. Rev. 250 (2006) 765-775.

[230] for an overview, see the special issue: 2013 Nuclear Chemistry, H. Nitsche (Ed.), Chem. Rev. 113 (2013) 855-1312.

[231] L. Pavelek, V. Ladányi, M. Necas, S. Vallová, K. Wichterle, Polyhedron 107 (2016) 89-96.

[232] E.E. Hardy, K.M. Wyss, M.A. Eddy, A.E.V. Gorden, Chem. Commun. 53 (2017) 5718-5720.

[233] A.A. Khandar, S.A. Hosseini-Yazdi, Aust. J. Chem. 56 (2003) 1255-1257.

[234] K. Sayin, D. Karakas, J. Clust. Sci. 28 (2017) 3075-3086.

[235] M. Vicente, C. Lodeiro, H. Adams, R. Bastida, A. Blas, D.E. Fenton, A. Macyas, A. Rodryguez, T. Rodryguez-Blas, Eur. J. Inorg. Chem. (2000) 1015-1024.

[236] M. Vicente, R. Bastida, C. Lodeiro, A. Macias, A.J. Parola, L. Valencia, S.E. Spey, Inorg. Chem. 42 (2003) 6768-6779. 
[237] V. Artero, M. Fontecave, Coord. Chem. Rev. 249 (2005) 1518-1535.

[238] S. Li, J. Xia, D. Yang, Y. Xu, D. Li, M. Wu, W. Tang, Inorg. Chem. 41 (2002) 1807-1815.

[239] K.P. Wainwright, Adv. Inorg. Chem. 52 (2001) 293-334.

[240] L. Siegfried, A. Comparone, M. Neuburger, T.A. Kaden, Dalton Trans. (2005) 30-36.

[241] J. Costamagna, G. Ferraudi, B. Matsuhiro, M. Campos-Vallette, J. Canales, M. Villagra'n, J. Vargas, M.J. Aguirre, Coord. Chem. Rev. 196 (2000) 125-164.

[242] A.A. Khandar, S.A. Hosseini-Yazdi, Polyhedron 22 (2003) 1481-1487.

[243] A.A. Khandar, S.A. Hosseini-Yazdi, M. Khatamian, P. McArdle, S.A. Zarei, Polyhedron 26 (2007) 33-38.

[244] A.A. Khandar, S.A. Hosseini-Yazdi, M. Khatamian, P. McArdle, S.A. Zarei, Polyhedron 29 (2010) 995-1000.

[245] F. Bonadio, M.-C. Senna, J. Ensling, A. Sieber, A. Neels, H. Stoeckli-Evans, S. Decurtins, Inorg. Chem. 44 (2005) 969-978.

[246] B. Drahos, R. Herchel, Z. Travnıcek, RSC Adv. 6 (2016) 34674-34684.

[247] H. Keypour, M. Mahmoudabadi, A. Shooshtari, L. Hosseinzadeh, F. Mohsenzadeh, R.W. Gable, Polyhedron 127 (2017) 345-354

[248] H. Keypour, M. Rezaeivala, L. Valencia, P. Pérez-Lourido, A.H. Mahmoudkhani, Polyhedron 28 (2009) 3415-3418.

[249] A. Del Zotto, W. Baratta, M. Ballico, E. Herdtweck, P. Rigo, Organometallics 26 (2007) 56365642 .

[250] A. Barandov, U. Abram, Polyhedron 28 (2009) 1155-1159.

[251] E. Deutsch, K. Libson, J.-L. Vanderheyden, A. Ketring, H.R. Maxon, Nucl. Med. Biol. 13 (1986) 465-477.

[252] S. Jurisson, D. Berning, W. Jia, D. Ma, Chem. Rev. 93 (1993) 1137-1156. 
[253] U. Abram, R. Alberto, J. Braz. Chem. Soc. 17 (2006) 1486-1500.

[254] A. Barandov, U. Abram, Inorg. Chem. 48 (2009) 8072-8074.

[255] A.H. Mirza, M.H.S.A. Hamid, S. Aripin, M.R. Karim, Md. Arifuzzaman, M. Akbar Ali, P.V. Bernhardt, Polyhedron 74 (2014) 16-23.

[256] M. Akbar Ali, P.V. Bernhardt, M.A.H. Brax, J. England, A.J. Farlow, G.R. Hanson, L.L. Yeng, A.H. Mirza, K. Wieghardt, Inorg. Chem. 52 (2013) 1650-1657.

[257] M. Akbar Ali, A.H. Mirza, W.Y. Ting, M.H.S.A. Hamid, P.V. Bernhardt, R.J. Butcher, Polyhedron 48 (2012) 167-173.

[258] M. Akbar Ali, A.H. Mirza, C.Y. Yee, H. Rahgeni, P.V. Bernhardt, Polyhedron 30 (2011) 542548.

[259] M. Akbar Ali, A.H. Mirza, R.J. Butcher, M.T.H. Tarafder, M.A. Ali, Inorg. Chim. Acta 320 (2001) 1-6.

[260] M. Akbar Ali, A.H. Mirza, C.W. Voo, A.L. Tan, P.V. Bernhardt, Polyhedron 22 (2003) 34333438.

[261] M. Akbar Ali, A.H. Mirza, L.K. Wei, P.V. Bernhardt, O. Atchade, X. Song, G.E.L. May, J. Coord. Chem. 63 (2010) 1194-1206.

[262] M. Akbar Ali, A.H. Mirza, R.J. Butcher, P.V. Bernhardt, M.R. Karim, Polyhedron 30 (2011) 1478-1486.

[263] M. Akbar Ali, A.H. Mirza, L.K. Wei, A.L. Tan, P.V. Bernhardt, Polyhedron 23 (2004) 20372043

[264] M.T. Basha, J.D. Chartres, N. Pantarat, M. Akbar Ali, A.H. Mirza, D.S. Kalinowski, D.R. Richardson, P.V. Bernhardt, Dalton Trans. 41 (2012) 6536-6548.

[265] T.-J. Khoo, M.K.B. Break, K.A. Crouse, M. Ibrahim, M. Tahir, A.M. Ali, A.R. Cowley, D.J. Watkin, M.T.H. Tarafder, Inorg. Chim. Acta 413 (2014) 68-76.

[266] N.K. Singh, M.K. Bharty, S.K. Kushawaha, U.P. Singh, P. Tyagi, Polyhedron 29 (2010) 1902- 
1909.

[267] M.R. Maurya, D.C. Antony, S. Gopinathan, C. Gopinathan, Bull. Chem. Soc. Jpn. 68 (1995) $554-558$.

[268] P. Bera, C.H. Kim, S. Il Seok, Inorg. Chim. Acta 362 (2009) 2603-2608.

[269] A. Nunez-Montenegro, R. Carballo, E.M. Vazquez-Lopez, Polyhedron 27 (2008) 2867-2876.

[270] M. Yazdanbakhsh, R. Takjooa, Struct. Chem. 19 (2008) 895-903.

[271] Y. Tian, C.Y. Duan, C. Zhao, X. You, T.C.W. Mak, Z.Y. Zhang, Inorg. Chem. 36 (1997) 12471252.

[272] Z.A. Abu-Raqabah, G. Davies, M.A. El-Sayed, A. El-Toukhy, S.N. Shaikh, J. Zubieta, Inorg. Chim. Acta 193 (1992) 43-56.

[273] Z.H. Liu, C.Y. Duan, J. Hu, Inorg. Chem. 38 (1999) 1719-1724.

[274] C.Y. Duan, X.Z. You, Chem. Lett. (1999) 1063.

[275] M. Dieng, O. Diouf, M. Gaye, A.S. Sall, P. Pérez-Lourido, L. Valencia, A. Caneschi, L. Sorace, Inorg. Chim. Acta 394 (2013) 741-746.

[276] A.H. Mirza, M.A. Ali, P.V. Bernhardt, I. Asri, Polyhedron 81 (2014) 723-727.

[277] R. Pedrido, M.R. Bermejo, M.J. Romero, M. Vazquez, A.M. Gonzalez-Noya, M. Maneiro, M.J. Rodriguez, M.I. Fernandez, Dalton Trans. (2005) 572-579.

[278] G.F. de Sousa, V.A. da Silva Falcomer, Y.P. Mascarenhas, J. Ellena, J.D. Ardisson, J. ValdesMartınes, S. Hernandez-Ortega, Trans. Met. Chem. 31 (2006) 753-759.

[279] M.A. Ali, A.H. Mirza, J.D. Chartres, P.V. Bernhardt, Polyhedron 30 (2011) 299-306.

[280] H.H. Nguyen, C.T. Pham, U. Abram, Inorg. Chem. 54 (2015) 5949-5959.

[281] H.H. Nguyen, C.T. Pham, U. Abram, Polyhedron 99 (2015) 216-222.

[282] G. Prakash, R. Ramachandran, M. Nirmala, P. Viswanathamurthi, W. Linert, Monatsh. Chem. 145 (2014) 1903-1912. 
[283] E.C. Constable, G. Zhang, C.E. Housecroft, M. Neuburger, J. Mol. Struct. 975 (2010) 367371.

[284] R. Sessoli, H.L. Tsai, A.R. Schake, S. Wang, J.B. Vincent, K. Folting, D. Gatteschi, G. Christou, D.N. Hendrickson, J. Am. Chem. Soc. 115 (1993) 1804-1816.

[285] S. Amabilino, R.J. Deeth, Inorg. Chem. 56 (2017) 2602-2613.

[286] S. Wang, Y.-J. Li, F.-F. Ju, W.-T. Xu, K. Kagesawa, Y.-H. Li, M. Yamashita, W. Huang, Dalton Trans. 46 (2017) 11063-11077.

[287] B. Gildea, M.M. Harris, L.C. Gavin, C.A. Murray, Y. Ortin, H. Müller-Bunz, C.J. Harding, Y. Lan, A.K. Powell, G.G. Morgan, Inorg. Chem. 53 (2014) 6022-6033.

[288] S. Wang,Y.-H. Li, W. Huang, Eur. J. Inorg. Chem. (2015) 2237-2244.

[289] H. Miyasaka, A. Saitoh, S. Abe, Coord. Chem. Rev. 251 (2007) 2622-2664.

[290] S. Wang, W.-T. Xu, W.-R. He, S. Takaishi, Y.-H. Li, M. Yamashita, W. Huang, Dalton Trans. 45 (2016) 5676-5688.

[291] S. Salehzadeh, R. Golbedaghi, I.S. Tidmarsh, N.K. Al-Rasbi, H. Adams, M.D. Ward, Polyhedron 27 (2008) 3549-3556.

[292] S. Sarkar, S. Biswas, M.-S. Liao, T. Kar, Y. Aydogdu, F. Dagdelen, G. Mostafa, A.P. Chattopadhyay, G.P.A. Yap, R.-H. Xie, A.T. Khan, K. Dey, Polyhedron 27 (2008) 3359-3370.

[293] R. Golbedaghi, M. Rezaeivala, L. Albeheshti, J. Mol. Struct. 1076 (2014) 673-678.

[294] N. Chantarasiri, V. Ruangpornvisuti, N. Muangsin, H. Detsen, T. Mananunsap, C. Batiya, N. Chaichit, J. Mol. Struct. 701 (2004) 93-103.

[295] Y. Xu, D. Yuan, Y. Wang, Y. Yao, Dalton Trans. 46 (2017) 5848-5855.

[296] M.M. Weliange, D.S. McGuinness, M.G. Gardiner, J. Patel, Dalton Trans. 44 (2015) 1528615296.

[297] G. Martínez, J. Chirinos, M.E.G. Mosquera, T. Cuenca, E. Gómez, Eur. J. Inorg. Chem. (2010) $1522-1529$. 
[298] V.K. Jakhar, M. K. Barman, S. Nembenna, Org.Lett. 18 (2016) 4710-4713.

[299] R.B. Lauffer, Chem. Rev. 87 (1987) 901-927.

[300] K. Binnemans, Chem. Rev. 109 (2009) 4283-4374.

[301] S. Pandya, J. Yu, D. Parker, Dalton Trans. (2006) 2757-2766.

[302] A. Panagiotopoulos, T.F. Zafiropoulos, S.P. Perlepes, E. Bakalbassis, I. Masson-Ramade, O. Kahn, A. Terzis, C.P. Raptopoulou, Inorg. Chem. 34 (1995) 4918-4920.

[303] A. Rizzi, R. Baggio, R. Calvo, M.T. Garland, O. Peña, M. Perec, Inorg. Chem. 40 (2001) 3623-3625.

[304] B. Biswas, P. Raghavaiah, N. Aliaga-Alcalde, J.-D. Chen, R. Ghosh, Polyhedron 29 (2010) 2716-2721.

[305] I. Buta, L. Cseh, C. Cretu, D. Aparaschivei, C. Maxim, P. Lönnecke, E. Hey-Hawkins, N. Stanica, E. Ohler, E. Rentschler, M. Andruh, O. Costisor, Inorg. Chim. Acta 475 (2018) 133-141.

[306] Y. Ge, Y. Qin, Y. Cui, Y. Pan, Y. Huang, Y. Li, W. Liu, Y.-Q. Zhang, Chem. Asian J. 13 (2018) 3753-3761.

[307] M. Turkyilmaz, J. Therm. Anal. Calorim. 129 (2017) 451-460.

[308] A. Fetoh, K.A. Asla, A.A. El-Sherif, H. El-Didamony, G.M. Abu El-Reash, J. Mol. Struct. $1178(2019$,$) 524-537.$

[309] A.K. Singh, P. Singh, S. Banerjee, S. Mehta, Anal. Chim. Acta 633 (2009) 109-118.

[310] D.A. Atwood, Coord. Chem. Rev. 176 (1998) 407-430.

[311] S. Sreedaran, S.K. Bharathi, A.K. Rahiman, L. Jagadish, V. Kaviyarasan, V. Narayanan, Polyhedron 27 (2008) 2931-2938

[312] P. Rajakumar, K. Sekar, V. Shanmugaiah, N. Mathivanan, Bioorg. Med. Chem. 18 (2008) 4416-4419.

[313] S. Chandra, L.K. Gupta, Spectrochim. Acta Part A Mol. Biomol. Spectrosc. 60 (2004) 1563- 
1571.

[314] S.O. Kang, Md.A. Hossain, K. Bowman-James, Coord. Chem. Rev. 250 (2006) 3038-3052.

[315] K. Wichmann, B. Antonioli, T. Sohnel, M. Wenzel, Ke. Gloe, Ka. Gloe, J.R. Price, L.F. Lindoy, A.J. Blake, M. Schroder, Coord. Chem. Rev. 250 (2006) 2987-3003.

[316] E. García-Espana, P. Díaz, J.M. Llinares, A. Bianchi, Coord. Chem. Rev. 250 (2006) 29522986.

[317] G. Crisponi, V.M. Nurchi, R. Silvagni, G. Faa, Polyhedron 18 (1999) 3219-3226.

[318] Z.D. Liu, R.C. Hider, Coord. Chem. Rev. 232 (2002) 151-171.

[319] L. Wojaczynski, L. Latos-Grazynski, Coord. Chem. Rev. 204 (2000) 113-171.

[320] H. Khanmohammadi, S. Amani, M.H. Abnosi, H.R. Khavasi, Spectrochim. Acta Part A Mol. Biomol. Spectrosc. 77 (2010) 342-347.

[321] S. Salehzadeh, M.D. Ward , H. Adams, Inorg. Chem. Commun. 12 (2009) 433-435.

[322] T. Marshall-Roth, S.N. Brown, Dalton Trans. 44 (2015) 677-685.

[323] J.W. Han, C.L. Hill, J. Am. Chem. Soc. 129 (2007) 15094-15095.

[324] I.A. lbarra, J.W. Yoon, J.-S. Chang, S.K. Lee, V.M. Lynch, S.M. Humphrey, Inorg. Chem. 51 (2012) 12242-12247.

[325] K. Ooi, Y. Tasaki-Handa, Y. Abe, A. Wakisaka, Dalton Trans. 43 (2014) 4807-4812.

[326] A. Chakraborty, J. Goura, P. Kalita, A. Swain, G. Rajaramand, V. Chandrasekhar, Dalton Trans. 47 (2018) 8841-8864.

[327] Y. -J. Cui, Y.-F. Yue, G.-G. Qian, B.L. Chen, Chem. Rev. 112 (2012) 1126-1162.

[328] S. Mizukami, H. Houjou, M. Kanesato, K. Hiratani, Chem. Eur. J. 9 (2003) 1521-1528.

[329] M. Kanesato, T. Yokoyama, O. Itabashi, T.M. Suzuki, M. Shiro, Bull. Chem. Soc. Jpn. 69 (1996) 1297-1302.

[330] M. Kanesato, T. Yokoyama, Chem. Lett. 29 (1999) 137-138. 
[331] M. Kanesato, S. Mizukami, H. Houjou, H. Tokuhisa, E. Koyama, Y. Nagawa, J. Alloys Compd. 374 (2004) 307-310.

[332] W.-K. Wong, H. Liang, J. Guo, W.-Y. Wong, W.-K. Lo, K.-F. Li, K.-W. Cheah, Z. Zhou, W.T. Wong, Eur. J. Inorg. Chem. (2004) 829-836.

[333] P. Dröse, J. Gottfriedsen, Z. Anorg. Allg. Chem. 634 (2008) 87-90.

[334] P.V. Bernhardt, B.M. Flanagan, M.J. Riley, Aust. J. Chem. 53 (2000) 229-231.

[335] P.V. Bernhardt, B.M. Flanagan, M.J. Riley, Aust. J. Chem. 54 (2001) 229-232.

[336] B.M. Flanagan, P.V. Bernhardt, E.R. Krausz, S.R. Lüthi, M.J. Riley, Inorg. Chem. 40 (2001) 5401-5407.

[337] M.W. Essig, D.W. Keogh, B.L. Scott, J.G. Watkin, Polyhedron 20 (2001) 373-377.

[338] M. Kanesato, K. Nagahara, K. Igarashi, K.-i. Sato, Y. Kikkawa, M. Goto, Inorg. Chim. Acta 367 (2011) 225-229.

[339] R. Golbedaghi, S. Moradi, S. Salehzadeh, A.G. Blackman, J. Mol. Struct. 1108 (2016) 727734.

[340] A. Masuya, C. Igarashi, M. Kanesato, H. Hoshino, N. Iki, Polyhedron 85 (2015) 76-82.

[341] A.R. Craze, X.-D. Huang, I. Etchells, L.-M. Zheng, M.M. Bhadbhade, C.E. Marjo, J.K. Clegg, E.G. Moore, M. Avdeev, L.F. Lindoyf, F. Li, Dalton Trans. 46 (2017) 12177-12184.

[342] D. Lionetti, V.W. Day, J.D. Blakemore, Dalton Trans. 46 (2017) 11779-11789.

[343] Y. Zhang, M. Bhadbhade, L. Kong, I. Karatchevtseva, R. Zheng, Polyhedron 138 (2017) 8287.

[344] R. Bikas, E. Shahmoradi, N. Noshiranzadeh, M. Emami, S. Reinoso, Inorg. Chim. Acta 466 (2017) 100-109.

[345] A. Jana, K. Das, S. Konar, A. Dhara, S. Biswas, S. Chatterjee, T.K. Mondal, J. Mol. Struct. 1100 (2015) 318-327. 
[346] J. Adhikary, P. Chakraborty, S. Samanta, E. Zangrando, S. Ghosh, D. Das, Spectrochim. Acta Part A.178 (2017) 114-124.

[347] X.-X. Sun, C.-M. Qi, S.-L. Ma, H.-B. Huang, W.-X. Zhu, Y.-C. Liu, Inorg. Chem. Commun. 9 (2006) 911-914.

[348] Q.-L. Zhang, B.-X. Zhu, L.F. Lindoy, G. Wei, Inorg. Chem. Commun. 11 (2008) 678-680.

[349] Z. Chu, W. Huang, Inorg. Chem. Commun. 11 (2008) 1166-1169.

[350] A. Roth, A. Buchholz, M. Rudolph, E. Sch6tze, E. Kothe, W. Plass, Chem. Eur. J. 14 (2008) $1571-1583$.

[351] A. Mukherjee, M.K. Saha, M. Nethaji, A.R. Chakravarty, New J. Chem. 29 (2005) 596-603.

[352] S. Banerjee, M. Nandy, S. Sen, S. Mandal, G.M. Rosair, A.M.Z. Slawin, C.J.G. Garcia, J.M. Clemente-Juan, E. Zangrando, N. Guidoling, S. Mitra, Dalton Trans. 40 (2011) 1652-1661.

[353] Y. Sun, Y. Cui, J. Xiong, Z. Dai, N. Tang, J. Wu, Dalton Trans. 44 (2015) 16383-16391.

[354] I. Majumder, P. Chakraborty, S. Das, H. Kara, S.K. Chattopadhyay, E. Zangrandod, D. Das, RSC Adv. 5 (2015) 51290-51301.

[355] A. Dees, A. Zahl, R. Puchta, N.J.R. van Eikema Hommes, F.W. Heinemann, I. Ivanovic'Burmazovic, Inorg. Chem. 46 (2007) 2459-2470.

[356] C. Ding, C. Gao, S. Ng, B. Wang, Y. Xie, Chem. Eur. J. 19 (2013) 9961-9972.

[357] M. Fondo, N. Ocampo, A.M. Garcia-Deibe, E. Ruiz, J. Tercero, J.Sanmartı, Inorg. Chem. 48 (2009) 9861-9873.

[358] M.G. Gichinga, S. Striegler, J. Am. Chem. Soc. 130 (2008) 5150-5156.

[359] K. Pramanik, P. Malpaharia, E. Colacio, B. Das, S.K. Chandra, New J. Chem. 42 (2018) 63326342 . 